PAGES International Project Office Sulgeneckstrasse 38 3007 Bern

Switzerland

Tel: +41313123133 Fax: +41313123168 pages@pages.unibe.ch

Text Editing: Leah Christen Layout: Christoph Kull

Circulation: 4000

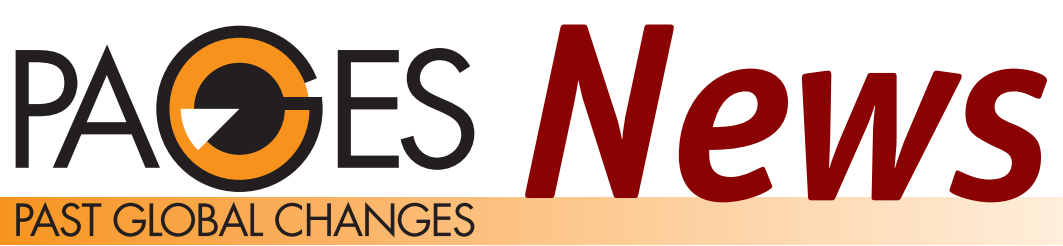

Hubertus Fischer, Christoph Kull and Thorsten Kiefer, Editors

Vol.14, No1 - APRIL 2006

\section{Ice Core Science}

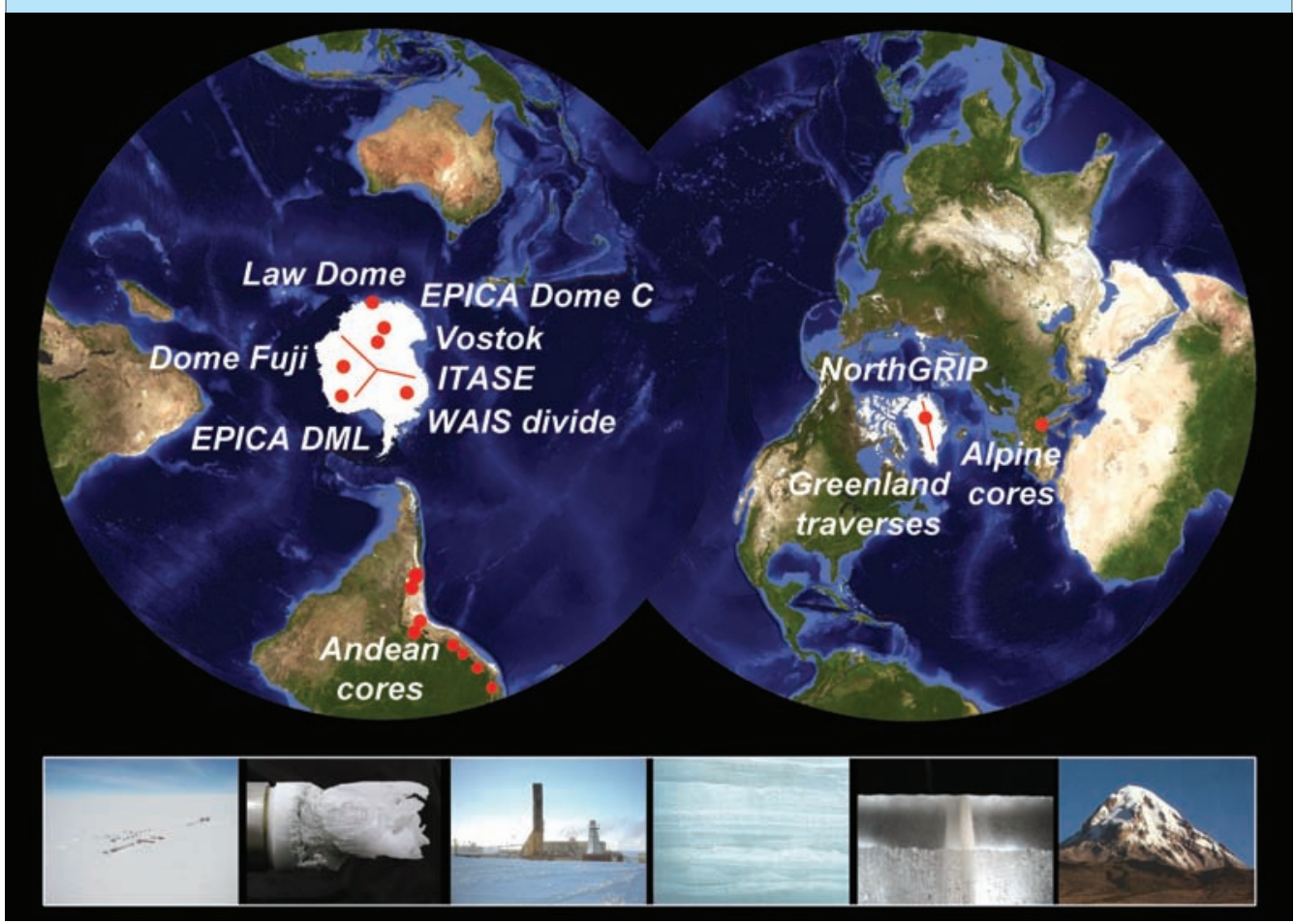

Ice cores provide unique high-resolution records of past climate and atmospheric composition. Naturally, the study area of ice core science is biased towards the polar regions but ice cores can also be retrieved from high altitude glaciers. On the satellite picture are those ice cores covered in this issue of PAGES News (Modified image of "The Blue Marble" (http://earthobservatory.nasa.gov) provided by kk+w - digital cartography, Kiel, Germany; Photos by PNRA/EPICA, H. Oerter, V. Lipenkov, J. Freitag, Y. Fujii, P. Ginot)

\section{Contents}

2 Announcements

- Editorial: The future of ice core research

- Inside PAGES

- New on the bookshelf

- Tales from the field

- In memory of Nick Shackleton

6 Program News

- The IPICS Initiative

- New sea-floor drilling equipment

- Relaunch of the PAGES Databoard

12 National Page

- Chile

13 Science Highlights

- NGT and PARCA ice cores - Greenland

- NorthGRIP ice core - Greenland

- Reconstructions from Alpine ice cores

- Tropical ice cores from the Andes
- Dating of ice cores

- Coastal ice cores - Antarctica

- WAIS Divide ice core - Antarctica

- ITASE project - Antarctica

- New Dome Fuji ice core - Antarctica

- Vostok ice drilling project - Antarctica

- EPICA ice cores - Antarctica

- 425-year precipitation history from Italy

- Sea-level changes: Black and Caspian Seas

- Quaternary climate change in Arabia

- 2nd Southern Deserts Conference - Chile

- Climate change and tree rings - Russia

- Global climate during MIS 11 - Greece

44 Last Page

- Calendar

- PAGES Guest Scientist Program
40 Workshop Reports 


\section{Editorial: Past, present and future ice core research}

Ice core science is still a young field of paleoclimatic and atmospheric research. Essentially, it all began in the 1960s when American, Danish and Swiss researchers retrieved the first deep ice core record from Camp Century, northwestern Greenland. From that point on, it has been a success story, with many national and international deep ice core projects changing our view of the Earth's climate system. The documentation of unprecedented rapid climate variations in Greenland ice cores during the last glacial (Dansgaard-Oeschger events, named after two pioneers in ice core research), and the quantitative reconstruction of greenhouse gas concentrations from air bubbles enclosed in the ice, are just two of the most striking examples of how ice core science has advanced our knowledge.

The success of ice cores alongside other outstanding paleoclimatic archives, such as marine and lake sediments, tree rings, corals, etc., stems from their high temporal resolution combined with their coverage of many glacial cycles. In addition, the combination of various climatological and atmospheric data streams (temperature, gases, aerosols, etc.) from the same independently dated archive make ice cores extremely valuable.

Despite its rather short history, ice core science has gained huge momentum and had a very strong impact on paleoclimatology. It

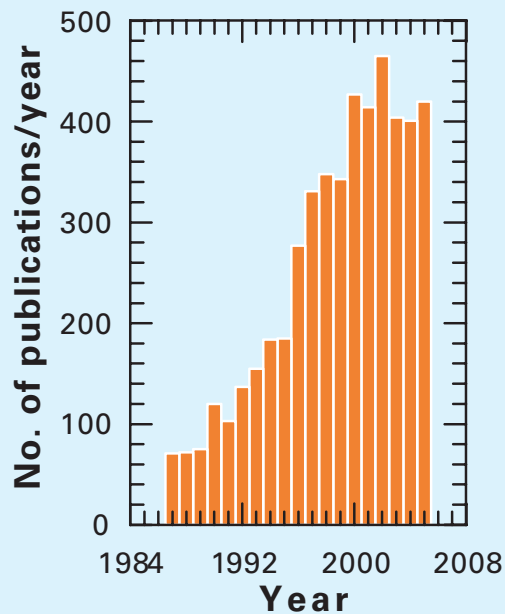

Figure: Publication history of papers with the keyword "ice core" from 1987-2005. Information was retrieved from SCOPUS (www.scopus.com/scopus/home.url). has reached full speed only within the last decade, as reflected by the extraordinary development of the publication history of ice core related papers (see Figure), which have experienced a six-fold increase in the last 15 years, and by the rapid multiplication of ice core drilling projects in different regions of the globe, bringing new national players such as China, Korea and India into the game.

High time to bring together the most important results gained from various research groups worldwide and to think about the future. Accordingly, this issue of PAGES News gives an overview of the results of many of the major ongoing ice core projects, reaching spatially from the poles to the equator and temporally from recent climate variability to paleoclimatology over the last 800,000 years. The need to look ahead and shape the future of ice core science in multinational collaborations has long been recognized. In the last two years, this has led to the "International Partnerships in Ice Core Sciences (IPICS)", an open planning body of currently 18 nations that has identified the most important scientific questions to be addressed in future ice core projects. These questions have been channeled into four IPICS white papers (www.pages-igbp. org/science/initiatives/ipics/), which are also summarized in this issue of PAGES news. The timing of this newsletter is also fitting, considering the upcoming International PolarYear (IPY). IPY will be the starting line for many of these future ice core projects, which will keep us glaciologists busy for another 10-20 years, and will provide the paleoclimate community with more detailed, quantitative and potentially paradigm-changing ice core results.

HuBERTUS FISCHER

PAGES Guest Editor

Alfred-Wegener-Institute for Polar and Marine

Research, Bremerhaven, Germany

hufischer@awi-bremerhaven.de

\section{PAGES newsletters: Would you prefer a digital copy?}

\section{Digital Newsletter}

PAGES News is also available electronically. If you subscribe to the digital newsletter, we will send you an email each time a new issue is published, with the link to the website where you can download a low- or highresolution Acrobat pdf. If you would like to sign up for the digital version, please send an email to Leah Christen (christen@pages.unibe.ch).

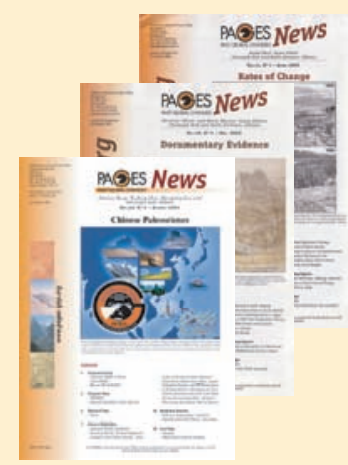




\section{Inside PAGES}

Lately, the PAGES IPO has been buzzing with visitors. Denis-Didier Rousseau (France) spent a week at the IPO preparing a Loess-dust activity, Hubertus Fischer (Germany) was in the office to guest-edit this special issue and work on the new IPICS website, Isabelle Larocque (Canada) is helping to establish a new PAGES Databoard Working Group and meeting, Dmitry Sonechkin (Russia) discussed a contribution to the PAGES/CLIVAR Intersection, Olga Solomina (Russia) will help to guestedit a GPC special issue on climate change in mountain regions, and Bert Rein (Germany) will be here to set up the National PAGES Germany website. More information about PAGES Guest Scientist Program can be found at: www.pages-igbp.org/ people/guestscientists.html.

\section{Outgoing PAGES SSC members}

At the end of 2005, PAGES Scientific Steering Committee said farewell to Daniel Olago (Kenya), Ashok Singhvi (India), and Olga Solomina (Russia). All three members made enormous contributions to PAGES during their time on the committee especially in building the community in their home countries, and we gratefully acknowledge their help and dedication. An open call for nominations for one additional SSC member will close 15 September 2006. We particularly encourage nominations of paleoscientists from Russia and former Soviet Union countries, since this geographic region is currently underrepresented on the SSC. For details on the nomination procedure, please go to: www.pages-igbp.org/people/ sscleaders/nominations.html.

\section{Incoming PAGES SSC members}

PAGES welcomes four new members to its SSC this year. Bette Otto-Bliesner (USA) is Head of the Paleoclimate Group at NCAR and Lead Author of the IPCC paleoclimate chapter. She brings knowledge and experience of climate modeling to the SSC. Indra Bir Singh (India) is Professor of Geology at the University of Lucknow. He has a background in terrestrial paleoenvironmental science and brings new expertise in sedimentology to the SSC. Mohammed Umer (Ethiopia), a palynologist, is Associate Professor of Earth Sciences at the University of Addis
Ababa. He has been active in PAGES as the PEP III African Coordinator. Cathy Whitlock (USA), a paleoecologist, is Professor of Earth Sciences at Montana State University. She has important links to the modeling and paleo-ecology communities.

\section{PAGES jobs database}

PAGES free online listing of paleoscience jobs has just been expanded to include a quick and simple form for you to add your job offer directly to the jobs page. Jobs are divided into categories (PhD, faculty, etc.) and will be posted the same day. Post or search for jobs at: www.pages-igbp. org/services/jobs/.

\section{Next issue of PAGES News}

The next issue of the PAGES newsletter will be published in July. Please send your general contributions to the open section, as well as program news, workshop reports and humorous tales from the field, to Christoph Kull (kull@pages. unibe.ch) by 15 May. Guidelines for contributions can be found at www.pages-igbp.org/products/ newsletters/instructions.html.

\section{HOLIVAR 2006 Open Science Meeting: Natural Climate Variability and Global Warming}

12 - 15 June 2006; Environmental Change Research Centre, University College London, UK

The meeting will examine how and why the natural climate system varies and assess the relative importance of natural processes and human activity in explaining global warming.

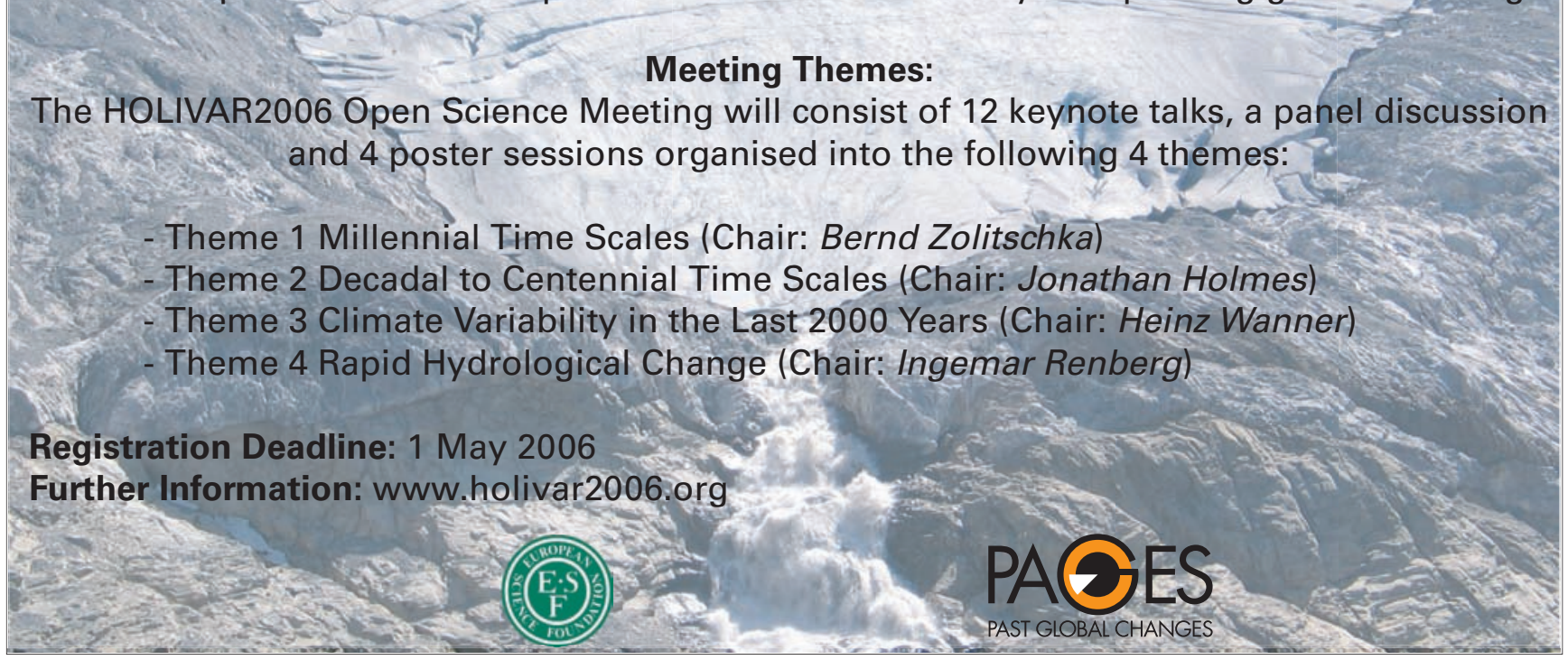




\section{Announcements}

\section{New on the PAGES bookshelf}

\section{Quaternary Research special issue: Late Quaternary Tropical Ecosystem Dynamics}

Rob Marchant and Hermann Behling (guest editors)

Quaternary Research, Vol. 64 (3), 2005

This special issue resulted from the session “Late Quaternary Tropical Ecosystem Dynamics: A Sensitive Tool for Unravelling Climate, Ecological and Human Impacts" convened in Granada, Spain, at the XIVth International Palynology Congress (IPC) in July 2004 and supported by PAGES.

\section{Contents:}

- Editorial: Late Quaternary tropical ecosystem dynamics, Rob Marchant and Hermann Behling

- Modern pollen-rain characteristics of tall terra firme moist evergreen forest, southern Amazonia, William D. Gosling, Francis E. Mayle, Nicholas J. Tate and Timothy J. Killeen

- Holocene dryness and human occupation in Brazil during the "Archaic Gap", Astolfo G.M. Araujo, Walter A. Neves, Luís B. Piló and João Paulo V. Atui

- 15,000-yr pollen record of vegetation change in the high altitude tropical Andes at Laguna Verde Alta, Venezuela Valentí Rull, Mark B. Abbott, Pratigya J. Polissar, Alexander P. Wolfe, Maximiliano Bezada and Raymond S. Bradley

- Paleoecological and climatic changes of the Upper Lerma Basin, Central Mexico during the Holocene, Beatriz Ludlow-Wiechers, Lucia Almeida-Leñero and Gerald Islebe

- Quantification strategies for human-induced and natural hydrological changes in wetland vegetation, southern Florida, USA, Timme H. Donders, Friederike Wagner and Henk Visscher - A 23,000-yr pollen record from Lake Euramoo, Wet Tropics of NE Queensland, Australia, Simon G. Haberle

- A Holocene pollen and diatom record from Vanderlin Island, Gulf of Carpentaria, lowland tropical Australia , Matiu Prebble, Robin Sim, Jan Finn and David Fink

- A comparison of late Quaternary forest changes in New Caledonia and northeastern Australia, Janelle Stevenson and Geoffrey Hope

- Interactions between human activity, volcanic eruptions and vegetation during the Holocene at Garua and Numundo, West New Britain, PNG, W.E. Boyd, C.J. Lentfer and J. Parr

- How a wet tropical rainforest copes with repeated volcanic destruction, Leigh C.F. Jago and William E. Boyd

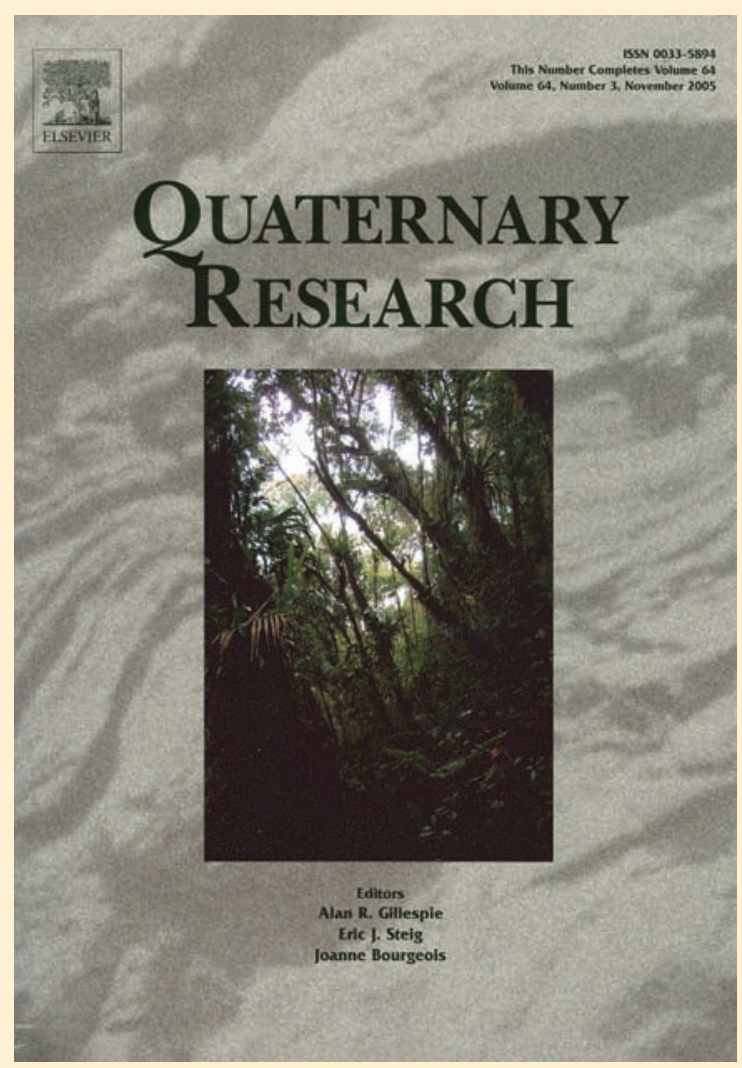

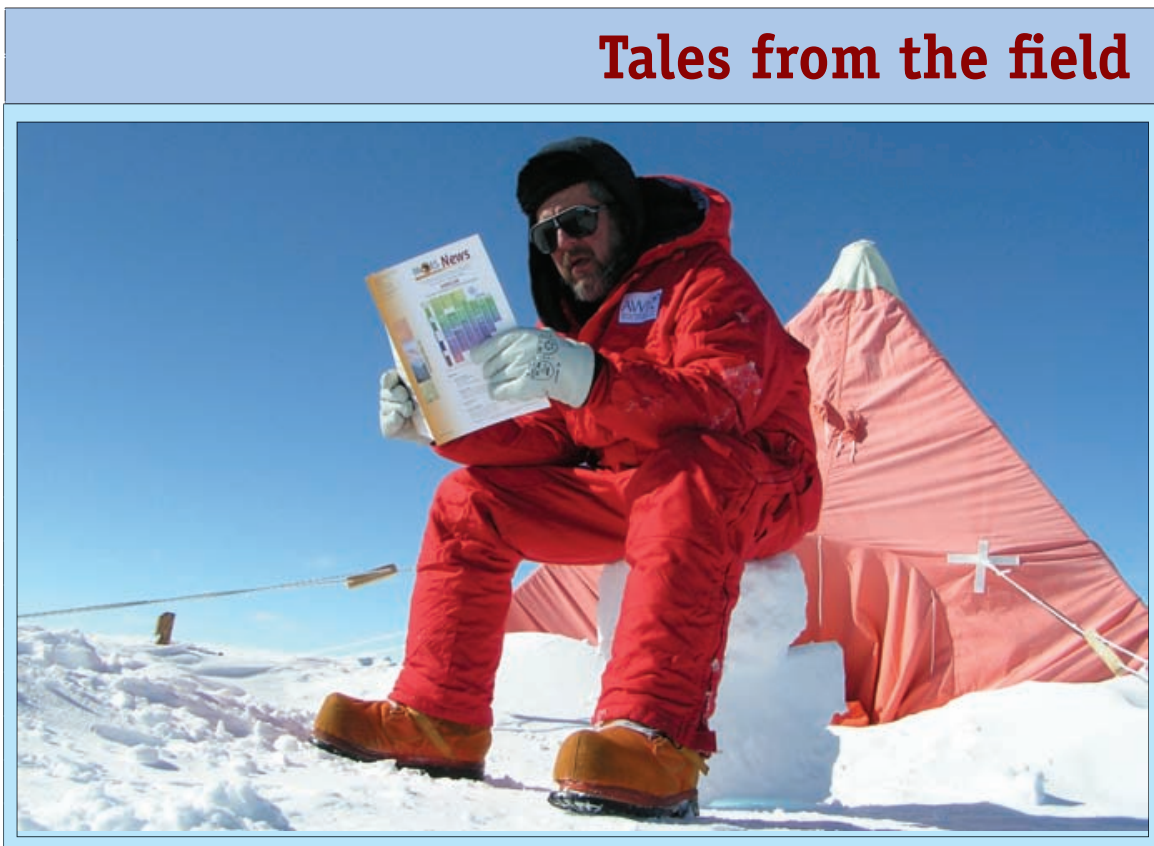

PAGES on ice:

Fernando Valero-Delgado from the Alfred-Wegener-Institute for Polar and Marine Research is not only the first Ecuadorian to reach the North Pole but most likely also the one who has advanced furthest into the Antarctic. Here he takes a break from the EPICA ice core drilling in Dronning Maud Land, Antarctica, $\left(0^{\circ} \mathrm{W}, 75^{\circ} \mathrm{S}\right)$ with some relaxing literature.

Photo: Johannes Freitag, AWI, Bremerhaven, Germany 


\section{Nick Shackleton}

One of the most eminent geoscientists of all times

Professor Sir Nicholas Shackleton, "Nick", passed away on 24 January 2006, at the age of 69.

Since the late 1960s, when Nick had started to develop the techniques required for high-resolution isotope stratigraphy, he was at the forefront of research in paleoclimate and remained one of the most influential and brilliant scientists in this field. These techniques were fundamental in allowing us to obtain the first isotope records showing the history of ice-sheet fluctuations during the Quaternary. The reconstructed glacial-interglacial cycles were not only more numerous than previously supposed but also matched the long-term variations of the astronomical parameters. The paper he co-authored with Jim Hays and John Imbrie in Science in 1976, now a classic citation and one of the most important Quaternary research papers ever, showed that the variations in the Earth's orbit and axis of rotation are the pacemakers of the major climatic changes during the Quaternary. This paper, for the first time, validated the "Milankovitch" hypothesis.

Nick devoted most of his life to the investigation of the relationship between orbital forcing and climatic changes. He was particularly influential in the development of high-resolution astronomically tuned timescales for geological records, the re-evaluation of the Bruhnes-Matuyama geomagnetic polarity reversal and the investigation of high-frequency climate changes during the last glacial cycle. More recently, the success of the Quaternary isotope sequences convinced him to extend his research into the Neogene (and even the $\mathrm{Pa}$ leogene). His effort contributed to the determination of an unprecedented continuous high-resolution timescale for the last fifteen million years. One of his last major contributions, published in Science in 2000, clarifies a long-standing puzzle of the phaserelationship between astronomical forcing, ice sheets, carbon dioxide concentration and ocean temperature.Throughout his career, Nick advised a large number of scientists at all levels and participated in numerous commissions in charge of clari-

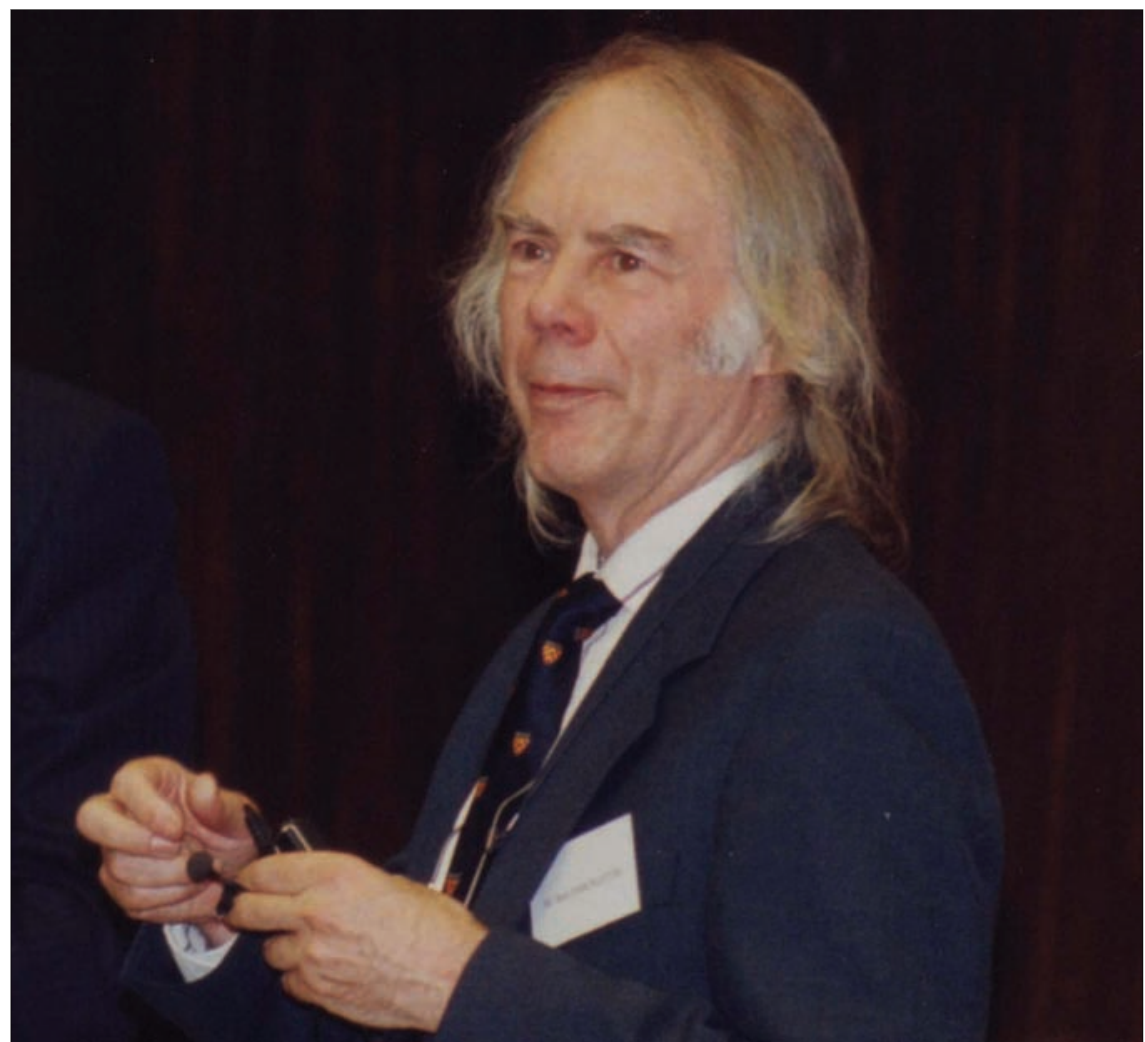

Nick Shackleton at the meeting on "Climate and Ozone at the Dawn of the Third Millennium" organized by Drs A. Ghazi and A. Berger in Brussels, 13-14 May 1996 in honor of Paul Crutzen (Nobel Prize 1995), B. Bolin (Blue Planet Prize 1995), W. Dansgaard and N. Shackleton (Crafoord Prize 1995). Photo by André Berger.

fying Cenozoic stratigraphy. His role in INQUA, where he was President from 1999 to 2003, was particularly influential, leading to the Union becoming a full member of the International Council of Scientific Unions in 2005. Furthermore, he was one of the pioneers who launched the IMAGES program within PAGES in the mid 1990s, served as a member on the IMAGES SSC, and demonstrated in numerous papers how a new generation of high-resolution paleoceanographic sediment records from well-chosen high-rate deposition sites can uncover mechanisms of rapid climate changes.

In view of such accomplishments, it is not surprising that Nick received the most prestigious awards allocated to geosciences: the Blue Planet Prize of the Asahi Glass Foundation (2005) and the Crafoord Prize of the Royal Swedish Academy of Sciences (1995). He was Fellow of the Royal Society, Foreign Associate of the US National Academy of Sciences, and an Honorary Doctor of Dalhousie,
Stockholm and Padova Universities. He was invited to deliver many prestigious lectures and was awarded a knighthood by Queen Elizabeth II for "services in the Earth Sciences" in 1998. Nick was not only a renowned scientist but also a brilliant clarinetist. His collection of clarinets is unique in the world (even more so than his scientific work, he told me once!) One of his great pleasures was performing in dedication to his friends each time he had the opportunity.

Professor Sir Nicholas Shackleton was definitely one of the greatest geoscientists of all times, but most of us are also losing Nick, a good friend.

\section{ANDré Berger}

Honorary President

European Geosciences Union

Institut d'Astronomie et de Géophysique Université Catholique de Louvain Louvain-la-Neuve, Belgium berger@astr.ucl.ac.be 


\section{The future of ice coring: International Partnerships in Ice Core Sciences (IPICS)}

Edward J. Brook ${ }^{1}$, Eric WolfF ${ }^{2}$, Dorthe Dahl-Jensen ${ }^{3}$, Hubertus Fischer ${ }^{4}$, Eric J. Steig ${ }^{5}$, on behalf of the IPICS Steering Committee

'Dept. of Geosciences, Oregon State University, Corvallis, USA; brooke@geo.oregonstate.edu

${ }^{2}$ British Antarctic Survey, Cambridge, UK; ewwo@bas.ac.uk

${ }^{3}$ Niels Bohr Institute, University of Copenhagen, Denmark, ddj@gfy.ku.dk

${ }^{4}$ Alfred Wegener Institute, Bremerhaven, Germany; hufischer@awi-bremerhaven.de

${ }^{5}$ Dept. of Earth and Space Sciences, University of Washington, Seattle, USA; steig@ess.washington.ed

\section{Introduction: Goals of IPICS}

Ice cores provide information about past climate and environmental conditions on timescales from decades to hundreds of millennia, and direct records of the composition of the atmosphere. As such, they are cornerstones of global change research. For example, ice cores play a central role in showing how closely climate and greenhouse gas concentrations were linked in the past, and in demonstrating that very abrupt climate switches can occur. With the completion of major projects in Greenland and Antarctica over the last 15 years, the international ice coring community is planning for the next several decades. The costs and scope of future work create the need for coordinated international collaboration. Developing this international collaboration is the charge of IPICS, International Partnerships in Ice Core Sciences, a planning group currently composed of ice coring scientists, engineers, and drillers from 18 nations.

Two international meetings in 2004 and 2005 (Brook and Wolff, 2006) lead to an ambitious four-element framework that both extends the ice core record in time and enhances spatial resolution. The four projects were defined as:

1) A deep ice coring program in Antarctica that extends through the mid-Pleistocene transition, a time period where Earth's climate shifted from 40,000 year to 100,000 year cycles.

2) A deep ice core in Greenland recovering an intact record of the last interglacial period.

3) A bipolar network of ice core records spanning approximately the last 40,000 years.

4) A global network of ice core records spanning the last 2,000 years.
A fifth, and critical, element of IPICS is the development of advanced ice core drilling technology.

\section{The oldest ice core}

- A 1.5 million year record of climate and greenhouse gases from Antarctica

We currently live in the latest warm phase in a series of cold/warm oscillations occurring every 100,000 years. Ice core records show that for the last 650,000 years, carbon dioxide and other greenhouse gases have been closely linked to these climate cycles (Fig. 1). However, we still lack understanding of the natural regulation of carbon dioxide, and the amplifications that make the climate system so sensitive. Both of these factors are important as we try to predict the future.

Furthermore, our oldest ice core, from the European Project for Ice Coring in Antarctica (EPICA), extends back 800,000 years into the past. However, we know that just before this time, the characteristic frequency of climate variability was different, with cycles of 40,000 years (Fig. 1). The origin of this shift is a major puzzle. Studying the interactions of climate and biogeochemistry during and before the transition will allow us to:

- Understand the natural variability that has led to our current climate.

- Test the hypothesis that the change from 40,000 to 100,000 year cycles was caused by a lowering of atmospheric carbon dioxide concentrations.

- Better understand the timescales and processes that control exchange of carbon dioxide (including excess $\mathrm{CO}_{2}$ from human activities) between reservoirs, and the links between climate and the natural cycles of gases such as methane, and of terrestrial and marine aerosols.

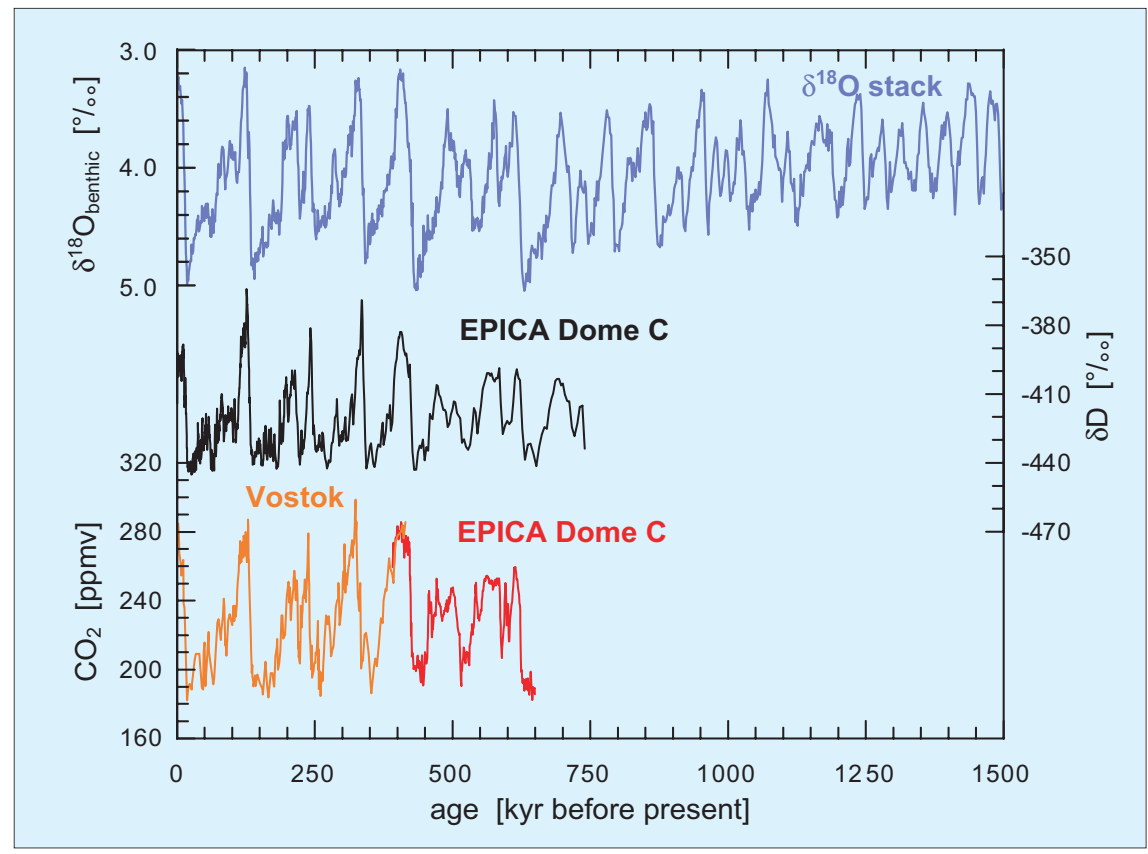

Fig. 1: Top: benthic oxygen isotope stack from Lisiecki and Raymo (2005) showing the shift from $40 \mathrm{ka}$ to $100 \mathrm{ka}$ global climate cycles in the mid-Pleistocene. Middle: EPICA Dome C stable isotope record showing the evolution of central east Antarctic climate for the last 800,000 years (EPICA community members, 2004). Bottom: $\mathrm{CO}_{2}$ record from the Vostok (Petit et al., 1999) and Dome $C$ ice cores (Siegenthaler et al., 2005). 


\section{Program News: Ice Core Science}

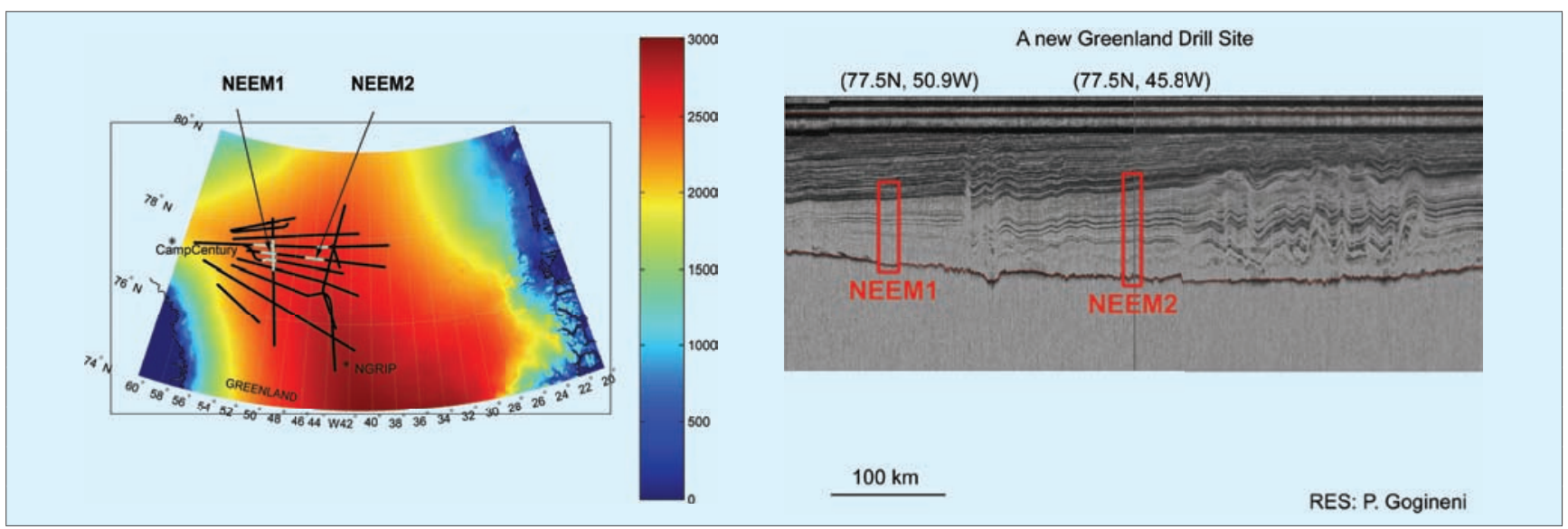

Fig. 2: Left: Surface elevation ( $m$ ) of the northern section of the Greenland ice sheet (Bamber et al., 2001) and radar echo sounding section from NEEM 1 to NEEM 2 (http://tornado.rsl.ku.edu/Greenlanddata.htm). NEEM 1 is the likely location of the new core in NW Greenland.

To accomplish these objectives, we need to obtain a reliable ice core record of climate and biogeochemistry extending through several of the 40,000 year cycles and up to the present. This requires that we produce a replicated record extending at least 1.2 million and, preferably, 1.5 million years into the past.

Undoubtedly, ice older than 800,000 years does exist in the Antarctic ice sheet. The first task will be to carry out an iterative process of modeling and survey to identify possible sites in the relatively littlesurveyed interior of East Antarctica, where accumulation rates are low and ice thickness is high. Observation of internal radar layers, allowing us to follow layers of known age from existing drill sites, will be critical.

The drilling itself poses no unique technical challenges, apart from extremely cold conditions, but will require a significant logistical effort. Some required survey work is already planned for the International Polar Year (IPY; 2007-2008). IPICS will assess the results of this work in order to recommend one or more target drilling sites. Many recent major ice core projects have been multinational, and we anticipate that the pooled survey, drilling, analytical and intellectual capacity of all the major players will be needed to achieve the Oldest Ice project.

IPICS will now start drawing up plans for how to implement the project, with drilling starting early in the next decade.

\section{The last interglacial and beyond}

- A northwest Greenland deep ice core drilling project

Greenland ice cores provide a compelling picture of the abrupt, milIennial-scale, climatic flips of the last glacial period (DansgaardOeschger events). Understanding the cause of these events, and their implications for future change, is one of the hottest topics in climate studies, with significant policy implications. However, the existing Greenland cores are deficient in one important respect. The last interglacial (Eemian) has proved to be a difficult target; even in the most recent NorthGRIP core (NGRIP Members, 2004), the Eemian record was incomplete due to basal melting.

The last interglacial period is critical because it appears to have been warmer than the present, allowing us to see what happens in a climate like the one we are approaching. Models suggest that the Greenland ice sheet will waste away under warmer conditions; the last interglacial provides a test of such models. Supplementing existing low-resolution records from other archives, a new Greenland ice core would indicate the character of the Eemian in the North Atlantic region and allow us to:

- Chart the full course of an interglacial from termination to inception at very high resolution.

- Determine if rapid climate changes occurred in such a warmer climate or in the preceding glacial period.

- Relate climate variations from the present and the last interglacial period to the predicted scenarios under global warming.
IPICS plans to obtain a reliable highresolution Greenland ice core record of the onset of the Eemian period and possibly the previous glacial perioda record of at least 140,000 years. The first step is to identify a suitable site, where the full Eemian period is present and not disturbed by flow. Based on radio echo sounding profiles produced by the University of Kansas, the team at the University of Copenhagen has deduced that the most likely candidate area is in northwest Greenland (Fig. 2). They traced internal layers dating back to 82,000 years before present to a preferred site where the ice is $2542 \mathrm{~m}$ thick, and the Eemian section is estimated to be $80 \mathrm{~m}$ thick, with no signs of folding or other problems.

IPY is a target for the start of the deep Greenland drilling. The logistical, technological and scientific challenges require an international effort that builds on the successful North GRIP program, and scientists from several nations have already expressed interest in participating.

\section{The IPICS 40,000 year network}

- A bipolar record of climate forcing and response

Recent paleoclimate reconstructions clearly document that the Earth's climate is an intricate interplay of oceanic, atmospheric, biogeochemical, and cryospheric processes. However, the reasons for changes in greenhouse gas concentrations and aerosol loads, sea-level and ice masses, as well as their coupling to atmospheric and ocean circulation, are still not sufficiently understood. Previous ice core records from cen- 
tral Greenland and East Antarctica defined the overall features of glacial and interglacial periods and transitions between them, and the characteristics of rapid climate change during the last ice age, at a few individual sites. However, the spatial evolution of deglaciation and abrupt climate change, particularly differences between northern and southern hemisphere patterns, and the processes responsible for those changes, cannot be diagnosed from single locations. The IPICS 40,000 year network of temporally synchronized, high-resolution ice cores from both polar regions will provide data needed to decipher climate change mechanisms. The focus is on the last 40,000 years because this period includes the major Earth System reorganizations of the last glacial-interglacial transition, climate variations of the Holocene, and the well-dated and documented sequence of abrupt climate changes in marine isotope stage 3 (Fig. 3). The 40,000 year network will:

- Determine spatial patterns in environmental parameters related to ocean surface conditions (e.g. sea ice and marine biological productivity).

- Construct the sequence of events from 40,000 years to present in different geographic areas of both polar regions at the highest resolution possible.

- Synchronize the new records using high-resolution measurements of $\mathrm{CH}_{4}, \mathrm{CO}_{2}$, and dust, as well as isotopic compositions of air components.

- Quantify the spatial and temporal evolution of rapid climate changes in both polar regions.

- Identify climate modes and teleconnection patterns under different climate boundary conditions (orbital forcing, greenhouse gas concentration, land ice masses). In addition, we need to understand the response of the ice sheets to climate change. Ice sheet models differ in predictions of the extent and thickness of the major ice sheets at the Last Glacial Maximum, and their contribution to global sea level. With the expansion of the ice sheets dur-

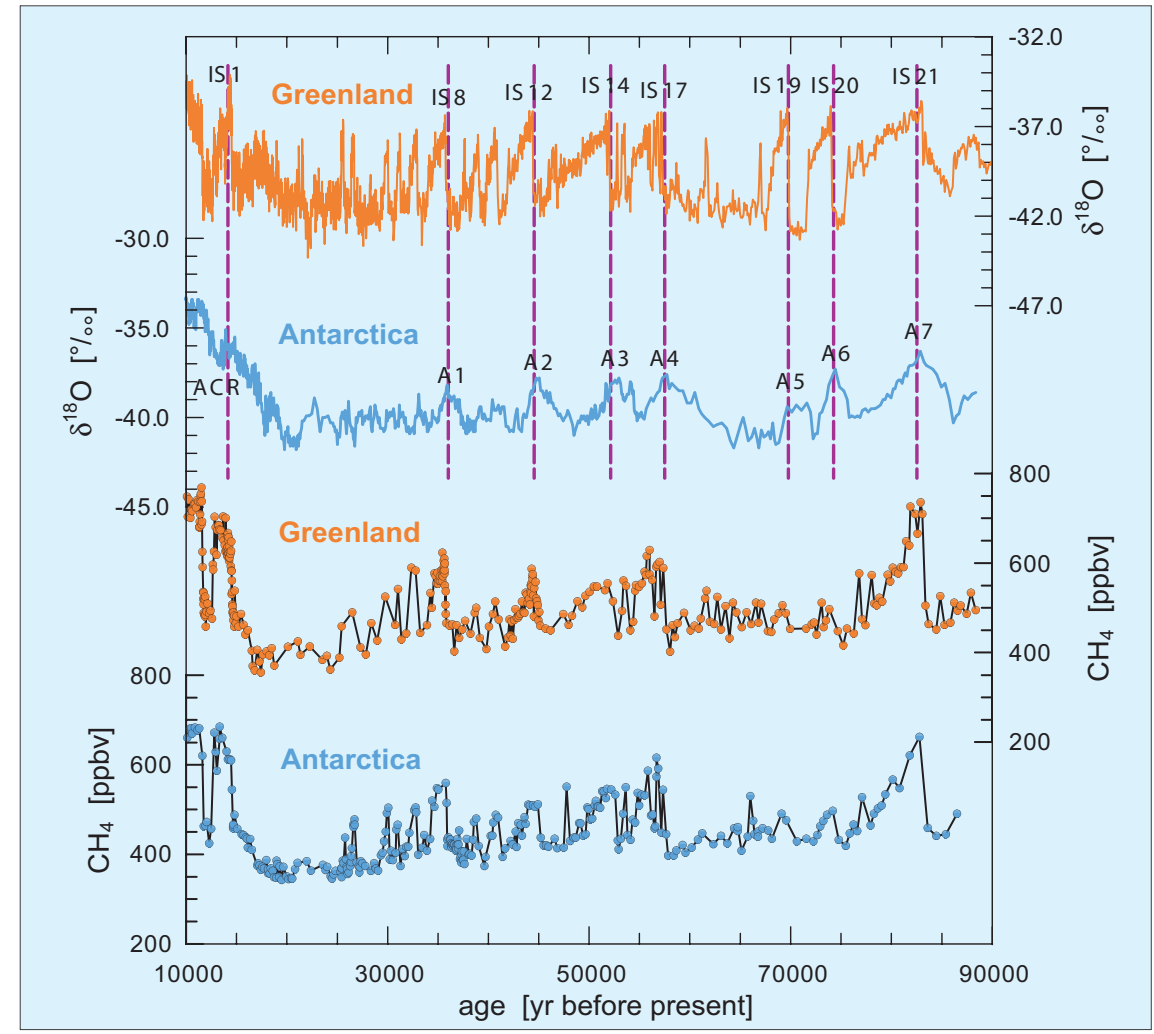

Fig. 3: Comparison of climate records from Antarctica and Greenland covering the last 90,000 years. The last 40,000 years is the best documented time period of both abrupt shifts in climate in both hemispheres, and the large change from glacial to interglacial conditions. From Blunier and Brook (2001).

ing the glacial period, some modern coastal ice domes may have merged with the inland ice. Ice cores from these locations can provide basic information (snow accumulation, temperature, altitude, ice sheet extent) on changes in the mass balance of ice caps and ice sheets.

A site selection team will identify optimal new core sites and coordinate cooperation between individual coring projects. A science plan will be developed to ensure that comparable data sets will be available for all drill sites, and to coordinate efforts for process-related studies in parallel to the deep ice core drilling. Two new sites have already been identified and will be completed in the near future: WAIS Divide (see Severinghaus, this issue) and Talos Dome (see Morgan, this issue). Further cores will complete the network over the following decade.

\section{The IPICS $2 \mathrm{k}$ array}

- A network of ice core climate and climate forcing records for the last two millennia.

Climate variability on decadal to century timescales is too low in frequency to be assessed from the instrumental record, and too spatially heterogeneous to be adequately characterized by the small number of existing highly resolved, well-dated paleoclimate records. For example, temperature reconstructions for the past thousand years remain widely debated because there are insufficient data prior to about AD 1600. The spatial and temporal variability of past precipitation, atmospheric circulation, and sea ice extent on these timescales remains even less well known. Similarly, while greenhouse gas concentrations are globally well mixed and can be determined from a small number of records, variations in important climate feedback variables, such as continental dust and pollution aerosol concentrations, are highly regional. Improved reconstructions of all of these variables are needed to answer fundamental questions about the natural variability of the climate system, and to put potential anthropogenic climate change in context.

Polar regions and high altitudes are especially poorly represented. Recent work under the International Trans Antarctic Scientific Expedition 


\section{Program News: Ice Core Science}

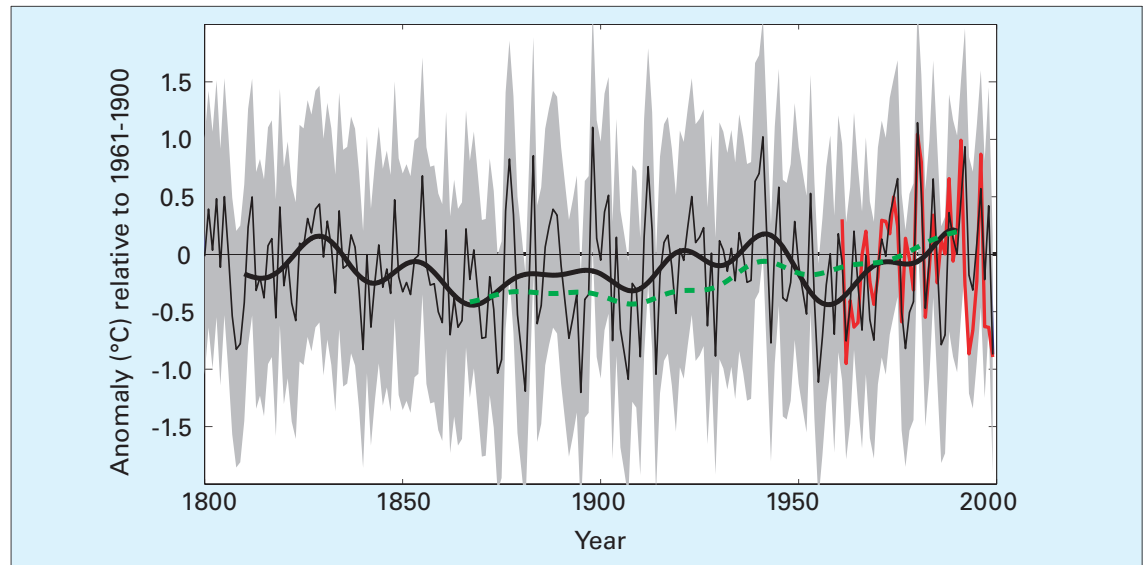

Fig. 4: Reconstructed continent-wide average Antarctic temperature anomalies from calibrated ice core stable isotope records. Black lines show annual data, 20-year smoothing (bold), and 2s (annual) uncertainties. Also shown for comparison are annual average Antarctic temperatures from instrumental data (red), and 20-year smoothed instrumental records of Southern Hemisphere temperature (dashed green). After D.P. Schneider, PhD thesis, University of Washington, 2005.

(ITASE) program in Antarctica (see Mayewski, this issue) demonstrated the feasibility of obtaining quantitative climate reconstructions on these timescales, given sufficient number and distribution of highly resolved records (Fig. 4).

However, most existing ice core records have inadequate temporal resolution, are too short to allow for quantitative reconstructions greater than one or two centuries in length, or do not overlap with modern satellite observations. The IPICS 2k Array will provide a larger network of ice cores, extending high altitude and high latitude proxy climate and climate forcing observations to the last two millennia. The target time frame of two thousand years (2k) includes both the industrial era and a long enough prior period to allow statistically meaningful assessment of natural century-scale variability. This will provide an ice core contribution to the global climate reconstructions being presented to policymakers. Important criteria for records in the IPICS 2k Array include:

- The highest possible resolution, and precise and accurate dating.

- Spatial distribution that captures the dominant patterns of climate variability.

- Multiple data sets from each core, to enable combination of multiple records in statistically meaningful reconstructions.

The IPICS 2k Array will build on results from previous and ongoing ice core networks, including the dozens of ice cores collected in Greenland (see McConnell, this issue) and on the Arctic islands, in Antarctica, and from high mountains at lower latitudes. While many of these records are only $100-200$ years in length, they can provide guidance for the selection of new drilling locations. At other locations, existing long records will need to be updated because many provide only limited information after the 1970s (when satellite measurements began), hampering calibration.

Compilation and analysis of existing data will be an important part of the effort, including improved statistical analyses and the use of tracer-enabled general circulation models. International planning and logistics cooperation for core collection and analysis will be needed. Archiving data at a single World Data site is planned.

\section{Ice core drilling technology}

- Improvements in drilling technology are needed to accomplish the IPICS goals.

Major issues include finding a replacement for commonly used drilling fluid components being phased out for environmental reasons, developing a system for replicate coring from the same ice core borehole, and drilling in relatively warm ice near the bed/ice interface, which has proved difficult in a number of recent projects. A fluid that will allow drilling in very cold ice in East Ant- arctica, where the longest ice core records are expected, is a particular need, currently being addressed by drilling engineers. Lightweight drills capable of drilling to perhaps 1000 $\mathrm{m}$, and deployed without heavy logistics loads, will also be important.

\section{Implementing IPICS}

A major purpose of the IPICS2 meeting in Brussels (October 2005) was to establish consensus around the four IPICS projects, and to develop a steering committee and timeline for future work. At this meeting also representatives from PAGES (Past Global Changes) and SCAR (Scientific Committee on Antarctic Research) participated and a formal relationship between IPICS and these organizations is currently discussed. With the consensus in hand, writing teams have finalized "white paper" documents for each project, and are now moving on to developing detailed science and funding plans (for details of the white papers see http:// www.pages-igbp.org/ipics). A steering committee with representatives from all the nations involved has been formed, and a third meeting is planned within the next year or two to discuss and adopt the science plans. Initial stages of IPICS projects should be underway by then, and the scientific community can look forward to a richer spectrum of ice core data in the future.

\section{Project facts}

Project: International Partnership in Ice Core Sciences (IPICS)

Contact: Ed Brook (brooke@geo.oregonstate. edu), Eric Wolff (ewwo@bas.ac.uk)

Participants: Scientists from Australia, Belgium, Canada, China, Denmark, France, Germany, Italy, Japan, Korea, Netherlands, New Zealand, Norway, Russia, Sweden, Switzerland, United Kingdom, United States

Funding: Support for planning from US NSF and European Polar Board. Support for projects to be sought from national agencies.

Where: Global

When: 2006 and following 1-2 decades

What: Comprehensive international ice coring program on all available timescales, multiparameter data sets

Web page: www.pages-igbp.org/science/ initiatives/ipics/ 


\section{REFERENCES}

Bamber, J. L., Ekholm, S. and Krabill, W.B., 2001: A new, high-resolution digital elevation model of Greenland fully validated with airborne laser altimetry, Journal of Geophysical Research, 106(B4): 6733-6746, 10.1029/2000JB900365

Blunier, T. and Brook, E.J., 2001: Timing of millennialscale climate change in Antarctica and Greenland during the last glacial period, Science 291: 109-112.

Brook E. and Wolff, E., 2006: The future of ice core science, EOS, 87 (4): 39.

EPICA-community-members, 2004: Eight glacial cycles from an Antarctic ice core, Nature, 429: 623-628.
Lisiecki, L. E., and Raymo, M.E., 2005: A Pliocene-Pleistocene stack of 57 globally distributed benthic $\delta^{18} 0$ records, Paleoceanography, 20, doi:10.1029/.

NGRIP Members, 2004: High resolution record of northern hemisphere climate extending in to the last interglacial period, Nature, 431: 147-141.

Petit, J. R., Jouzel, J., Raynaud, D., Barkov, N.I., Barnola J.-M., Basile, I., Bender, M., Chappellaz, J., Davis, M., Delaygue, G., Masson-Delmotte, V., Kotlyakov, V.M., Legrand, M., Lipenkov, V.Y., Lorius, C., Pepin, L., Ritz, C., Saltzman, E., and Stievenard M., 1999: Climate and atmospheric history of the past 420,000 years from the Vostok ice core, Antarctica, Nature, 399: 429-436.
Schneider, D.P., 2005: Antarctic climate of the past 200 years from an integration of instrumental, satellite and ice core proxy data, Ph.D. Thesis, University of Washington, 2005

Siegenthaler, U., Stocker, T. F., Monnin, E., Lüthi, D. Schwander, J., Stauffer, B., Raynaud, D., Barnola J. -M., Fischer, H., Masson-Delmotte, V. and Jouzel, J. 2005: Stable carbon cycle-climate relationship during the late Pleistocene, Science, 310: 1313-1317.

\section{The sea-floor drill rig "MeBo": Robotic retrieval of marine sediment cores}

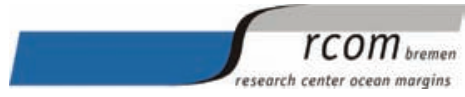

Tim Freudenthal and Gerold Wefer

Research Center Ocean Margins, University of Bremen, Germany; freuden@rcom-bremen.de, gwefer@rcom-bremen.de

Retrieval of marine sediment cores is conventionally carried out either by gravity coring or by drilling from a ship. Although a number of research vessels allow for gravity coring, the length of the retrieved cores is often shorter than desired. While this limitation can be overcome by drilling into deep-sea sediments, the availability and cost of drill-ships imposes a severe limitation on this approach. To bridge this gap in sediment-coring techniques, we developed a remotely operated underwater drill rig "MeBo" ("Meeresboden-Bohrgerät"; German for "sea-floor drill rig"). This portable drill can be operated from research vessels of opportunity. It is deployed on the sea floor and is capable of retrieving 50-m-long cores from sediments and hard rocks.

The drill is an electro-hydraulic system that is remotely controlled from the ship (Fig. 1). A steel armored umbilical with a diameter of $32 \mathrm{~mm}$ is used to lower the 10-tonheavy device to the sea bed, where four legs arm out in order to increase the stability of the rig. Copper wires and fiber optic cables within the umbilical supply energy from the vessel and allow communication between the MeBo and the control unit on deck. The system utilizes commercial rotary core barrels with diamond or tungsten carbide bits, as well as push coring barrels, and can set a casing as needed for various lithologies. The MeBo stores drilling rods and casing tubes, as well as push-coring and rotary barrels, on two rotating magazines that can be loaded with a

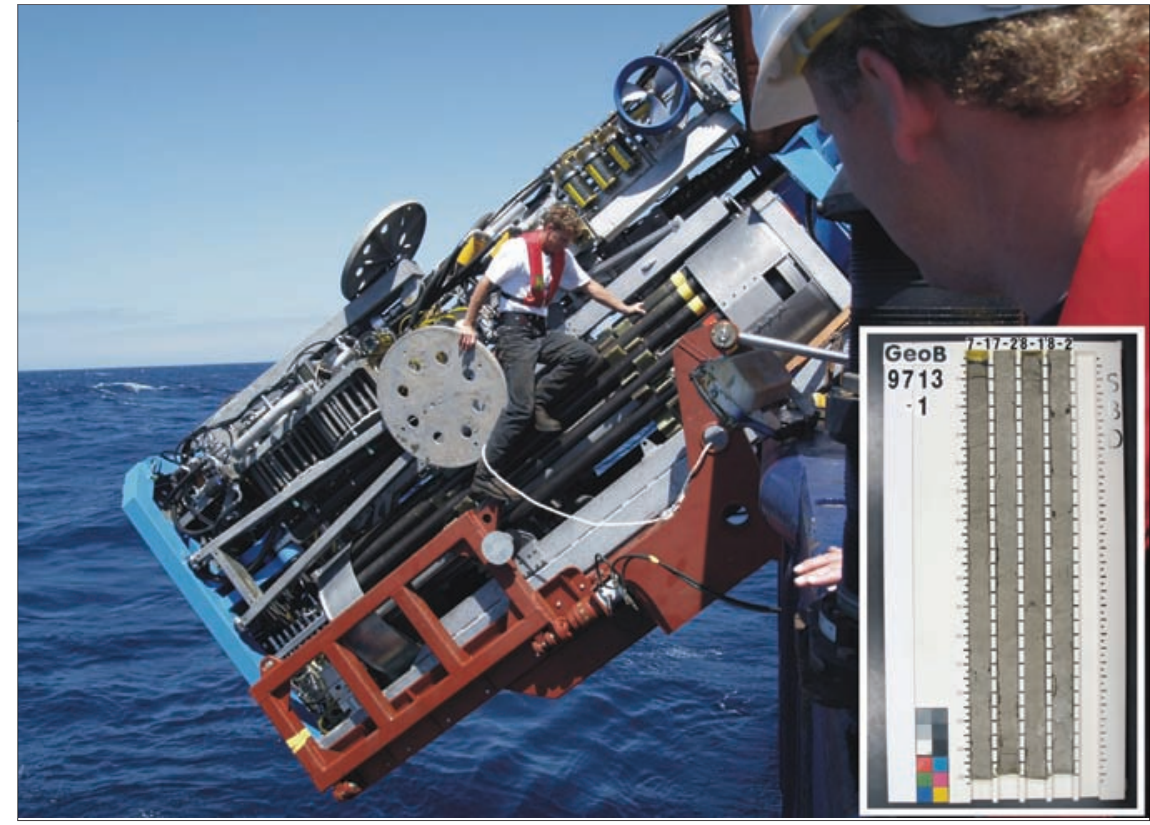

Fig. 1: Last checks on the newly developed sea-floor drill rig MeBo before the first deep-water test from the German research vessel METEOR. (Inset) Consolidated Pliocene marls retrieved by rotary drilling with the MeBo in $1700 \mathrm{~m}$ water depth off NW Africa.

mixture of tools specifically required for a drill job. The drill string is composed of 3-m sections. The MeBo has the capability to drill up to $50 \mathrm{~m}$ into the sea floor, to recover cores with 74-84 $\mathrm{mm}$ diameter, and to stabilize the drilled hole to a depth of $40 \mathrm{~m}$. The complete MeBo system, including drill, winch, launch and recovery system, control unit, as well as workshop and spare drill tools, is shipped within six 20' containers.

The MeBo was successfully tested on two cruises, from the research vessels METEOR (at the continental slope off NW Africa; cruise M65-3) and CELTIC EXPLORER (near the island of Rügen in the southern Baltic Sea; cruise CE0511). During theses tests, the MeBo was deployed ten times in 25-1700 m water depth, with a maximum drill depth of $23.65 \mathrm{~m}$. In total, about $105 \mathrm{~m}$ were drilled in sand, unconsolidated and consolidated marls, as well as glacial till. The total core length recovered was about $50 \mathrm{~m}$. Especially in cohesive sediments, a recovery rate of nearly $100 \%$ was achieved.

A major advantage of the MeBo compared to drill ships is that the drilling operations are independent of any ship movements due to waves, wind or currents. This allows the recovery of non-fractured cores of high quality (Fig. 1, inset). 


\section{Relaunch of PAGES Databoard activities}

ISABELLE LAROCQUE

Institut National de Recherche Scientifique, Centre Eau, Terre et Environnement Québec, Canada; isabelle_larocque@inrs-ete.uquebec.ca

Submitting published data to data centers should be part of the ethics of paleoscience. Data centers have the mandate to collect, organize and provide data to users, but they face reluctance from some scientists to submit their published data. One of the major tasks of the PAGES Databoard, launched in March 2002 (see box), is to "establish a protocol to define the expected flow of data from scientists". Four years after this launch, there is still a lack of engagement from individual scientists from the paleo-community in making their data available. The PAGES SSC recently voted for more prominent actions within the PAGES Databoard. In the new structure of PAGES, data management will become a cross-cutting theme. PAGES thereby aims to reinforce the submission of data from scientists working within PAGES Foci and beyond.

\section{(2) PAGES Databoard}

The PAGES Databoard consists of members from all of the major data archives such as NOAA, PANGAEA and MEDIAS-France as well as from thematic data collection efforts such as the African, European and North American Pollen databases and the IMAGES program. Membership in the PAGES Databoard is open to all interested scientists and organizations.

\section{Goals of the Databoard are to:}

1) establish networks for data management,

2) provide tools to facilitate data contribution,

3) increase data sharing through a common format for data and metadata interchange.

The success of this initiative depends on the cooperation of various database managers but most importantly, it depends on the willingness of individual scientists to submit their data to a participating archive.

\section{Agenda}

First meeting and launch of the initiative: Kandersteg, Switzerland, 4-6 March 2002 Second meeting (planned, closed):

Bern, May 2006

Open meeting: end 2006, early 2007
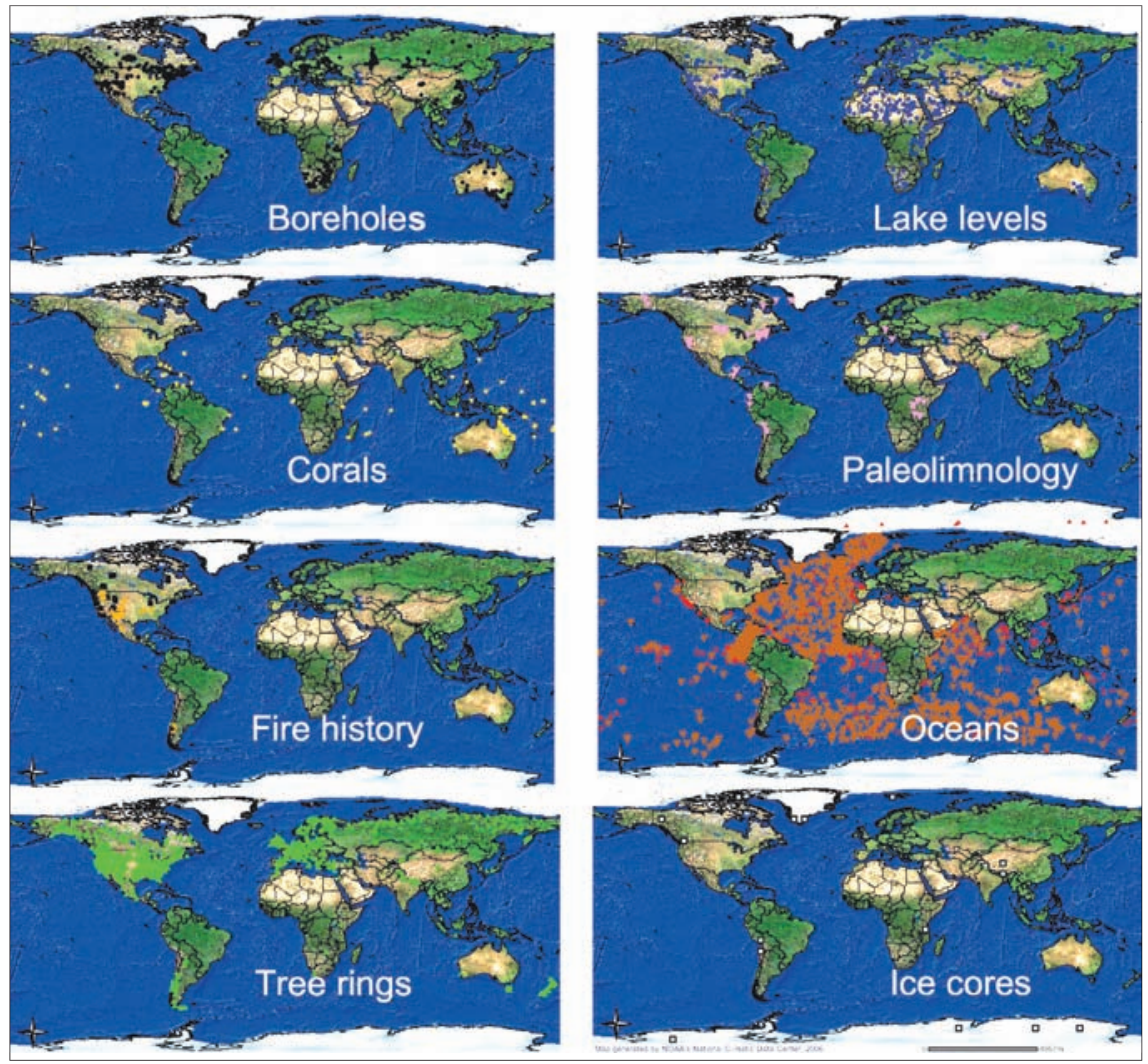

Figure: Maps of the data, divided by paleoarchives, available at the NOAA paleo-data center. The maps were created using free software available on the NOAA website

To reach their goals, data centers need data from around the world, which is far from the case in various paleoresearch fields (see figure). Although many funding agencies have created policies that couple further funding to the submission of data from previous projects, PAGES will adopt a strategy based on science ethics. Every scientist should be proactive in helping to better understand the climate system by submitting his or her individual data to a data center. The more data there is freely available, the easier it is to compare sites and proxies, and to synthesize research results at the local, regional and global scale.

In the new PAGES structure, modeling is emphasized as an integral approach across all Foci, but very few data centers contain modeling data, either input datasets or results from model simulations. This issue will also be targeted by the PAGES Databoard.
The PAGES Databoard will meet in the middle of this year to discuss ways to increase the flow of data to data centers, and to promote a web portal that is user friendly and provides online access to all available data around the world using simple keywords. A list of data centers will soon be updated on the PAGES website. In the following months, PAGES members will be approached in various ways with requests to submit their data to data centers. We hope that by reminding scientists how important data availability is, the PAGES Databoard will strengthen the data-sharing ethic.

If you want to be part of the PAGES Databoard or you want more details on how and where to submit data, please contact Isabelle Larocque at isabelle_ larocque@inrs-ete.uquebec.ca. 


\section{National PACEE}

NATIONAL CONTACT:

\section{Chile}

Dr. Antonio Maldonado

CAEZA, Universidad de La Serena

Casilla 599, La Serena, Chile

amaldonado@userena.cl

www.ceaza.cl/Members/bioloter/Integrantes/Antonio/

Chile is characterized by a wide latitudinal range $\left(18-56^{\circ} \mathrm{S}\right)$, which is reflected in a large number of different ecosystems and geographical features, such as mountains and volcanoes up to almost $6000 \mathrm{~m}$ asl and marine depths of $7800 \mathrm{~m}$. Several types of climate are present, including one of the driest deserts worldwide and one of the more rainy extratropical places, with annual precipitation records up to $8000 \mathrm{~mm}$ in the southern part of Chile. There are three main climatic features that determine this gradient along Chile: the tropical circulation, which brings precipitation to the northern Altiplano plateau; the westerly belt-winds, which affect the entire southern part of Chile; and the subtropical southeastern Pacific anticyclone, which interacts with the westerly belt-wind system and determines the Mediterranean climate in subtropical Chile. Together with these three climatic features, the interaction between the cold Humboldt Stream and the presence of the Andes Cordillera, result in some of the climatic characteristics, such as the hyperaridity of the Atacama Desert. Additionally, Chile is affected by ENSO events.

\section{National Science Highlight: Nothofagus pumilio tree-ring based reconstruction of minimum annual temperature for Chilean Southern Patagonia $\left(519-55^{\circ}\right.$ S) from 1829 to 1996}

\section{Aravena et all., 2002}

Several Nothofagus pumilio tree-ring chronologies have been developed from trees in northern Patagonia, Tierra del Fuego (Photo) in Chile and Argentina and the central Andes in Chile. These studies have demonstrated the relationship between spring-summer climate and Nothofagus pumilio tree-growth. The current climate of the west coast of southern Patagonia is dominated by a precipitation and humidity gradient. Precipitation originates mainly from the influence of the westerly winds. The reconstruction shows (Figure) that during most of the 19th century, minimum annual temperatures remained below average and increased to values fluctuating around the mean during the 1900-1960 period, followed by arclear trend with above-average values after 1963.

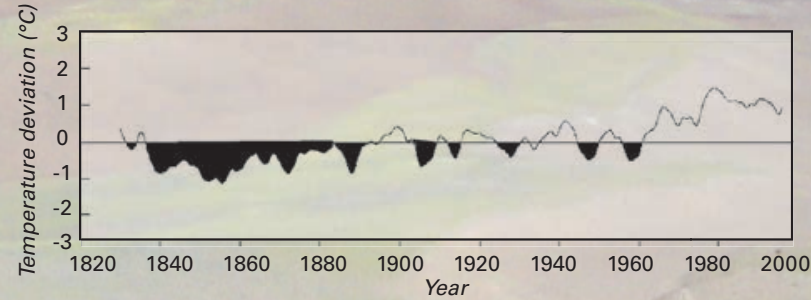

Fig. Nothofagus pumilio tree-ring based reconstruction of minimum annual temperature for Chilean southern Patagonia $\left(51^{\circ}-55^{\circ}\right.$ S) from 1829 to 1996.

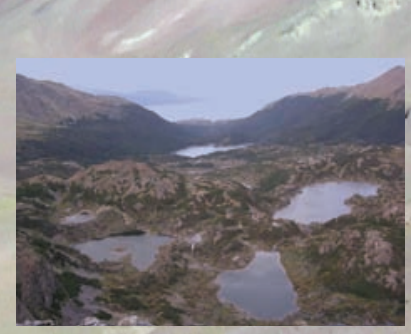

Photo: Nothofagus pumilio forest in Navarino Island in the southern extreme of Chilean Patagonia (55 $\mathrm{S})$

\section{References:}

Aravena, J.C., Lara, A., Wolodarsky-Franke, A., Villalba, R. y Cuq, E. (2002) Tree-ring growth patterns and temperature reconstruction from Nothofagus pumilio (Fagaceae) forests at the upper tree line of southern Chilean Patagonia. Revista Chilena de Historia Natural, 75: 361-376

Villalba, R., Lara, A., Boninsegna, J.A., Masiokas, M., Delgado, S., Aravena, J.C., Roig, F.A., Schmelter, A., Wolodarsky, A. y Ripalta, A. (2003) Large-scale temperature changes across the southern Andes: 20th-century variations in the context of the past 400 years. Climatic Change 59: 177-232.

\section{Research Institutions:}

- CEAZA, Centro de Estudios Avanzados en Zonas Aridas www.ceaza.cl

- FORECOS, Forest Ecosystem Services under Climatic Fluctuations

www.forecos.net

- CEQUA, Centro de Estudios del Cuaternario de Fuego-

Patagonia y Antártica

www.cequa.cl

- COPAS, Center for Oceanic Research

www.copas.cl

- CECS, Centro de Estudios Científicos

www.cecs.cl/web

CMEB, Centro Milenio de Estudios Avanzados en Ecología y Biodiversidad www.cmeb.cl

- CASEB, Center of Advanced Studies in Ecology \& Biodiversity www.bio.puc.cl/case

\section{Funding Agencils}

$$
\text { iil }
$$

Chilean Research Counci www.conicyt.cl

- Fundacion Andes www.fundandes.cl

Number of Chilean subscribers in the PAGES People Database (www.pages-igbp.org/people) on March 7 th: 25 


\title{
The NGT and PARCA shallow ice core arrays in Greenland: A brief overview
}

\author{
Joseph R. McConnell ${ }^{1}$ Sepp Kipfstuhl ${ }^{2}$ and Hubertus Fischer ${ }^{2}$ \\ 'Desert Research Institute, Nevada System of Higher Education, Reno, USA; jmcconn@dri.edu \\ ${ }^{2}$ Alfred-Wegener-Institute for Polar and Marine Research, Bremerhaven, Germany \\ kipfstuhl@awi-bremerhaven.de, hufischer@awi-bremerhaven.de
}

\section{Introduction}

Ice cores provide the most direct and highest temporal resolution record of past atmospheric and precipitation chemistry, and local to regional-scale meteorology. Such records have been used to reconstruct changes in oceanic and atmospheric circulation, to document industrial pollution and volcanic emissions, and to investigate current and past surface mass balance and net snowfall. An ice core chemical record reflects changes in both emissions from the source regions and transport pathways, so arrays of ice core records are required to distinguish between these often covarying phenomena. Moreover, arrays of ice cores offer the potential to identify spatial variability in emissions, climate, and meteorology. Extensive arrays of ice cores (Fig. 1) have been collected recently on the Greenland Ice Sheet (GIS) under two projects: the Alfred-Wegener-Institute North Greenland Traverse (NGT) (following the 1990 to 1992 German/Swiss glaciological study along the old line of the Expedition Glaciologique International au Groenland (EGIG) in central Greenland) and the U.S. Program for Arctic Regional Climate Assessment (PARCA).

\section{North Greenland traverse}

The NGT array includes 33 shallow and 13 deeper ice cores collected as part of 1993 to 1995 overland traverses in the data sparse northern GIS (Fig. 1). Isotopic and glaciochemical analyses on selected cores included discrete measurements of $\delta^{18} \mathrm{O}$, and major and trace ions, which have been used to address a range of geophysical issues. For example, the cores were used to document the preindustrial climate variability and precipitation history in northern Greenland (see below). Fischer et al. (1998) analyzed the array to characterize deposition mechanisms for

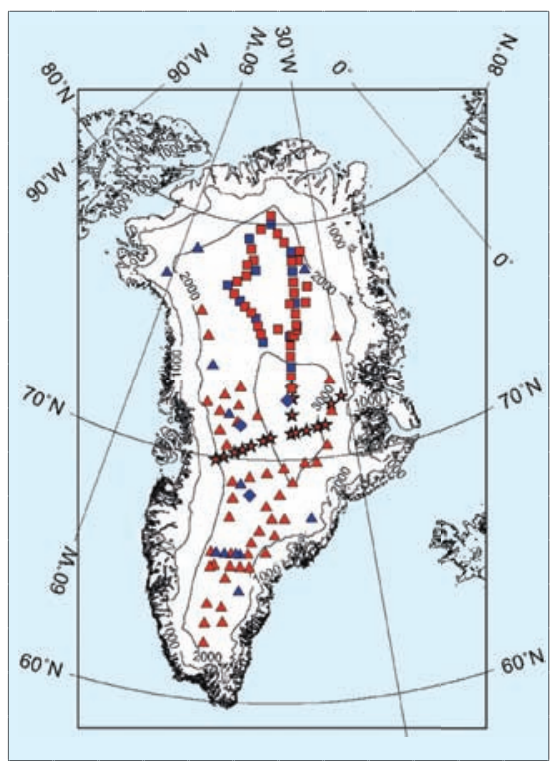

Fig. 1: Map showing locations of the NGT (shallow cores: red squares, deeper cores: blue squares) and PARCA (shallow cores: red triangles, deeper cores: blue triangles) arrays of ice cores in Greenland. Cores identified as shallow are less than $50 \mathrm{~m}$ in depth. Cores funded by NSF (deeper cores: blue diamonds) and EGIG (shallow cores: red stars) are shown for completeness.

nitrate and sulfate (Fig. 2) and the impact of industrial emissions on north Greenland precipitation. More recently, measurements of sea salt tracers from the NGT deeper cores were used to investigate interannual to multidecadal modes in atmosphere/ocean dynamics in the North Atlantic over the past millennium (Fischer and Mieding, 2005).

\section{PARCA campaigns}

Ice cores are the primary indicator of net snowfall over the ice sheet at all temporal scales. The PARCA array of $>80$ ice cores was collected during a series of primarily airborne campaigns beginning in 1995 and continuing to the present, and was designed to investigate the spatial and temporal variability in net snowfall and the meteorological changes that drive that variability. For both logistical and scientific reasons, the array includes mostly cores spanning the last few decades, with a few extending over recent centuries. The majority of the ice cores were collected from higher accumulation, data sparse areas of the central and southern GIS, where altimetry measurements indicate the most change (Fig. 1). For validation of satellite and meteorological model estimates of net snowfall, a multi-parameter approach to dating is used that includes high-resolution chemical measurements from traditional and expanded continuous flow analysis (CFA), together with discrete water isotope, beta radiation, and dust particle measurements for some cores.

Although the primary focus of PARCA has been on snowfall and mass balance, the array also pro-

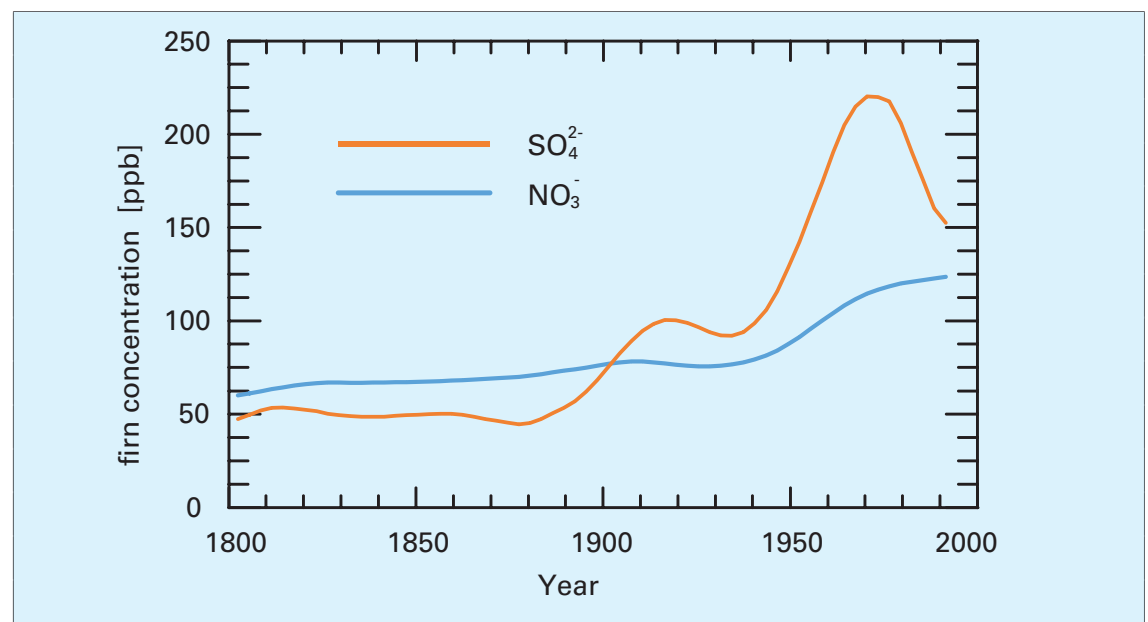

Fig. 2: Long-term trend in sulfate and nitrate concentrations in the NGT B21 $\left(80.0^{\circ} \mathrm{N}, 41.1^{\circ} \mathrm{W}\right)$ core. 


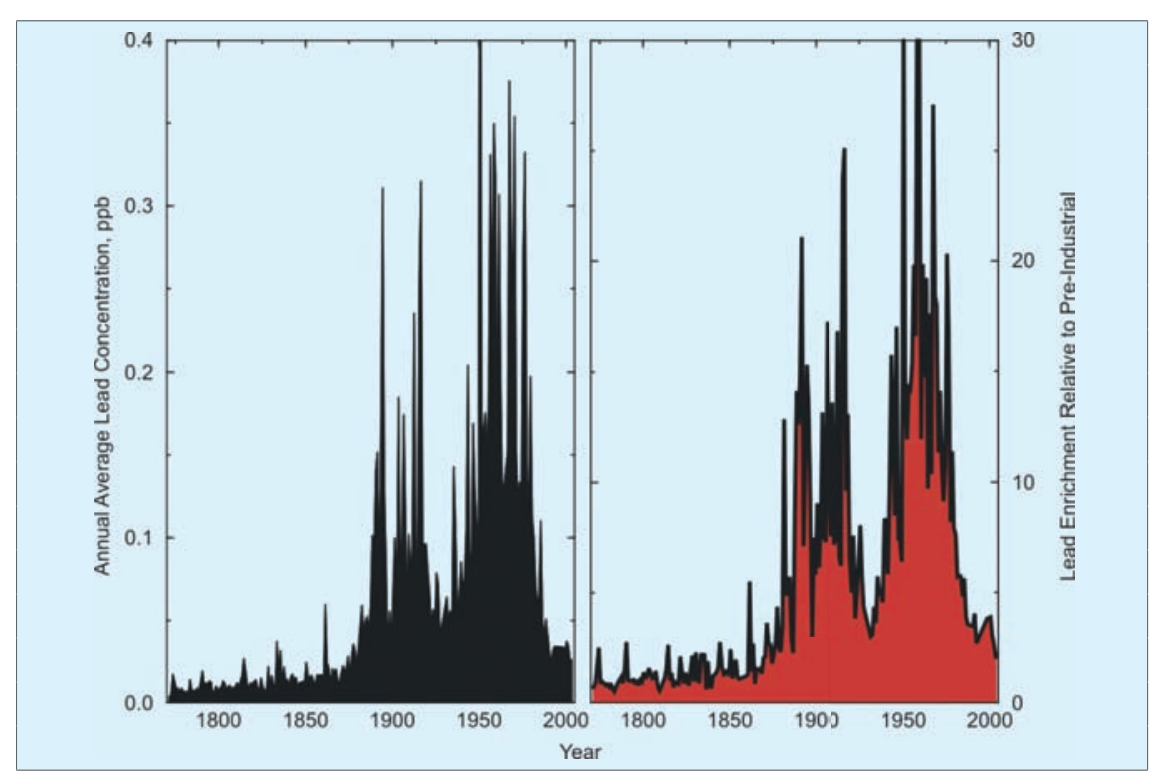

Fig. 3: High-resolution record of lead concentration and lead enrichment (relative to aluminum) measured in the PARCA ACT2 ice core $\left(66.0^{\circ} \mathrm{N}, 45.2^{\circ} \mathrm{W}\right)$.

vides a unique spatially distributed record of precipitation and atmospheric chemistry, dust and sea salt flux, and volcanic fallout. Particularly, recently collected cores have been analyzed with a newly developed CFA system that also includes trace elements. For example, the records document dramatic changes in lead pollution in Greenland precipitation over recent decades to centuries in response to industrialization and the efficacy of subsequent government interventions in the early 1970s (Fig. 3). Interpretations of the chemical measurements from the PARCA ice core array are ongoing and will address a range of environmental and paleoclimate questions.

\section{New GIS accumulation estimates}

The Greenland Ice Sheet (GIS) contains enough ice to raise sea level by $7 \mathrm{~m}$, so understanding the current and past mass balance is critical to sea level prediction. Recent repeat altimetry studies show little change in overall mass at higher elevations, although some areas have experienced significant thinning or thickening during the past few decades. However, multiple factors determine ice sheet elevation change, including changes in ice dynamics and melt, as well as short and long-term changes in net snowfall.

Ice-core accumulation measurements from the PARCA and NGT arrays provide a much better understanding of the temporal and spa- tial variability in net snowfall on the GIS. To date, results have been used

\section{Project facts}

PARCA - Program for Regional Climate Assessment)

Contact: Joe McConnell, jmcconn@dri.edu

Participants: Roger Bales (University of California, Merced), Joe McConnell (Desert Research Institute), Ellen Mosley-Thompson (Ohio State University)

Funding: NASA, with additional support from NSF

Where: Greenland

When: 1995-present

What: $>80$ shallow to intermediate ice cores spanning decades to the last millennium, Traditional CFA, dust concentration, water isotopes, beta horizons for earlier cores,

Expanded CFA for more recent cores including $>20$ elements and chemical species measured at $\sim 1 \mathrm{~cm}$ effective depth resolution.

Web Page: http://nsidc.org/data/parca/

NGT - North Greenland Traverse

Contact: Sepp Kipfstuhl,

kipfstuhl@awi-bremerhaven.de

Participants: Sepp Kipfstuhl, Hubertus Fischer (Alfred-Wegener-Institute for Polar and Marine Research, Bremerhaven), Dietmar Wagenbach (Institute for Environmental Physics, University of Heidelberg), Thomas Stocker (Climate and Environmental Physics, Physics Institute, University of Bern)

Funding: National contributions from Germany and Switzerland

Where: Northern Greenland

When: 1993-95

What: Snow pits, shallow and intermediate ice cores spanning up to 1000 years, water isotopes $\left(\delta^{18} 0, \delta \mathrm{D}\right.$, deuterium excess),

major and traces, radioisotopes

Database: www.pangaea.de to develop both long-term mean (e.g., Bales et al., 2001; Dethloff et al., 2002) and year-by-year maps of net snowfall for all or parts of the ice sheet, to validate meteorological model estimates of net snowfall, and to interpret repeat altimetry surveys. For example, using year-by-year accumulation records from ice cores, together with firn densification modeling, it was found that much of the 1978 to 1988 spatial pattern in icesheet elevation change observed by repeat altimetry could be attributed to short-term variability in snowfall (McConnell et al., 2000), with such elevation change masking any thickening and thinning associated with long-term, ice-dynamics-driven changes in mass balance. More recently, net accumulation measurements have been used to validate the ERA-40 reanalysis. Results indicate that, as with other meteorological model outputs, ERA-40 simulations capture much of the temporal variability in snowfall but not the magnitude of snowfall around the ice sheet (Hanna et al., 2005).

\section{ReFERENCES}

Bales, R.C., McConnell, J.R., Mosley-Thompson, E. and Lamorey, G., 2001: Accumulation map for the Greenland Ice Sheet: 1971-1990. Geophysical Research Letters, 28: 2967-2970.

Dethloff, K., Schwager, M., Christensen, J. H., Kiilsholm, S., Rinke, A., Dorn, W., Jung-Rothenhäusler, F., Fischer, H., Kipstuhl, S. and Miller H. 2002: Recent Greenland accumulation estimated from regional climate model simulations and ice core results, Journal of Climate, 15: 2821-2832.

Fischer, H. and Mieding, B., 2005: A 1,000-year ice core record of interannual to multidecadal variations in atmospheric circulation over the North Atlantic. Climate Dynamics, 25: 65-74.

Fischer, H., Wagenbach, D., and Kipfstuhl, J., 1998: Sulfate and nitrate firn concentrations on the Greenland ice sheet: 1. Large scale geographical deposition changes. Journal of Geophysical Research, 103(D17): 21927-21934.

Hanna, E., McConnell, J., Das, S., Cappelen, J. and Stephens A., 2005. Observed and modeled Greenland Ice Sheet snow accumulation, 1958-2003, and links with regional climate forcing. Journal of Climate, in press.

McConnell, J.R., Arthern, R.J., Mosley-Thompson, E., Davis, C.H., Bales, R.C., Thomas, R., Burkhart, J.F. and Kyne J.D., 2000: Changes in Greenland icesheet elevation attributed primarily to snow-accumulation variability. Nature, 406: 877-879. 


\title{
NGRIP ice core reveals detailed climatic history 123 kyrs back in time
}

\author{
DoRThe DahL-Jensen
}

Niels Bohr Institute, University of Copenhagen, Denmark; ddj@gfy.ku.dk

\section{Introduction}

In 2003, for the first time, an undisturbed Greenland ice core record reaching further back than the glacial period was completed. The 3090 $m$ long ice core from NGRIP, on the northern part of the Greenland Ice Sheet, contains layers of snowfall from the last 123,000 years. The annual layers close to the surface are $0.19 \mathrm{~m}$ thick, corresponding to the present accumulation rate (in ice equivalent) and the annual layers at the base are all around $1 \mathrm{~cm}$ thick. The basal annual layer thickness is so well preserved due to a basal melt of $7 \mathrm{~mm} / \mathrm{yr}$, reducing the thinning near the bed (Dahl-Jensen et al., 2003). This very high-resolution record contains $1490 \mathrm{~m}$ of ice from the present interglacial period (0-11,703 yr b2k (before AD 2000)), $1600 \mathrm{~m}$ of ice from the glacial period $(11,703-115,000 \mathrm{yr} b 2 \mathrm{k})$ and $90 \mathrm{~m}$ of ice from the last interglacial period, the Eemian climatic period (NGRIP members, 2004)

\section{The NGRIP isotope record}

The stable isotope record from the NGRIP ice core is measured in $5 \mathrm{~cm}$ resolution. Down to a depth of 2900 $\mathrm{m}$ (105 kyr b2k), the record shows the same general climatic features as observed in other Greenland ice cores, including the Younger Dryas, the Bølling Allerød and the 24 abrupt and climatic warm Dansgaard/Oeschger (DO) events during the glacial period (NGRIP members, 2004). Whereas NorthGRIP and GRIP have very similar $\delta^{18} \mathrm{O}$ levels during the Holocene, glacial isotopic levels in the NorthGRIP record are systematically depleted by $1-2 \%$. The magnitude of the difference appears to be related to the Northern Hemisphere climate curve, as represented by a smoothed version of the NorthGRIP record, such that colder conditions have larger differences. A spatial pattern of glacial climate over Greenland begins to unfold. Our best theory is that the air masses reaching the two sites during the glacial were from different sources. In response to the

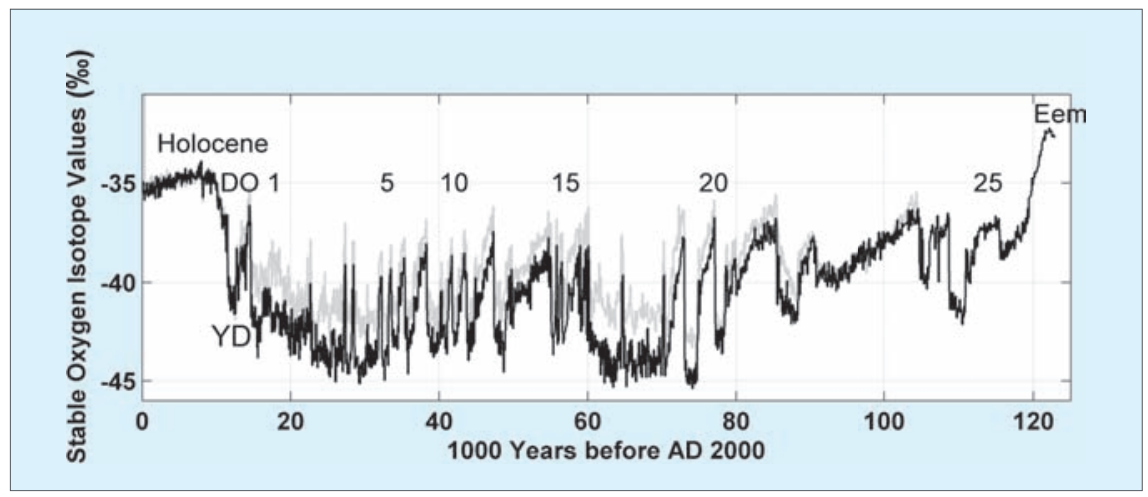

Fig. 1: The $\delta^{18} \mathrm{O}$ record from NGRIP (black) (NGRIP members, 2004) on the GICC05 timescale down to $2128.28 \mathrm{~m}$ (age 41,760 yr b2k) and below on a timescale based on a flow model that has been tuned to the GICCO5 timescale. The synchronized $\delta^{18} \mathrm{O}$ record from GRIP (gray) is shown down to 105,000 yr b2k so the two records can be compared. Some of the DansgaardOeschger warm stages (DO) are shown, and the Younger Dryas (YD), Holocene and Eemian climatic periods are marked.

extent of the Laurentide ice sheet, sea ice and the extensive North Atlantic ice shelves, NorthGRIP shows a more continental climate regime and may have seen a higher fraction of air coming over the northern side of the Laurentide ice sheet, bringing with it colder and more isotopically depleted moisture than GRIP might have seen. Taken as a whole, the findings here suggest that the atmospheric water cycle over Greenland is substantially different between modern and glacial worlds. The bottom $90 \mathrm{~m}$ of the NGRIP ice core contains ice from the last interglacial period. The isotopic value of this ice is high and corresponds to temperatures $5 \mathrm{~K}$ higher than the present. The part of the Eemian period from 123-115 kyr b2k found in the NGRIP ice core reveals that the period was warm and stable. The decline to glacial conditions happened slowly over 5000 years. It is interesting to note how soon the DO events begin to influence the climatic pattern. The first to be found at a depth of $3040 \mathrm{~m}$ (age 114 kyr b2k) might have happened before the full build up of the big glacial ice sheets was reached.

\section{Stratigraphic dating of the NGRIP ice core}

The very high resolution of the NGRIP ice core allows identification of the single annual layers down through large parts of the ice core. One of the goals of NGRIP has been to resolve these layers to gain understanding of the climate system and to produce a timescale based on counted annual layers. Chemical measurements using Continuous Flow Analysis (CFA), including dust and ECM on the melt water, visual stratigraphy (VS) and ECM on the frozen ice cores make it possible to resolve the annual layers down to 60 kyr b2k and perhaps further (Fischer et al., 2006; Rasmussen et al., 2005). The highly resolved records reveal that the abrupt climate changes like the warmings into DO events, the transition into the Bølling/Allerød and from the Younger Dryas into the Holocene happened over very short periods, sometimes only a few years. The highest resolution record is the visual stratigraphy with a resolution of $0.1 \mathrm{~mm}$ (Svenson et al., 2005). The annual layers can be seen here down to $100 \mathrm{kyr}$ b2k. The visual record also clearly demonstrates that the stratigraphy is preserved through the full NGRIP ice core.

A new Greenland Ice Core Chronology (GICC05) covering the last $41 \mathrm{kyr}$ has been constructed from stratigraphic annual layer counting of high-resolution records from the NGRIP ice core and from GRIP and Dye3 (Rasmussen, in press). Dating of the Holocene period back to the 8.2 kyr event is based partly on existing and partly on new stable isotope measurements of the Dye-3 (GISP1) ice core. For the interval 8.2-10 kyr 
b2k, the timescale has been obtained from Electrical Conductivity Measurements (ECM) of the solid ice and multiparameter chemical CFA of the GRIP ice core. Beyond $10 \mathrm{kyr} b 2 k$, the timescale is based on records from the NGRIP ice core: An extended spectrum of chemical paramaters using CFA, ECM, and the light intensity curve of the recorded VS. At any depth, the dating is based on the ice core with the best available high-resolution data, and the three ice cores are tied together using unambiguous reference horizons, such as volcanic ash layers or major acidity spikes. The maximum counting error at 41 kyr b2k is 1600 years. The new timescale places the Holocene/Pleistocene transition at $11,703 \mathrm{yr}$ b2k, the onset of Greenland Interstadial 3 (GIS3) at $27.8 \mathrm{kyr}$ b2k, and the onset of GIS8 at $38.3 \mathrm{kyr}$ b2k.

\section{Outlook}

At the base of the $3090 \mathrm{~m}$ thick ice sheet, the ice is melting and when bedrock was reached in 2003, basal water flooded the lowest $45 \mathrm{~m}$ of the borehole (Dahl-Jensen et al., 2003). The reddish refrozen basal water from the sub-glacial water system in the lowest $45 \mathrm{~m}$ of the borehole was recovered by drilling in 2004 and two macroscopic plant remains were recovered from the NGRIP core. One is a wood fragment of willow (Salix) and the other is a fragment of a bud scale, probably also from willow. Also, a few tiny fragments of spruce or larch (Picea/Larix) were found, potentially representing ancient vegetation from the time of

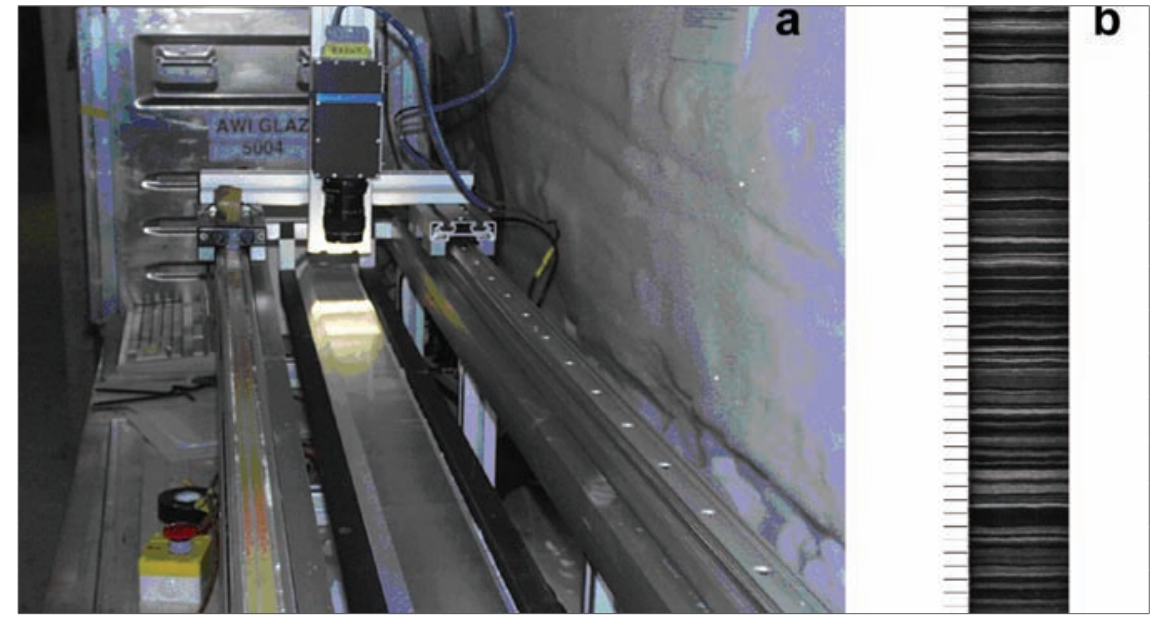

Fig. 2: As an example of the high-resolution data along the NGRIP ice core, data from the visual stratigraphy using the line scan instrument (a) is shown. A $50 \mathrm{~cm}$ long section of the record is shown in (b). The record is from $2358.0-2358.5 \mathrm{~m}$ where the age is $57 \mathrm{kyr} b 2 \mathrm{k}$ and the mean annual thickness is $1.2 \mathrm{~cm}$

the ice sheet formation. Many additional parameters like the gases, deuterium, deuterium excess, dust, as well as detailed comparisons with the Antarctic ice cores, are revealing

\section{Project facts}

Project: North Greenland Ice Core Project (NGRIP)

Contact: Dorthe Dahl Jensen, ddj@gfy.ku.dk

Participants: Numerous scientists from laboratories in 8 European nations and the USA.

Funding: Funding agencies in Denmark

(SNF), Belgium (FNRS-CFB), France (IPEV and INSU/CNRS), Germany (AWI), Iceland (Rannls), Japan (MEXT), Sweden (SPRS), Switzerland (SNF) and the USA (NSF, Office of Polar Programs)

Where: Northern Greenland

When: drilling 1996-2003, analysis ongoing.

What: $3090 \mathrm{~m}$ ice core from surface to bed-

rock, multiparameter analysis

Web page: www.glaciology.gfy.ku.dk/ngrip/ index_eng.htm

Database: www.glaciology.gfy.ku.dk/ngrip/ index_eng.htm outstanding results and will soon be published.

\section{REFERENCES}

Dahl-Jensen, D., Gundestrup, N., Gogineni, P. and Miller, H., 2003: Basal melt at NorthGRIP modeled from borehole, ice-core and radio-echo sounder observations. Annals of Glaciology, 37: 207-212.

Fischer, H., Siggard-Andersen, M.L. and Ruth U., submitted: Glacial/interglacial changes in mineral dust and sea salt records in polar ice cores: sources, transport, and deposition. Reviews of Geophysics.

North Greenland Ice-Core Project (NorthGRIP) Members, 2004: High resolution Climate Record of the Northern Hemisphere reaching into the last Glacial Interglacial Period. Nature, 431: 147-151.

Rasmussen, S. O., Andersen, K. K., Svensson, A. M., Steffensen, J. P., Vinther, B. M., Clausen, H. B., Andersen, M. -L., Johnsen, S. J., Larsen, L. B., Bigler, M., Röthlisberger, R., Fischer, H., Goto-Azuma, K., ice core chronology for the last glacial termination, Journal of geophysical research. in press.

Svensson, A., Wedel Nielsen, S., Kipfstuhl, S., Johnson, S.J., Peder Steffensden, J.P., Bigler, M., Ruth, U. and Röthlisberger, R., 2005: Visual stratigraphy of the North Greenland Ice Core Project (NorthGRIP) ice core during the last glacial period. Journal of Geophysical Research 110, D02108, doi:10.1029/ 2004JD005134. Hansson, M. E. and Ruth, U., 2005: A new Greenland

\section{Paleoenvironmental reconstruction from Alpine ice cores}

MARGIT ScHWIKoWSKI

Paul Scherrer Institute, Villigen, Switzerland; margit.schwikowski@psi.ch

\section{Introduction}

The European Alps, located in South-Central Europe, extend 800 $\mathrm{km}$ in the west-east and 150-200 $\mathrm{km}$ in the north-south direction (44$\left.48^{\circ} \mathrm{N}, 5.5-16^{\circ} \mathrm{E}\right)$. They form a great arc from the Riviera coast on the Mediterranean Sea, along the borders of northern Italy and adjacent regions of southeast France, Switzerland, southwest Germany and
Austria, into Slovenia. The total number of glaciers is 5422, covering an area of $3010 \mathrm{~km}^{2}$ (Paul et al., 2004). Glaciers with sufficiently cold firn temperatures, where melt-water percolation is negligible and which are therefore suitable for ice core studies, can be found above $4000 \mathrm{~m}$ asl in the northern part and above $4300 \mathrm{~m}$ asl in the southern part of the Alps (Suter et al., 2001). Thus, potential ice core sites are limited to a few high-elevation areas, such as the Bernese Alps, and the Monte Rosa and Mont Blanc areas.

The Alps are especially interesting for ice core studies because a dense network of instrumental meteorological measurements is available there and in the surrounding countries. The existence of such exclusive data sets is a ma- 


\section{Science Highlights: Ice Core Science}

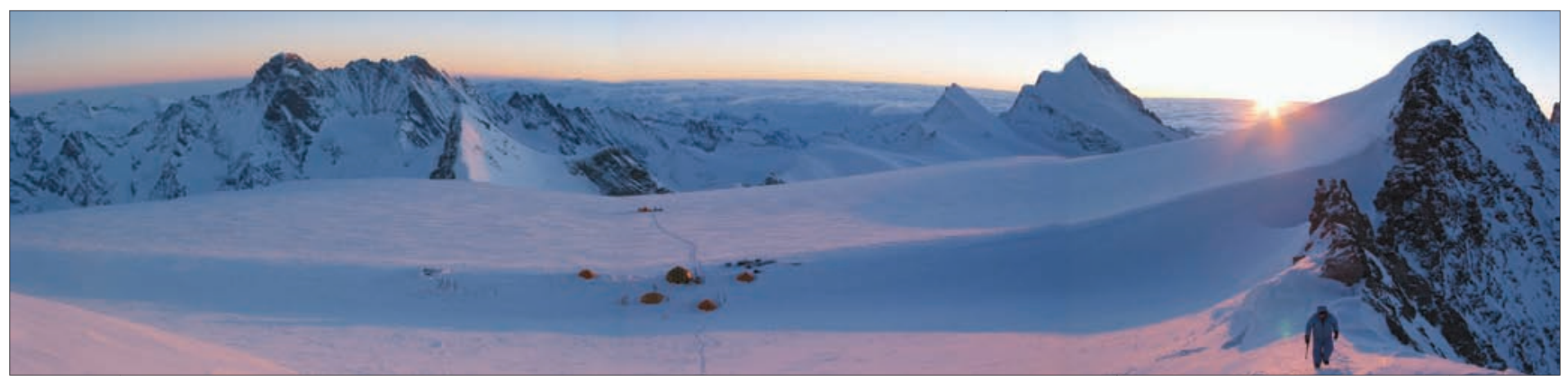

Fig. 1: Ice core drilling camp on Fiescherhorn glacier, Swiss Alps, in December 2002. (Photo A. Schwerzmann)

jor advantage compared to other ice core sites, since the ice core climate proxy records can be calibrated. This is extremely important for an improved understanding of the characteristics of the glacier archives. Some of the instrumental records reach back over 250 years (Böhm et al., 2001). Not only temperature data but also precipitation data are available and, furthermore, historical air quality measurements exist.

\section{Drill sites}

Mean annual precipitation in the Alps varies between 500 and 3000 $\mathrm{mm}$. Accordingly, relatively high annual net accumulation rates were observed at most of the ice core sites, i.e. $\sim 1.3 \mathrm{~m}$ water equivalent (weq) at Fiescherhorn glacier (Fig. 1), Bernese Alps, $1.5 \mathrm{~m}$ weq at Col du Dôme, Mont Blanc, 1.6 m weq at Lys Glacier, $2.7 \mathrm{~m}$ weq at Grenzgletscher, both Monte Rosa area, and $2.6 \mathrm{~m}$ weq at Piz Zupó, Bernina area. With typical glacier thicknesses of 80 to $150 \mathrm{~m}$ in the accumulation areas, ice core records from these sites cover rather short time periods of, at best, a few hundred years. A noteworthy exception is the Colle Gnifetti glacier saddle in the Monte Rosa area on the border between Switzerland and Italy. Due to the preferential wind erosion of dry winter snow the annual snow accumulation is in the order of only $30 \mathrm{~cm}$ weq, implying preservation of potentially more than the last 1000 years at reasonable time resolution. Indeed, 3D glaciological flow models indicate that the ice close to bedrock is more than 2000 years old (Lüthi and Funk, 2000). Here, a dramatic decrease of $\delta^{18} \mathrm{O}$ values (Wagenbach, 1994) suggests that the basal layer may be made up of Pleistocene ice. However, the $\delta^{18} \mathrm{O}$ values of $\mathrm{O}_{2}$ entrapped in air bubbles are not as high to unequivocally confirm this hypothesis (M. Leuenberger, personal communication).

\section{Results}

An important aspect of Alpine ice cores is their proximity to emission sources of anthropogenic pollution. Especially for aerosol particles and related gaseous species, with short atmospheric lifetimes, changes in the atmospheric load due to human activities and their possible impact on climate are most pronounced in industrialized areas. Detailed studies have been conducted on atmospheric transport from the emission source areas to the high altitudes, where the glacier archives are located. They show that the highaltitude aerosol concentration, and subsequently also the concentration of aerosol constituents in snow and ice, is mainly controlled by the seasonally varying intensity in vertical mixing (see e.g. Baltensperger et al., 1997). Therefore, the seasonal am-

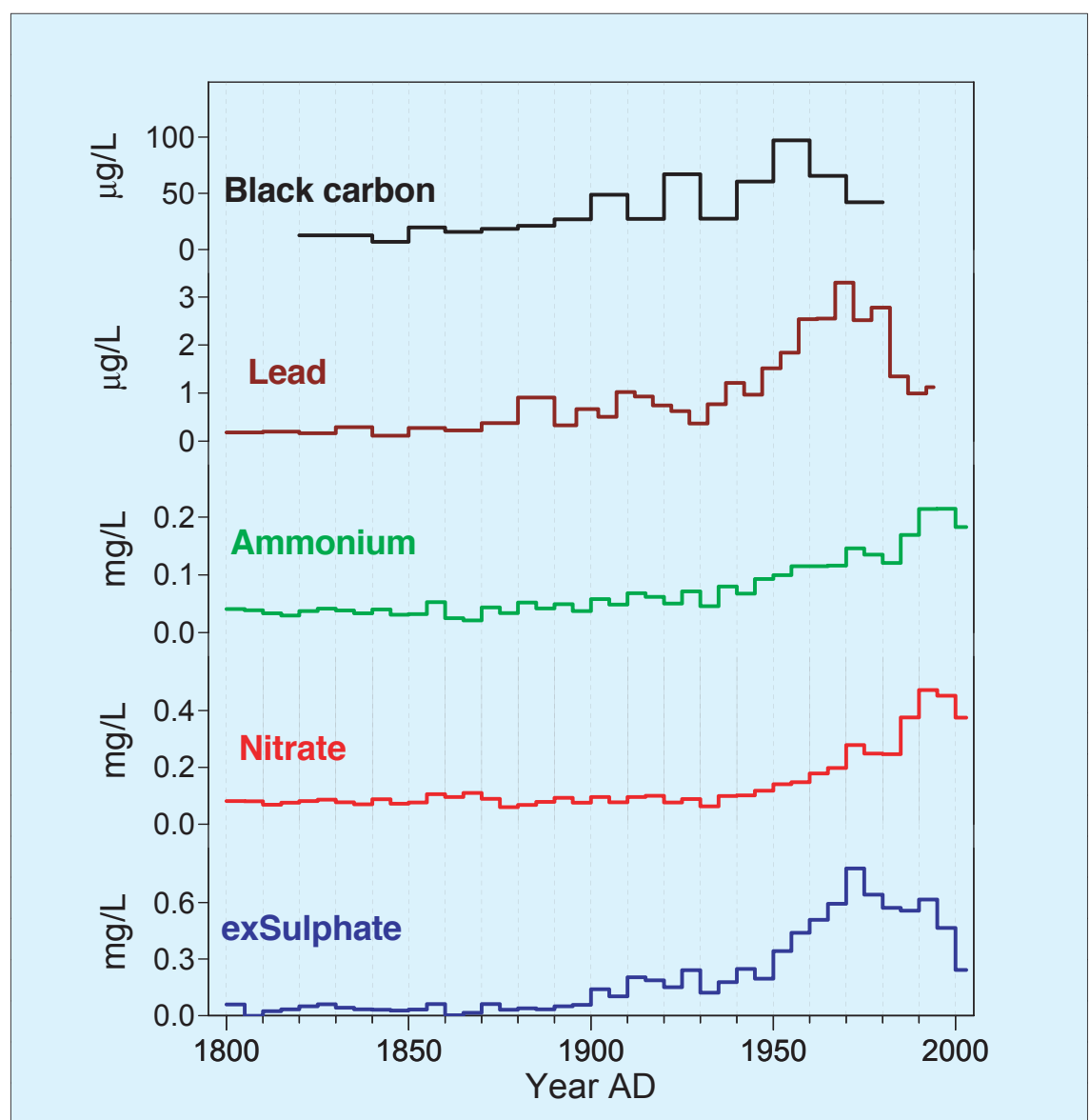

Fig. 2: Concentration trends of ex-sulphate, nitrate, ammonium, lead, and black carbon in ice cores from Colle Gnifetti, Swiss Alps. Ex-sulphate represents sulphate corrected for the sea-salt and mineral dust contribution and is assumed to originate exclusively from oxidation of sulphur dioxide in the atmosphere. Given are 5-year averages lone 4-year average for 2000-2003; composite records from cores drilled in 1982 and 2003), except for lead (10-year averages from 1800-1900, composite record from cores drilled in 1982 and 1995 (Schwikowski et al, 2004)) and black carbon (10-year averages, from a core drilled in 1982 (Lavanchy et al., 1999)). 
plitudes of aerosol concentrations are large compared to their longterm trends. This also applies to the temperature reflected in the stable isotope ratios in precipitation.

Various concentration records of a number of chemical trace species and gases obtained from the different Alpine ice cores have been published. These records clearly demonstrate the impact of anthropogenic emissions on the impurity content of snow. They show a generally consistent picture of a vastly altered atmospheric composition due to industrialization. This is the case for major aerosol components such as sulphate, nitrate, ammonium, and carbonaceous particles as well as trace substances, for example, heavy metals, fluoride, chloride, and radionuclides. Furthermore, the presence of organochlorine pesticides in Alpine ice has been shown (Villa et al., 2003). Most of the pollutants have a concentration maximum in the 1970s and early 1980s, and responded to air pollution control measures in Europe (such as introduction of filters, catalytic converters, unleaded fuel) with a downward trend in concentration, as illustrated in Figure 2 with the examples of sulphate, lead, and black carbon. Notable exceptions are nitrate (see e.g. Preunkert et al., 2003) and ammonium, which are still at a high level. In the case of nitrate, reduction of $\mathrm{NO}_{x}$ emissions in individual cars has been counterbalanced by increasing traffic. Ammonium originates from agricultural activities, such as animal manure and fertilizer application, where no control measures have been introduced.

Ice core derived concentration records of aerosol species have been used to estimate the aerosol effect on climate. For this purpose, records from mid-latitude glaciers are extremely important. On the one hand because only few long-term records of tropospheric aerosols exist, and on the other hand because data from the emission source areas are needed due to the regional nature of aerosol concentrations. Sulphate concentrations in ice cores from the Alps display the strongest anthropogenic influence during the last

\section{Project facts}

CARBOSOL - Present and Retrospective State of Organic versus Inorganic Aerosol over Europe: Implications for climate (long term ice core records of organic aerosol species)

Contact: Michel Legrand mimi@Igge.obs.ujf-grenoble.fr

Participants: LGGE-Grenoble, IUP Heidelberg

Funding: European Community coordinator: Michel Legrand

When: 2002-2005

Web page: www.vein.hu/CARBOSOL/

ALPCLIM - Environmental and Climatic Records from High Elevation Alpine Glaciers, (glacio-chemical and stable isotope studies at Monte Rosa and Mt.Blanc)

Contact: Susanne Preunkert, ps@Igge.obs.ujf-grenoble.fr

Participants: LGGE-Grenoble,University Zürich,VAW/ETH-Zürich, KUP-University Bern, DISAT-Milano, IUP Heidelberg

Funding: European Community coordinator: Dietmar Wagenbach

When:1997-2001

Web page: www.geo.unizh.ch/ hoelzle/

ALP-IMP - Multi-Centennial Climate Variability in the Alps based on Instrumental Data, Model simulations and Proxy Data (stable isotope studies on deep Monte Rosa and Mt. Blanc cores)

Contact: Dietmar Wagenbach, Dietmar.Wagenbach@iup.uni-heidelberg.de Participants: University Zürich,LSCE- Saclay, IUP Heidelberg

150 years, with a concentration increase by a factor of 13 between the pre-industrial and industrial period. The level in the Alps in the period of maximum industrial emissions is about a factor of five higher than in Greenland ice cores, whereas in Antarctica no anthropogenic sulphate could be detected (Cole-Dai et al., 2000).

\section{REFERENCES}

Böhm, R., Auer, I., Brunetti, M., Maugeri, M., Nanni، T. and Schöner, W., 2001: Regional temperature variability in the European Alps: 1760-1998 from homogenized instrumental time series, Int. J. Clim., 21 (14): 1779-1801.

Lüthi, M., and Funk, M., 2000: Dating ice cores from a high Alpine glacier with a flow model for cold firn, Annals of Glaciology, 31: 69-79.

Paul, F., Kaab, A., Maisch, M., Kellenberger, T. and Haeberli, W., 2004: Rapid disintegration of Alpine glaciers observed with satellite data, Geophys. Res. Lett., 31 (21), L21402, doi:10.1029/ 2004GL020816,

Preunkert, S., Wagenbach, D., and Legrand, M. 2003: A seasonally resolved alpine ice core record
Funding: European Community, coordinator: Reinhard Böhm

When: 2002-2006

Web page: www.zamg.ac.at/ALP-IMP

Klimageschichte im Alpenraum - aus Analysen von Eisbohrkernen

Contact: H.W. Gäggeler, heinz.gaeggeler@psi.ch

Participants: Paul Scherrer Institut and KUP Funding: Swiss National Science Foundation When: 1993-1996

VITA - Varves, Ice cores, and Tree rings - Archives with annual resolution

Contact: Margit Schwikowski, margit.schwikowski@psi.ch

Participants: Paul Scherrer Institut, University of Bern

Funding: Swiss National Science Foundation (in the frame of the NCCR Climate Program)

When: 2002-2005

Web page: www.nccr-climate.unibe.ch/

VIVALDI - Variability in Ice, Vegetation and Lake Deposits - Integrated

Contact: Margit Schwikowski, margit.schwikowski@psi.ch

Participants: University of Bern, Paul Scherrer Institut, EAWAG

Funding: Swiss National Science Foundation (in the frame of the NCCR Climatep pogram)

When: 2005-present

Web page: www.nccr-climate.unibe.ch/ of nitrate: Comparison with anthropogenic inventories and estimation of preindustrial emissions of NO in Europe, J. Geophys. Res., 108 (D21): 4681 Schwikowski, I., Barbante, C., Doering, T., Gäggeler H.W., Boutron, C., Schotterer, U, Tobler, L., Van De Velde, K.V., Ferrari, C., Cozzi, G., Rosman, K. and Cescon, P., 2004: Post-17th-century changes of European lead emissions recorded in high-altitude alpine snow and ice, Environ. Sci. Tech., 38 (4): 957-964.

Villa, S., Vighi, M., Maggi, V., Finizio, A. and Bolzacchini, E., 2003: Historical trends of organochlorine pesticides in an Alpine glacier, J. Atmos. Chem., 46 (3): 295-311.

Wagenbach, D., 1994: Results from the Colle Gnifetti ice-core programme, in: ESF/EPL Workshop on Greenhouse gases, isotopes and trace elements in glaciers as climatic evidence of the Holocene, edited by W. Haeberli, Stauffer, B., VAW Arbeitsheft. 19-22, Zürich.

For full references please consult: www.pages-igbp.org/products/newsletters/ref2006_1.html 


\section{South American Andes: A unique area for ice core-based tropical paleoclimate reconstruction}

Françoise Vimeux and Patrick Ginot

IRD Great Ice, Lab. des Sci. du Climat et de I'Environm., Gif-sur-Yvette, France; vimeux@Isce.saclay.cea.fr; ginot@lgge.obs.ujf-grenoble.fr

\section{Introduction}

The Andean summits stretch out along about $7000 \mathrm{~km}$ of South America in a north-south transect from northern hemisphere low latitudes (Columbia, $5^{\circ} \mathrm{N}$ ) to southern hemisphere high latitudes (south Chile, $55^{\circ} \mathrm{S}$ ). Along this natural atmospheric circulation boundary, a large number of peaks reaching between $5000 \mathrm{~m}$ and $7000 \mathrm{~m}$ are covered with glaciers but only a few of them in Ecuador, Peru, Bolivia, Chile and Argentina are suitable for ice core paleoclimate investigation. The Andes are a specific area in the tropics where both Atlantic and Pacific influences on past climate variations can be explored. This is mainly because the atmospheric circulation can be roughly divided in two components (e.g. Montecinos et al., 2000): (i) north of $20^{\circ} \mathrm{S}$, tropical NE-winds or Trade winds transport Atlantic Ocean moisture over the Amazonian basin to the Andes, (ii) south of $20^{\circ} \mathrm{S}$, Pacific Ocean moisture is directly transported by SW westerly winds. Polar front inputs may also influence the southern Andes. Between these two areas, the South American Arid Diagonal is one of the driest regions in the world, where no glaciers exist. Thus, tropical ice cores are likely to contain information on both the Intertropical Convergence Zone and Hadley cells, and ENSO in the Pacific Ocean. Important modifications of this system started a few decades ago and will intensify in connection with industrial and agricultural development (IPCC, 2001). A detailed knowledge of the background state of the area (before anthropogenic influence) is essential to understand the anthropogenic effect on climate changes. In this context, a comprehensive study of Andean ice cores is essential to provide a comprehensive spectrum of climatic and environmental proxies.

Over the last few decades, several institutions have developed ice-coring programs in the Andes.

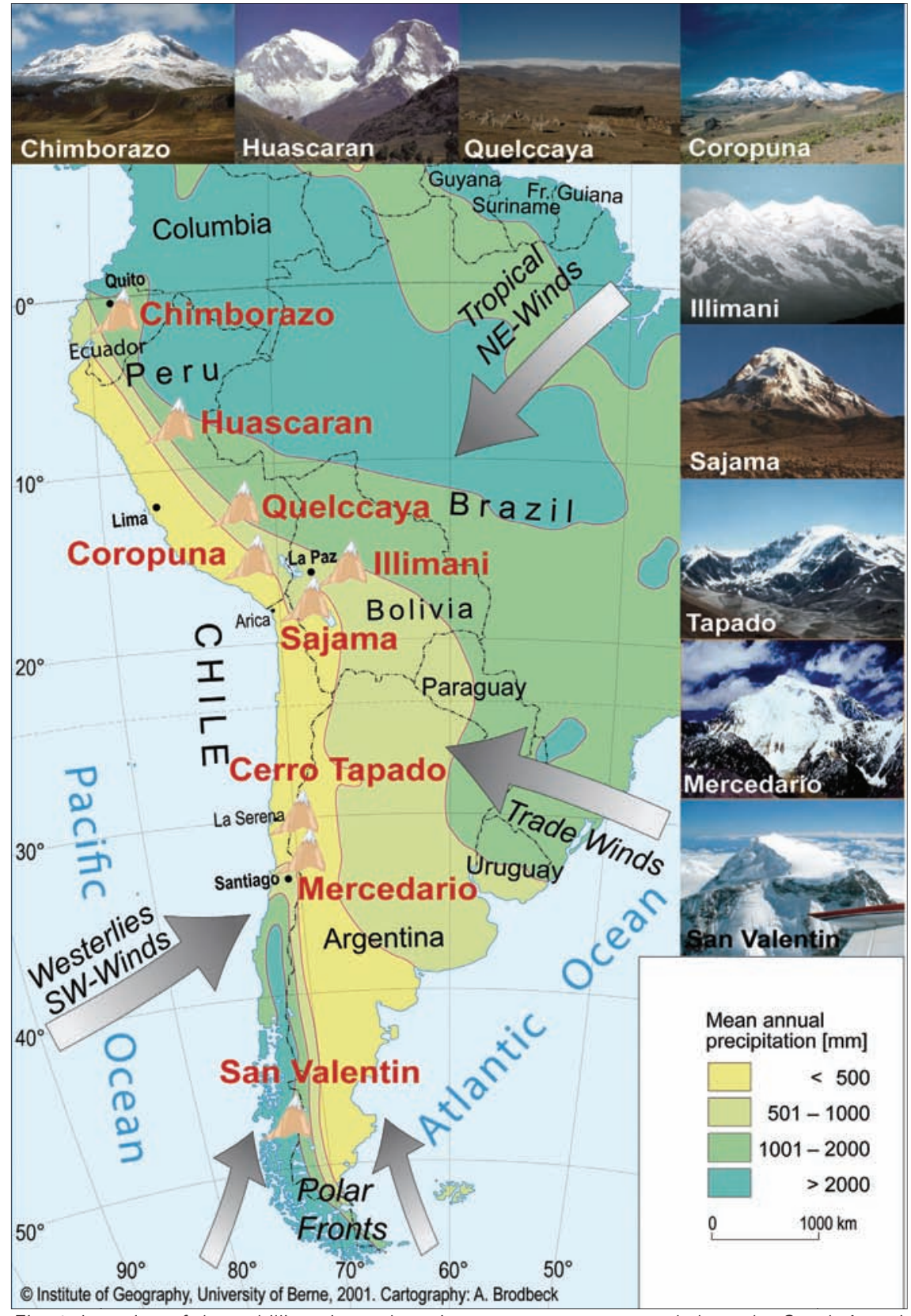

Fig. 1: Location of deep drilling sites where ice cores were extracted along the South American Andes. Arrows indicate the main atmospheric circulation paths, map colors illustrate the mean annual precipitation

Lonnie Thompson (Byrd Polar Research Center - OSU) pioneered these activities in 1983 on the Quelccaya glacier (Peru), followed by Huascarán (Peru) and Sajama (Bolivia). Since 1997, other institutions (Institut de Recherche pour le Développement - Great Ice - France, Paul Scherrer Institut - Switzerland, and their South American partners: Instituto Hydraulica y Hidrologia Bolivia, Instituto Nacional de Me- teorologia y Hidrologia - Ecuador, Servicio Nacional de Meteorologia e Hidrologia - Peru, Centro de Estudios Cientificos - Chile, etc.) have joined this effort to extend the ice core investigation on Cerro Tapado (Chile), Illimani (Bolivia), Chimborazo (Ecuador), Mercedario (Argentina) and Coropuna (Peru), in order to reconstruct a latitudinal transect of paleoclimate records (Fig. 1). A new deep ice core program is being 


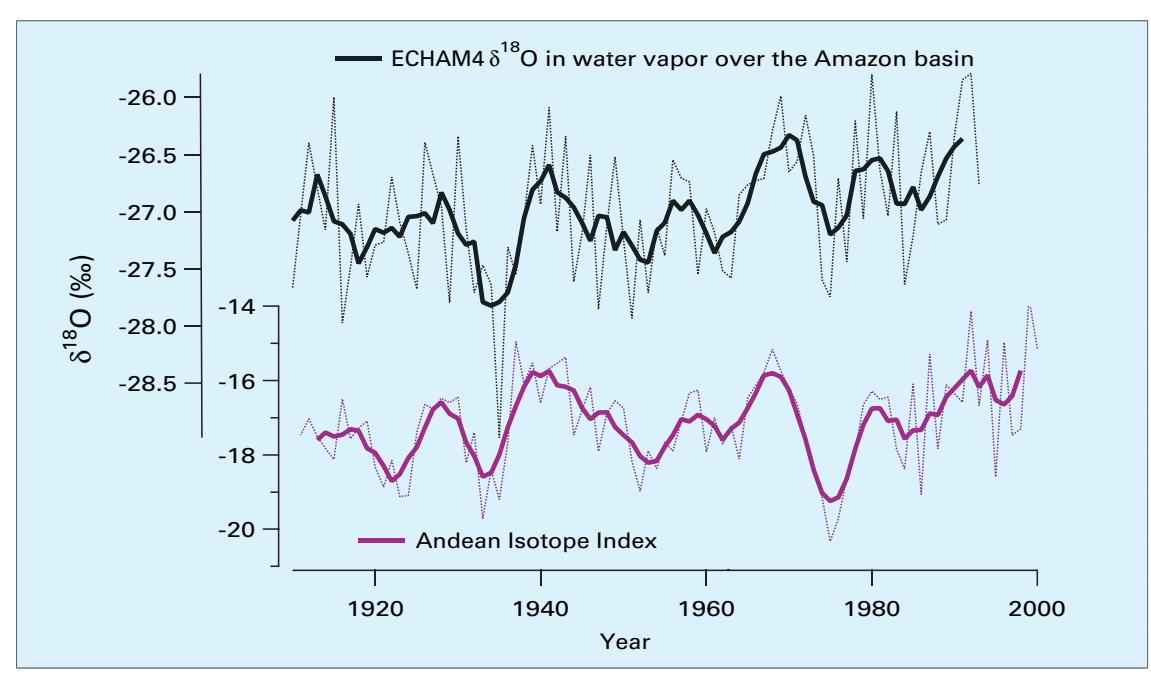

Fig. 2: Andean Isotope Index calculated from $\delta^{18} \mathrm{O}$ records from Illimani, Sajama, Huascaran, Quelccaya and $\delta^{18} \mathrm{O}$ of water vapor over the Amazonian region as simulated by the atmospheric general circulation model ECHAM 4. For both curves, the dotted line is raw data, the solid line is the 5-year running average (adapted from Hoffmann et al., 2003).

developed at mid-latitudes to fill the gap between the Andes and Antarctica (summits of San Valentin, Chile and San Lorenzo, Argentina). Thus, ice from the South American Andes is a climate archive that can offer a continuous record of our past climate, with identical proxies, from the equator to high latitudes.

\section{Results from Andean ice cores}

The different programs have demonstrated well that tropical ice cores can be dated, analyzed and interpreted in terms of climate changes. For dating, a combination of different methods is typically applied: annual layer counting, identification of reference horizons, such as past thermo-nuclear tests and volcanic eruptions (De Angelis et al., 2003), and radionuclide decay (Knüsel et al., 2003). Chemical and isotopic analyses on these ice cores strongly suggest that the tropics have participated in the well-known climate transitions over the last 20,000 years. The Sajama record goes back to around 25,000 years (Thompson et al., 1998) and is the oldest reconstruction along the Andes but other records from Huascarán (Thompson et al., 1995), Illimani (Ramirez et al., 2003) and Coropuna (P. Ginot, pers. comm.) also cover the last glacial transition and interestingly show similar isotopic variations compared with polar ice cores (a glacial maximum, a deglaciation interrupted by a "reversal" event, a Holocene optimum). The open question is which teleconnections could explain such similar climate changes.

Tropical ice cores also offer a high temporal resolution (seasonal resolution over the last centuries), allowing a detailed study of specific events or periods, such as the Little Ice Age or the last few centuries. For example, the isotopic composition of the ice ( $\delta D$ and $\delta^{18} O$ ), insoluble dust mass and ice core stratigraphy were the first proxies investigated in the Quelccaya ice core and allowed a 1000-year accumulation history reconstruction in the Andes (Thompson et al., 1985). Another in-

\section{Project facts}

Project: Andean ice core investigations

ginot@Igge.obs.ujf-grenoble.fr, Lonnie Thompson, thompson.3@osu.edu,

M. Schwikowski, margit.schwikowski@psi.ch

Participants: IRD Great Ice, LGGE, LSCE

(France), Byrd Polar Research Center (USA),

Paul Scherrer Institut, University Bern

(Switzerland), and South American partners

IHH (Bolivia), SENAMHI (Peru), INAMHI

(Ecuador), CECS (Chile)

Funding: IRD, The Award for Enterprise Rolex for Chimborazo operation, NSF, Paul Scherrer Institut, University Bern (Switzerland).

Where: Andes

When: Since 1974

What: Ice cores back to LGM, Multiproxy studies.

Web page: www.mpl.ird.fr/hydrologie/greatice/ www-bprc.mps.ohio-state.edu/lcecore/, http://lch.web.psi.ch/index.html

Database: www-bprc.mps.ohio-state.edu/ Icecore/dataandimages.html
Contact: Patrick Ginot, teresting result is the water stable isotope decadal signal over the 20th century common to all the ice cores (Quelccaya, Huascarán, Sajama and Illimani) (Hoffmann et al., 2003). This Andean Isotopic Index (Fig. 2) is fairly well reproduced by atmospheric general circulation models (AGCM) and, according to recent studies dealing with both direct observations (Vimeux et al., 2005) and AGCM (Vuille and Werner, 2005), it should be related to past humidity changes in tropical South America and over the tropical Atlantic Ocean. However, when the reconstruction reaches a high temporal resolution, such as seasonal variations, some important post-depositional effects like those resulting from high sublimation affecting chemical proxies have to be considered (Ginot et al., In press; Ginot et al., 2001). The impact of such effects on isotope records is highly dependent on the drilling sites (Stichler et al., 2001; F. Vimeux, pers. comm.). Accordingly, further systematic studies on tropical ice cores sites are needed to fully exploit this unique high-resolution natural climate archive.

\section{REFERENCES}

De Angelis, M., Simões, J. C., Bonnaveira, H., Taupin, J. D., and Delmas, R. J., 2003: Volcanic eruptions recorded in the Illimani ice core (Bolivia): 1918-1998 and Tambora periods. Atmospheric Chemistry and Physics, 3: 1725-1741.

Ginot, P., Kull, C., Schotterer, U., Schwikowski, M., and Gäggeler, H. W., in press: Glacier masse balance reconstruction by sublimation induced enrichment of chemical species on Cerro Tapado (Chilean Andes). Climate of the Past.

Knüsel, S., Ginot, P., Schotterer, U., Schwikowski, M., Gaeggeler, H. W., Francou, B., Simões, J. C., Petit, J. R., and Taupin, J. D., 2003: Dating of two nearby ice cores from the Illimani, Bolivia. Journal of Geophysical Research, 108: 4181

Montecinos, A., Diaz, A., and Aceituno, P., 2000: Seasonal Diagnostic and Predictability of Rainfall in Subtropical South America Based on Tropical Pacific SST. Journal of Climate, 13: 746-758.

Stichler, W., Schotterer, U., Fröhlich, K., Ginot, P., Kull, C., Gäggeler, H. W., and Pouyaud, B., 2001: The influence of sublimation on stable isotopes records from high altitude glaciers in the tropical Andes. Journal of Geophysical Research, 106: 22613-22621.

Thompson, L. G., Davis, M. E., Mosley-Thompson, E., Sowers, T. A., Henderson, K. A., Zagorodnov, V. S., Lin, P.-N., Mikhalenko, V. N., Campen, R. K., Bolzan, J. F., Cole-Dai, J., and Francou, B., 1998: A 25000-year tropical climate history from Bolivian ice cores. Science, 282: 1858-1864.

For full references please consult: www.pages-igbp.org/products/newsletters/ref2006_1.html 


\title{
Dating ice cores
}

\author{
JAKOB SCHWANDER
}

Climate and Environmental Physics, Physics Institute, University of Bern, Switzerland; schwander@climate.unibe.ch

\section{Introduction}

An accurate chronology is the basis for a meaningful interpretation of any climate archive, including ice cores. Until now, the oldest ice recovered from a continuous core is that from Dome Concordia, Antarctica, with an estimated age of over 800,000 years (EPICA Community Members, 2004). But the recently recovered cores from near bedrock at Kohnen Station (Dronning Maud Land, Antarctica) and Dome Fuji (Antarctica) compete for the longest climatic record. With the recovery of more and more ice cores, the task of establishing a good common chronology has become increasingly important for linking the findings from the different records. Moreover, in order to create a comprehensive picture of past climate dynamics, it is crucial to aim at a common chronology for all paleo-records. Here the different methods for dating ice cores are summarized.

\section{Layer counting}

Due to the seasonal variation of temperature, sunlight or atmospheric circulation, concentrations of many trace substances or isotopes show cyclic variations in the ice cores. In the ideal case, these annual cycles can be counted many thousand years back in time. Depending on the conditions in the ice (temperature, thinning of layers, etc.), variations are smoothed by diffusion or altered by chemical reactions or clustering. Diffusion can be reversed mathematically to a certain degree by a deconvolution algorithm (Johnsen, 1977), which extends the depth range for layer counting. Yet, there is always a lower limit below which the annual variations are lost. One reason for this is that wind is mixing the snow on the surface by scouring and relocation. Another reason is that the annual variations are already smoothed out when they are compacted to solid ice at the firn-ice transition. Best accuracy for layer counting is obtained by combining different tracers (Fig. 1) (Fuhrer et

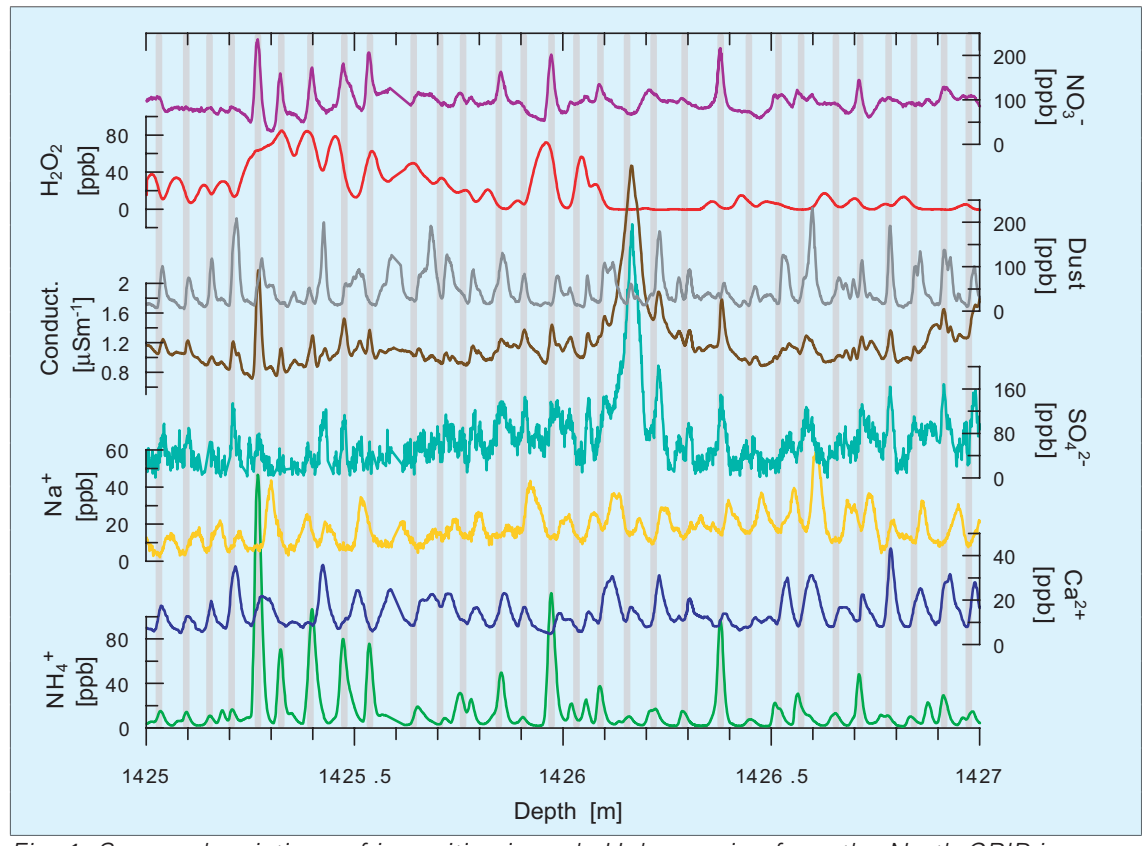

Fig. 1: Seasonal variations of impurities in early Holocene ice from the North GRIP ice core. Summer layers are indicated by grey lines.

al., 1993, Rasmussen et al., 2006). Ideally the counting uncertainty is on the order of $1 \%$.

\section{Ice flow modeling}

Ice is a fluid with an empirical relation between stress and strain rate (power law with an exponent of approx. 3, known as Glen's law (Glen, 1955)). With the knowledge of all material properties and boundary conditions, the plastic deformation of a glacier or ice sheet could be modeled in detail (Fig. 2). However, these boundary conditions and properties are generally poorly known. The bedrock topography is not resolved in sufficient detail and past surface conditions (temperature, precipitation) can only be estimated indirectly. The same holds for the parameters that determine the flow properties, like ice temperature, crystal orientation, impurities and basal sliding. Flow profiles at a certain site can often be approximated by simple flow models that are determined by local parameters, like ice sheet thickness, basal sliding, basal melting, and few parameters to describe the horizontal flow. These parameters are either measured or constrained by age fixpoints. If thinning $\varepsilon_{z}$ at any depth z is assessed with such a model, then one can construct a chronology of the ice if past accumulation rates $\mathrm{a}(\mathrm{z})$ are known.

$\operatorname{age}(z)=\int_{z}^{H} \frac{d z^{\prime}}{\varepsilon_{z^{\prime}} \cdot a\left(z^{\prime}\right)}$

( $\mathrm{H}$ is surface elevation of ice sheet)

The estimate of past accumulation rates is the Achilles' heel of dating by flow models. Such estimates are mostly based on a functional dependence of precipitation and local temperature (estimated from the stable isotope records). There are, however, other causes for variations in past accumulation rates, like changes in circulation or changes in local surface topography. In order to improve the accuracy of the age model, parameters can be constrained by assigning well-dated time horizons to corresponding depths. Such events are, e.g., glacial terminations or minima of Earth's magnetic field that have been dated with best possible accuracy on other paleoarchives (Parrenin et al., 2001). The age uncertainty obtained by flow models depends on the accuracy of accumulation rate estimates (in the order of $20 \%$ ) and on the existence of local flow disturbances. 


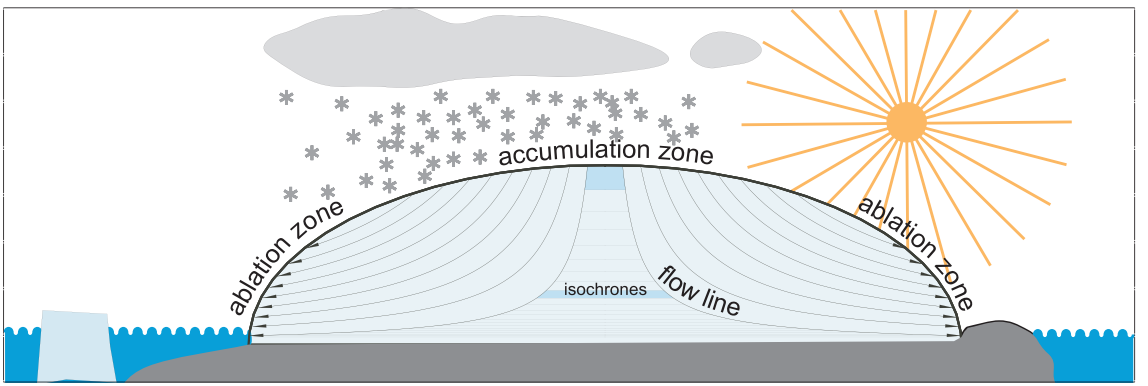

Fig. 2: Cross-section through an idealized ice sheet. Layers are stretched and thinned by plastic flow. The two highlighted layers (blue) comprise the same number of annual layers.

\section{Radiometric dating}

Because both layer counting and flow models may be subject to systematic errors, absolute radiometric clocks are needed. A number of radioactive isotopes have been used to estimate the age of natural ice samples or the occluded air. These include fission products, ${ }^{3} \mathrm{H}$ (Tritium), ${ }^{210} \mathrm{~Pb},{ }^{32} \mathrm{Si},{ }^{39} \mathrm{Ar},{ }^{85} \mathrm{Kr},{ }^{14} \mathrm{C},{ }^{81} \mathrm{Kr},{ }^{36} \mathrm{Cl},{ }^{10} \mathrm{Be}$, and Uranium series. Fission products resulting from nuclear weapon testing in the atmosphere during the 1950s and 60s, can easily be detected by total beta-activity measurements. Other radiometric dating methods have failed to be competitive with current dating tools because the initial concentrations of the radioactive isotopes are too variable. However, these methods remain interesting, e.g., to estimate the age of very old ice near bedrock.

\section{Synchronisation with other paleo-records}

Ice core chronologies often rely on indirect dating, i.e. by comparison with other, better-dated paleo-archives, including other ice cores. In the ideal case, the well-dated record is annually laminated (Hughen et al., 1998, Zolitschka, 1998). Yet, these varved sediments are often affected by hiatuses or do not extend to the present but they can provide valuable information on the duration of climatic events. Other archives are well suited for absolute dating methods, like U/Th-dated speleothems or corals.

The prerequisite for a correlation with ice core records is that events exist in the ice core record that are unequivocally assignable to a synchronous event in the other record. Such events can be volcanic eruptions, Milankovitch-type variations, abrupt climate variations (Dansin the Earth's magnetic field or solar activity, etc. Global records of methane and $\delta^{18} \mathrm{O}_{\text {atm, }}$, for example, have been used to synchronize ice core records from Greenland and Antarctica (Blunier and Brook, 2001).

In the second half of the 19th century, James Croll proposed that the Pleistocene ice ages are caused by periodic changes in the Earth's orbit around the Sun. Milutin Milankovitch improved the astronomical theory, leading to a presently general acceptance of the causality between Earth's orbital parameters and climate variations. There are three astronomical parameters that determine the latitudinal and seasonal variation of insolation on Earth: Precession (periods: 22, 24 kyr), Obliquity (41, 40 kyr), and Eccentricity (404 kyr and several around $100 \mathrm{kyr}$ ).

Tuning to the Milankovitch cycles is accomplished by changing its correlation with the target curve (e.g. summer insolation at a certain latitude) is increased. A shortcoming of the method is the problem of overtuning. Recent orbital tuning work has therefore been as conservative as possible (Karner et al., 2002, Lisiecki and Raymo, 2005). The uncertainty in the phasing between paleo-records and the astronomical cycles is on the order of $5 \mathrm{kyr}$. Ice core records can be correlated to the Milankovitch cycles either directly or indirectly via synchronization, e.g., with marine sediment records (EPICA Community Members, 2004). Direct tuning includes the temperature-sensitive stable isotope ratios of the ice, the $\delta^{18} \mathrm{O}$ of oxygen in the trapped air (Parrenin et al., 2001), and the $\mathrm{O}_{2} / \mathrm{N}_{2}$ ratio (Bender, 2002). Age uncertainties obtained by synchronization techniques vary from one year (e.g.
gaard-Oeschger events), variations the chronology of a record such that historic volcanic signals) to several thousand years.

\section{Age of the gaseous records}

The upper 50-120 m of an ice sheet is made of consolidated snow (firn), permeable to air. Air occluded at the firn-ice transition is therefore substantially younger than the ice. This age difference can be estimated with densification/diffusion models (Schwander et al., 1997). The air at the firn-ice transition is on the order of one to a few decades. The age of the ice at the firn-ice transition spans a large range of a few tens to several thousand years under present conditions, depending mainly on temperature and accumulation rates. Locations with high accumulation rates and relatively high annual temperatures show the smallest ages, while sites in central Antarctica with accumulation rates of a few $\mathrm{cm}$ per year show the largest ages. The difference between the age of the ice and the age of the air has not remained constant over time. Under glacial conditions this age difference was generally several times larger than at present. Due to uncertainties in estimating the accumulation rate and the close-off depth in the past, the error in the age difference is around $10 \%$

\section{REFERENCES}

Bender, M. L., 2002: Orbital tuning chronology for the Vostok climate record supported by trapped gas composition. Earth and Planetary Science Letters, 204: $275-289$.

Blunier, T. and Brook, E. J., 2001: Timing of millennialscale climate change in Antarctica and Greenland during the last glacial period. Science, 291: 109-112.

Johnsen, S. J., 1977: In Proc. of Symp. on Isotopes and Impurities in Snow and Ice, Int. Ass. of Hydrol. Sci., Commission of Snow and Ice, I.U.G.G. XVI, General Assembly, Grenoble Aug.Sept., 1975. IAHS-AISH publication: 210-219.

Johnsen, S. J., Clausen, H. B., Dansgaard, W., Fuhrer, K., Gundestrup, N., Hammer, C. U., Iversen, P., Jouzel, J., Stauffer, B. and Steffensen, J. P., 1992: Irregular glacial interstadials recorded in a new Greenland ice core. Nature, 359: 311-313.

Schwander, J., Sowers, T., Barnola, J.-M., Blunier, T., Malaizé, B. and Fuchs, A., 1997: Age scale of the air in the summit ice: Implication for glacial-interglacial temperature change. Journal of Geophysical Research, 102: 19483-19494.

For full references please consult: www.pages-igbp.org/products/newsletters/ref2006_1.html 


\section{Records from coastal ice cores}

\section{Vin MoRgan}

Antarctic Climate and Ecosystems Cooperative Research Centre, and the Ice, Oceans, Atmosphere and Climate Programme, Australian Antarctic Division, Hobart, Australia; vin.morgan@utas.edu.au

\section{Introduction}

Ice cores drilled on the periphery of the Antarctic ice sheet provide environmental records that complement those from deep cores from the interior of the continent. On the high plateau of East Antarctica, isolation from the oceanic moisture sources, low rates of snow accumulation and the great ice thickness allow deep ice cores to provide records of broad scale climate over multiple glacial cycles.

On the coastal slopes and low elevation parts of Antarctica, the more variable geography-surface slope, proximity to the ocean, domes, crests, etc. - and the generally higher accumulation rates and thinner ice results in cores having shorter records but with higher resolution, at least for the recent period. Coastal cores record a more regional signal, particularly through the deglaciation when rising sea level and temperature elicited different responses at different locations on the ice sheet. The dynamic coastal band, with its high accumulation rates and faster ice flow, dominates the annual ice turnover of Antarctica. The mass balance of the coastal ice sheet, and thus its contribution to sea level change, can respond rapidly to climatic change but at the same time, the slow response time of the inland ice sheet (which is coupled to the coastal ice by ice flow) means that the ice sheet as a whole is still adjusting to the temperature and sea level changes of the last deglaciation. We know from existing records (see examples in Fig. 1) that different parts Last Glacial Maximum.

\begin{tabular}{|l|l|l|c|c|}
\hline $\begin{array}{l}\text { Core } \\
\text { Location }\end{array}$ & Study area & Drilling period & $\begin{array}{l}\text { Depth to } \\
\text { bedrock (m) }\end{array}$ & $\begin{array}{l}\text { Time period } \\
\text { covered (yrs) }\end{array}$ \\
\hline Berkner Island & Weddell Sea & $2002-2005$ & 949 & $\sim 50,000$ \\
\hline Byrd & WestAntarctica & 1968 & 2164 & $\sim 100,000$ \\
\hline LawDome & EastAntarctica & $1989-93$ & 1196 & $\sim 90,000$ \\
\hline Siple Dome & WestAntarctica & completed1999 & 1003 & $\sim 90,000$ \\
\hline Talos Dome & Ross Sea & $2005-07$ & $\sim 1500$ & $\sim 120,000$ \\
\hline Taylor Dome & Ross Sea & completed 1994 & 554 & $\sim 230,000$ \\
\hline
\end{tabular}

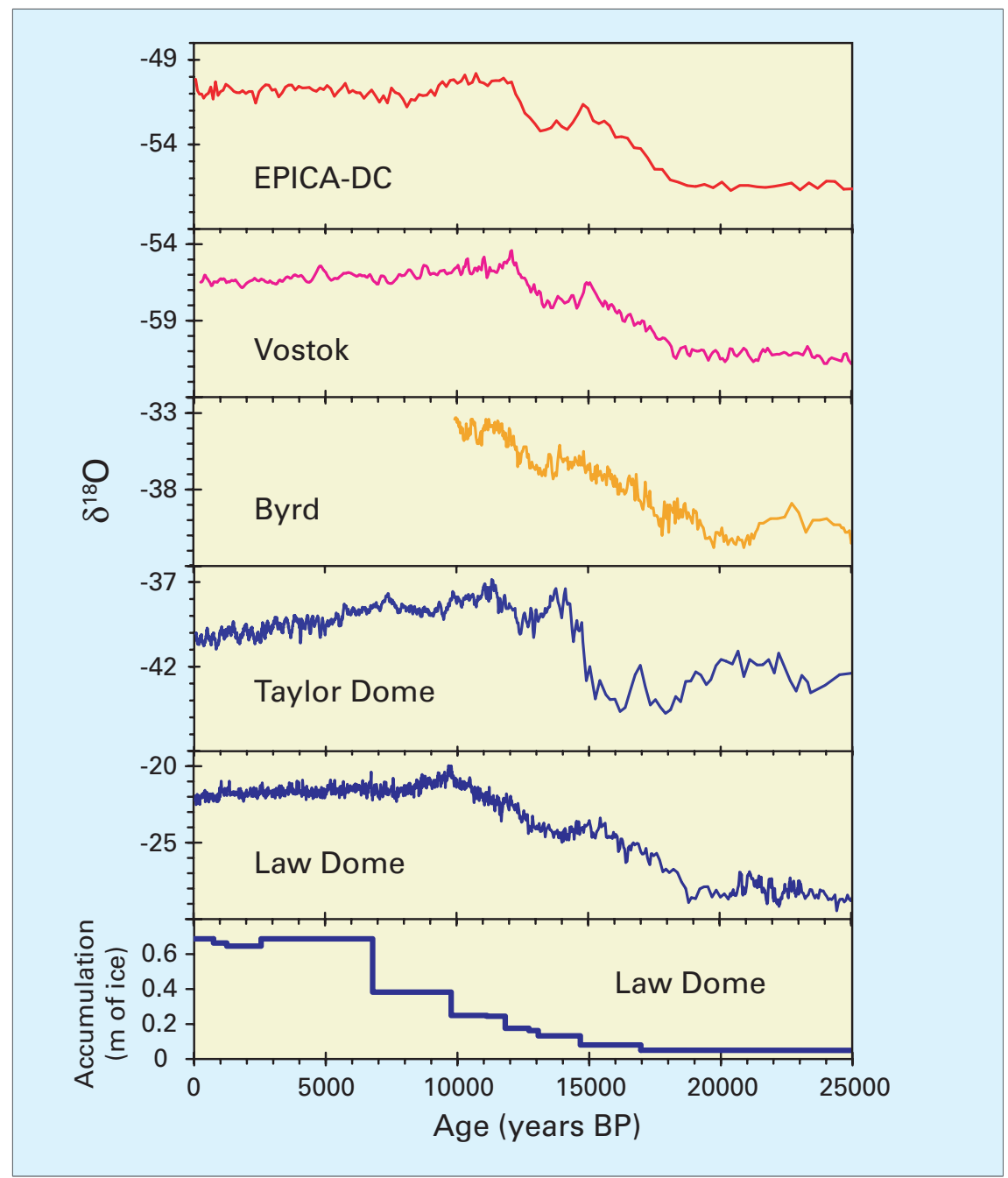

Fig. 1: Isotope records from two inland sites, EPICA-DC and Vostok, two coastal sites, Taylor Dome and Law Dome, and the Byrd record from West Antarctica. Also shown is Law Dome accumulation inferred from the dating model (van Ommen et al., 2004). Within dating errors, EDC and Vostok show a similar pattern. Law Dome shows a similar pattern to the inland cores from the LGM through the ACR but the $\delta^{18} \mathrm{O}$ increase is interrupted by a small dip at 11,500 $B P$ (close in time to the end of the Younger Dryas) and after the dip the increase continues until 10,000, about 2000 years after the inland cores. The Taylor Dome record, shown on the st9810 timescale, differs markedly from the others, showing cold glacial conditions continuing as late as 16,000, a later temperature reversal and continued warming through the Holocene. However, recent results (including isotope ratios of trapped atmospheric nitrogen) suggest there were periods during the deglaciation of little or no accumulation at Taylor Dome.

of the ice sheet have responded differently to the sea level and climate

cores that reach (or are expected to reach) the bution to sea level change, we need additional records from the coastal zone. Accordingly, drilling and analyzing of coastal Antarctic cores has become a major task in ice core research (for a list of some of the most important coastal Antarctic cores see Table 1)

Here we look at two results from the coastal Law Dome ice core. Both 


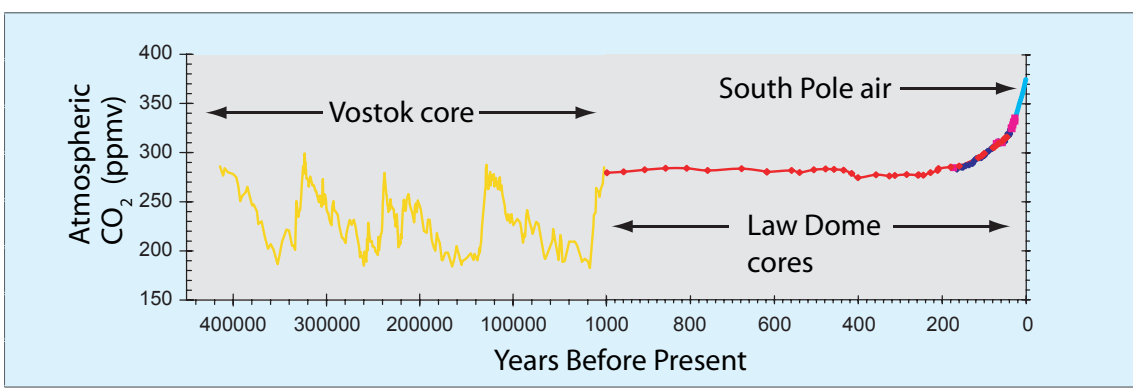

Fig. 2: Composite atmospheric $\mathrm{CO}_{2}$ concentration from 400,000 BP to $1978 \mathrm{AD}$. 400,000 BP to 2300 BP from Vostok (yellow line, Petit et al., 1999) 1000 BP to 1978 AD from the DSS, DE08 and DE08/2 Law Dome cores (Etheridge et al., 1996). 1978 AD to 2004 from South Pole air samples (Keeling and Whorf, 2005). DSS - red line, DE08 - blue line, DE08/2 - violet points, South Pole air - blue line.

involve the high accumulation rate at the core site as a key parameter.

\section{The coastal accumulation regime}

Under present day conditions, accumulation on the inland plateau is mainly in the form of "diamond dust" - clear sky ice crystal precipitation, principally in winter, that results from cooling of the atmosphere by radiative loss. The low air temperature limits available moisture, so inland accumulation rates are low and tend to follow temperature variation. On the coastal slopes, snowfall resulting from orographic uplift of moist air from cyclonic systems results in high accumulation rates that depend mainly on the frequency of cyclones and are largely independent of temperature.

Law Dome projects out from the coast of East Antarctica and is the most northerly part of the continent, apart from the extremity of the Antarctic Peninsula. Under present day meteorology, Law Dome receives precipitation from cyclonic systems, however, recent results (van Ommen et al., 2004) have shown that during the Glacial and through the early Holocene, accumulation rates were only some $10 \%$ of present day and varied with temperature. A similar situation appears to have existed at Taylor Dome, which also has a large accumulation rate change from the Glacial to the Holocene (Steig and others, 2000). It seems that during the Glacial, lower temperatures, more northerly paths of cyclonic systems and the ice sheet expansion allowed by lowered sea level resulted in a shift of the boundary between the inland clear-sky ice-crystal mode of precipitation and the coastal cy- clonic mode to the north of Law Dome. Determining how, when and if this change occurred at different locations is necessary because different precipitation mechanisms can change the calibration of the ice core recorder.

Further work using additional cores to determine the timing and the extent of this change in accumulation mechanism will give insights into changes in Antarctic climate and its possible effects on the ice sheet's mass balance. So far, the only coastal cores that have accumulation records extending into the Glacial are Law Dome and Taylor Dome. In the near future, we expect to be able to add the records from the Berkner Island and Siple Dome cores and in a few years time there will be a record from the new Talos Dome core.

\section{High-resolution gas records}

A feature of the high accumulation coastal cores, and one that is pre-

\section{Project facts}

Project: Deep Ice Drilling on Law Dome Contact: Vin Morgan, vin.morgan@utas.edu.au

Participants: Vin Morgan, Tas van Ommen, Mark Curran, Barbara Smith (Antarctic Climate and Ecosystems Cooperative Research Centre, and the Ice, Oceans, Atmosphere and Climate Programme, Australian Antarctic Division)

Funding: Australian Antarctic Division

Where: Coastal East Antarctica

When: Drilling 1988 to 1993, core analysis ongoing

What: $1200 \mathrm{~m}$ core from surface to bedrock $4.7 \mathrm{~km} \mathrm{SSW}$ of the summit of Law Dome, multiparameter analysis

Database: http://aadc-maps.aad.gov. au/aadc/portal/ www.ncdc.noaa.gov/paleo/icecore/antarctica/law/law.html served despite the layer thinning, is their small delta age values. Delta age is the difference between the age of the air trapped as bubbles in the ice and the age of the surrounding ice, and arises because the air is only trapped when the pores in the firn are closed off to form closed bubbles by the weight of the overlying snow. Close-off occurs around a depth of about $60 \mathrm{~m}$ at Law Dome so to a first approximation-neglecting the limited exchange with the atmosphere near close-off-delta age is the age of the ice at $\sim 60 \mathrm{~m}$. At low accumulation inland sites, delta age can be thousands of years but coastal sites have been found with values as low as 40 years. Figure 2 shows records of atmospheric carbon dioxide concentration from an inland site (Vostok) and a coastal site (Law Dome). Delta age for Vostok is about 2000 years, so the most recent data point is at $2300 \mathrm{BP}$. At DE08 on the eastern flank of Law Dome, the accumulation rate $1.2 \mathrm{~m}$ of ice equivalent per year leads to a delta age of 30 years. The coastal Law Dome site extends the record up to 1978 AD, overlapping direct air composition measurements at South Pole and delineating the increase due to anthropogenic input.

\section{REFERENCES}

Etheridge, D. M., Steele, L. P., Langenfelds, R. B., Francey, R. J., Barnola, J-M. and Morgan, V. I., 1996: Natural and anthropogenic changes in atmospheric $\mathrm{CO}_{2}$ over the last 1000 years from air in Antarctic ice and firn. Journal of Geophysical Research, 101(D2): 4115-4128.

Keeling, C.D. and Whorf, T.P., 2005: Atmospheric $\mathrm{CO}_{2}$ records from sites in the $\mathrm{SIO}$ air sampling network. In Trends: A Compendium of Data on Global Change. Carbon Dioxide Information Analysis Center, Oak Ridge National Laboratory, U.S. Department of Energy, Oak Ridge, Tenn., U.S.A

Steig, E.J. and 7 others, 2000: Wisconsinan and Holocene climate history from an ice core at Taylor Dome, Western Ross Embayment, Antarctica. Geogr. Ann., 82A(2-3): 213-235.

Petit, J. R., Jouzel, J., Raynaud, D., Barkov, N.I., Barnola, J.-M., Basile, I., Bender, M., Chappellaz, J., Davis, M., Delaygue, G., Masson-Delmotte, V., Kotlyakov, V.M., Legrand, M., Lipenkov, V.Y., Lorius, C., Pepin, L., Ritz, C., Saltzman, E., and Stievenard M., 1999: Climate and atmospheric history of the past 420,000 years from the Vostok ice core, Antarctica, Nature, 399: 429-436.

van Ommen, T., Morgan, V. and Curran, M., 2004: Deglacial and Holocene changes in accumulation at Law Dome, East Antarctica. Ann. Glaciol., 39: 359-365. 


\section{The WAIS Divide ice core: Progress and plans}

JefF SEVERINGHaUs

Scripps Institution of Oceanography, University of California, San Diego, USA; jseveringhaus@ucsd.edu

\section{Introduction}

For over 20 years, the international glaciological community has recognized the need for a deep ice core from the flow divide in central West Antarctica. This would provide the first Southern Hemisphere climate record of comparable resolution and duration to the Greenland ice cores, which have revolutionized our notion of past climate stability. It would also test models of West Antarctic lce Sheet (WAIS) history and stability, a major concern for future sea level. The WAISCORES initiative was launched by the U.S. National Science Foundation in the 1990s to realize these goals through the drilling of two deep cores. The first was a deep core at the coastal site Siple Dome (Brook et al., 2005; Severinghaus et al., 2003; Taylor et al., 2004), which is now complete, and the second is a deep core at the ice flow divide in the center of the WAIS, known as the WAIS Divide core (Fig. 1). This article discusses the current state of the WAIS Divide project, the scientific questions to be addressed, and future plans.

The WAIS Divide ice core drilling

Site selection was recently completed for the WAIS Divide project (see box). During the 2005-2006 season just finished, a camp was established, shallow cores were retrieved, and firn air sampling was conducted. A new deep drill (called the DISC drill) has been constructed for the WAIS Divide project and will be tested at Greenland summit in summer 2006. This test will focus on optimizing core quality in the brittle ice zone, and will reach a depth of $600 \mathrm{~m}$. The 2006-2007 season will be devoted to drill setup at the WAIS Divide site, and deep drilling will begin in earnest in the 2007-2008 season.

The chosen site is an almost exact analog to GISP2 in Greenland in terms of temperature, accumulation rate, gas age-ice age difference, and other variables. The site is $\sim 24 \mathrm{~km}$ downslope of the flow divide, similar to GISP2, to insure that no divide

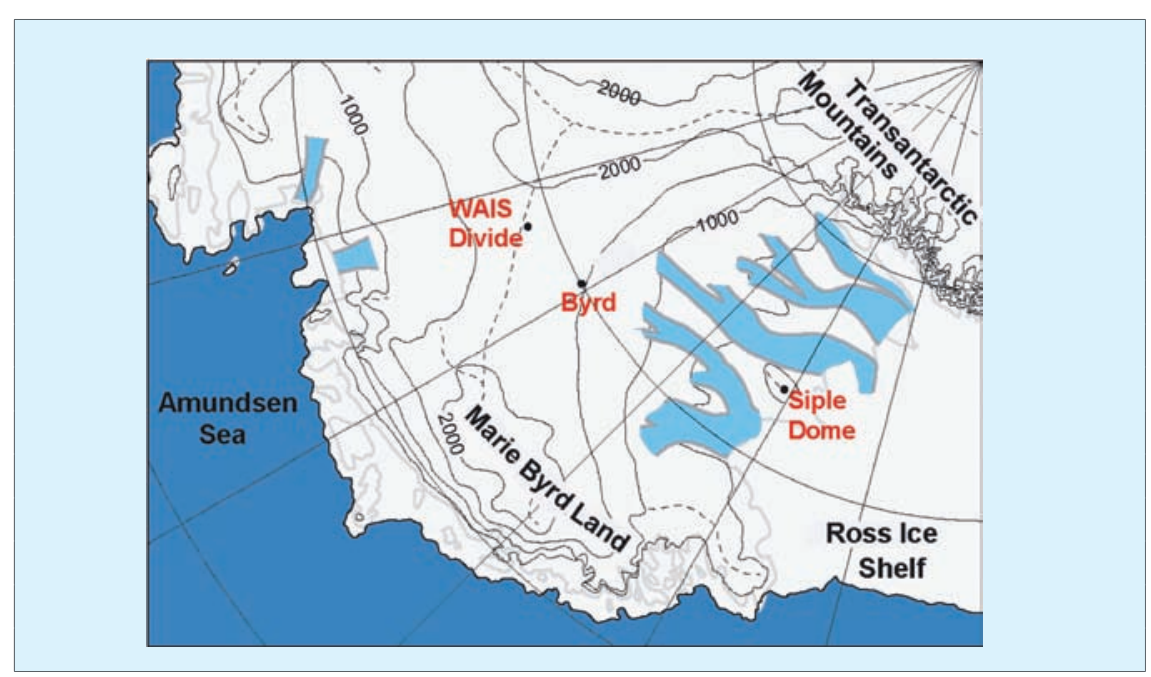

Fig. 1: Map showing locations of the existing Byrd and Siple Dome ice cores, and the planned WAIS Divide ice core.

migration has compromised the stratigraphy. Because this is the leeward side relative to the prevailing storm track, the accumulation rate at the site is substantially less than at the divide itself. This has the advantage of making the Holocene section of the core more compact, and older sections expanded, because deeper ice originated closer to the divide.

\section{Objectives}

Like GISP2, WAIS Divide is expected to yield a high-resolution record of temperature and atmospheric methane during the millennial-scale (Dansgaard-Oeschger) oscillations of the last glacial period. Because of the small age difference between the gases and the enclosing ice, a decadal-precision chronology relative to Greenland is expected, using methane and air ${ }^{18} \mathrm{O}$ as interhemispheric time markers. This will allow stringent tests of the bipolar see-saw hypothesis; that Atlantic ocean circulation changes caused the apparent asynchrony of Greenland and Antarctic climate records at millennial time scales.

One important difference from GISP2 is that an excellent atmospheric $\mathrm{CO}_{2}$ record is expected to be obtained because Antarctic ice has an order of magnitude less dust than Greenland ice. This will allow, for the first time, precise comparison of the relative timing of rapid variations in atmospheric methane and $\mathrm{CO}_{2}$ during the Dansgaard-Oeschger events. Atmospheric $\mathrm{CO}_{2}$ is known to respond quickly to changes in sea surface temperature, so the precise timing may shed light on the mechanism of these events. Many other gases and their isotopes will be measured at unprecedented precision and resolution $\left({ }^{13} \mathrm{CH}^{4}, \mathrm{~N}_{2} \mathrm{O}\right.$, $\mathrm{CH}_{3} \mathrm{Cl}, \mathrm{CH}_{3} \mathrm{Br} ;{ }^{15} \mathrm{~N}$ of $\mathrm{N}_{2} \cdot{ }^{18} \mathrm{O}$ and ${ }^{17} \mathrm{O}$ of $\mathrm{O}_{2},{ }^{40} \mathrm{Ar} /{ }^{36} \mathrm{Ar}, \mathrm{Kr} / \mathrm{N}_{2}, \mathrm{Xe} / \mathrm{N}_{2}$ among others). Overall the WAIS Divide core is expected to produce the best gas records of the past $100 \mathrm{kyr}$ yet obtained.

\section{Project facts}

Project: WAIS

Contact: Kendrick Taylor (Desert Research Institute, University of Nevada), kendrick.taylor@dri.edu

Steering committee: Richard Alley (Penn State), Ed Brook (Oregon State University), Jeff Severinghaus (Scripps Institution of Oceanography), Jim White (INSTAAR, University of Colorado)

Funding: NSF

Where: West Antarctic Ice Sheets (WAIS divide: $79.468^{\circ} \mathrm{S}, 112.086^{\circ} \mathrm{W}$, altitude $1765 \mathrm{~m}$, ice thickness $3465 \mathrm{~m}$

When: 2006-2011

What: Deep ice core covering approx. one glacial cycle

Web page: www.dri.edu/People/kendrick/ WDSprojmain.htm http://igloo.gsfc.nasa.gov/wais/ http://waiscores.dri.edu/ 
As in Greenland, the high accumulation rate and great ice thickness will permit high-confidence borehole thermometry-based temperature estimates for the past glacial period. Other Antarctic borehole thermometry efforts have been stymied by the low accumulation rate. WAIS Divide should provide the first reliable direct temperature estimate of the last glacial maximum in Antarctica. Other borehole logging (optical, sonic) will place unique constraints on ice deformation, which combined with accurate surface temperature history, timescale, and accumulation rate, will make a potent synergy for glaciological modeling of the history of the WAIS. This effort will address questions about the stability of this marine-based ice sheet, which would raise sea level $5 \mathrm{~m}$ if melted.

\section{Wider perspectives of the WAIS project}

International collaboration figures prominently in the WAIS Divide ef- fort. WAIS Divide is under the umbrella of the recently established International Partnerships for Ice Coring Science (IPICS), although its planning long predates IPICS. WAIS Divide is one of the first elements to get underway in the IPICS 40,000 Year Network, which will map spatial variation at the regional scale in order to better understand the dynamics of the last deglaciation (see Brook, this issue). The importance of spatial differences between cores within Antarctica has been highlighted recently by the Siple Dome record (Taylor et al., 2004). Improved understanding of regional variations in climate during the past $100 \mathrm{kyr}$ will help separate global from regional signals.

International collaboration has already greatly aided the DISC deep drill development, and it is anticipated that international partnerships on WAIS Divide drilling and science will continue at a heightened pace in the context of the International Polar
Year (2007-2008). Bottom-up, individual investigator-driven international collaborations on WAIS Divide are highly encouraged, although no formal, top-down structure for collaboration has been imposed.

\section{REFERENCES}

Brook, E.J., White, J.W.C., Schilla, A.S.M., Bender, M.L., Barnett, B., Severinghaus, J.P., Taylor, K.C., Alley, R.B., Steig, E.J., 2005: Timing of millennialscale climate change at Siple Dome, West Antarctica, during the last glacial period, Quaternary Science Reviews, 24: 1333-1343.

Taylor, K.C., White, J.W.C. Severinghaus, J.P., Brook, E.J., Mayewski, P.A., Alley, R.B., Steig, E.J., Spencer, M.K., Meyerson, E., Meese, D.A., Lamorey, G.W., Grachev, A., Gow, A.J. and Barnett, B.A., 2004: Abrupt climate change around $22 \mathrm{ka}$ on the Siple Coast of Antarctica, Quat. Sci. Rev., 23: 7-15. Severinghaus, J.P., Grachev, A., Luz, B., and Caillon, N., A, 2003: method for precise measurement of argon 40/36 and krypton/argon ratios in trapped air in polar ice with applications to past firn thickness and abrupt climate change in Greenland and at Siple Dome, Antarctica, Geochim. Cosmochim. Acta, 67: 325-343.

\section{International Trans Antarctic Scientific Expedition (ITASE)}

\section{Paul Andrew Mayewski}

Climate Change Institute, University of Maine, Orono, USA; paul.mayewski@maine.edu

\section{Introduction}

ITASE has as its primary aim the collection and interpretation of a continent-wide array of environmental parameters (Fig. 1), assembled through the coordinated efforts of scientists from 20 nations. ITASE offers the groundbased opportunities of traditional style traverse travel, coupled with the modern technology of GPS, crevasse detecting radar, satellite communications and multi-disciplinary research (Fig. 2). By operating predominantly in the mode of an oversnow traverse, ITASE offers scientists the opportunity to experience the dynamic range of the Antarctic environment. The combination of disciplines represented by ITASE provides a unique, multi-dimensional ( $x, y$, $z$ and time) view of the ice sheet and its history. As of 2004, ITASE has completed $>20,000 \mathrm{~km}$ of snow radar, recovered more than $240 \mathrm{firn} / \mathrm{ice}$ cores (total depth

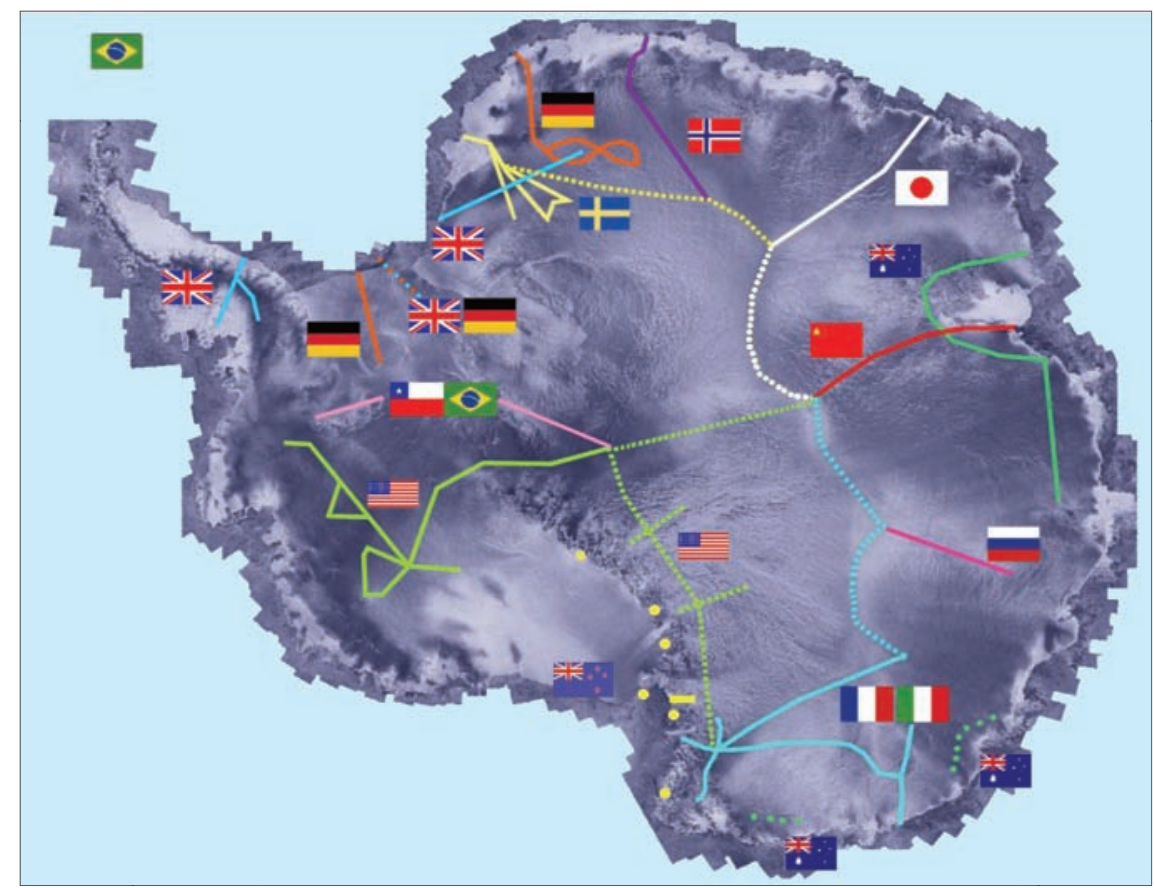

Fig. 1: ITASE national traverse routes superimposed on RADARSAT image. Solid lines represent completed traverses, dashed represent proposed or planned traverses.

$7000 \mathrm{~m})$, remotely penetrated to $\sim 4000 \mathrm{~m}$ into the ice sheet, and sampled the atmosphere to heights of $>20 \mathrm{~km}$.

\section{Results}

Although full-scale reconstructions of past climate over Antarctica have yet to be finalized, 


\section{Science Highlights: Ice Core Science}

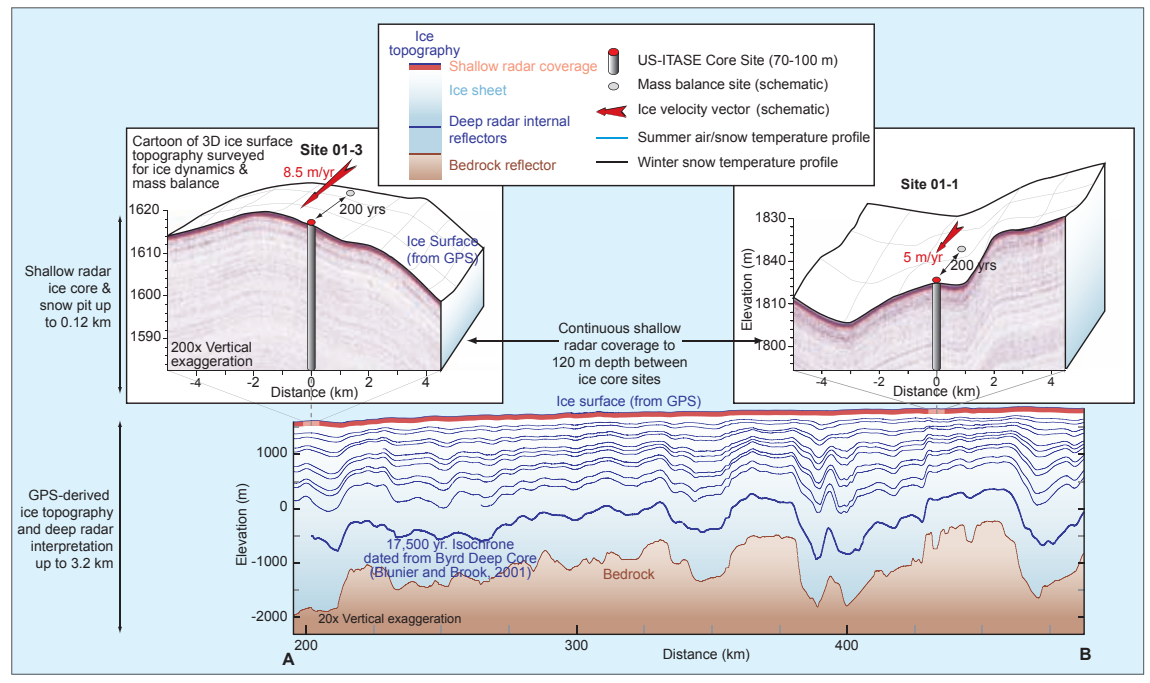

Fig. 2: Multi-dimensional approach to the multi-disciplinary ITASE objectives. Studies at a variety of spatial scales extending from the subglacial bedrock to the surface. Ice core sites along each traverse route produce 200-1000+ year annually dated climate records. Ice core site selection is determined by field interpretation of shallow radar data. Numerous measurements are made at each core site to provide context for the ice core climate records. These measurements include: high-resolution surface topography maps; snow pit measurements of density, chemistry, stable isotopes, temperature; and meteorological data. Ice mass balance and horizontal velocity studies located 200 years upstream provide past ice flow history for the ice cores. Shallow and deep-penetrating radio echo sounding data tie the ice cores together and provide large-scale context for ITASE cores and future deep ice core climate records. Internal stratigraphy in both radio echo sounding records represents isochronal events, and a record of depositional and ice flow history along the traverse. The radar data and interpretation, and ice topography along the radar profiles shown here are actual examples of the 2001 US-ITASE season. Figure by Brian Welch, St. Olaf College, US ITASE.

ITASE has pioneered calibration tools, reconstruction of climate indices, and evidence for climate forcing, using single-sites through to multiple arrays of sites. Initial syntheses of combined ITASE and deep ice core records demonstrate that inclusion of instrumentally calibrated ITASE ice core records allows the previously unavailable reconstruction of past regional to continental scale variability in atmospheric circulation and temperature. Emerging results demonstrate the utilization of ITASE records in comparisons with meteorological reanalysis products. Connections are now noted between ITASE climate proxies and global scale climate indices such as ENSO, in addition to major atmospheric circulation features over the Southern Hemisphere, such as the Amundsen Sea Low, East Antarctic High, and Antarctic Oscillation. Large-scale calibrations between satellite-deduced surface temperature and ITASE ice core proxies for temperature are also now available. ITASE is also developing proxies for sea ice, a critical component in the climate system. ITASE research is also fo- cused on understanding the factors that control climate variability over Antarctica and the Southern Ocean.

Understanding the distribution of snow precipitation over the Antarctic continent, and the surface processes on different spatial and temporal scales that redistribute this precipitation, is the area of greatest common interest between ITASE and another SCAR (Scientific Committee on Antarctic Research) activity, Ice Sheet Mass Balance and Sea Level (ISMASS). ITASE research reveals high variability in surface mass balance and the fact that single cores, stakes, and snowpits do not represent the geographical and environmental characteristics of a local region. Field observations show that the interaction of surface wind and subtle variations of surface slope have a considerable impact on the spatial distribution of snow at short and long spatial scales. Data collected in the ITASE framework and by associated projects (EPICA DC and DML, Siple Dome, Law Dome, Dome Fuji) also reveals systematic biases compared to previous compilations.

\section{Outlook}

Field measurements including new techniques, e.g. Lidar and airborne coherent GPR, laboratory ice flow studies, new computer modeling techniques, including new remote sensing techniques, e.g. Satellite Radar (SAR) interferometry, all contribute to ISMASS and ITASE goals. The extensive use along ITASE traverses of new techniques like GPR and GPS, integrated with core data, provide detailed information on surface mass balance. Some GPR layers have been surveyed extensively throughout Antarctica and they can be used as historical benchmarks to study past accumulation rates. In addition, coupling ground survey data with satellitebased observations provides new tools for measuring, for example, ice surface velocity and ice sheet surface temperature.

The growing ITASE database has the potential to explore temporal variability and recent evolution of Antarctic climate, utilizing an unprecedented spatio-temporal array. Data extraction and validation activities are an essential preliminary to the synthesis task. Such activities, together with the development of instrumental calibration techniques, have been a significant component of ITASE studies. Maps of surface distribution of chemical species (Bertler et al., in press) indicate the unprecedented scope for exploring climate variability as

\section{Project facts}

\section{Project: ITASE}

Contact: Paul Mayewski, paul.mayewski@maine.edu

Participants: Scientific and logistics institutions from 20 nations: Argentina, Australia, Belgium, Brazil, Canada, Chile, China, France, Germany, India, Italy, Japan, The Netherlands, New Zealand, Norway, Russia, South Korea, Sweden, UK, USA.

Funding: National contributions

Where: Antarctica

When: Endorsed by the Scientific Committee on Antarctic Research (SCAR). Activities since 1992 and ongoing.

What: Snow pits, shallow and intermediate ice cores covering decades to millennia, multiparameter analysis

Web page: www.ume.maine.edu/itase/ 
extended time-series become available over broad regions through ITASE and deep drilling projects. The Antarctic-wide comparison of glaciochemical records provides a unique opportunity to achieve an understanding of the fundamental factors that ultimately control the chemistry of a snow or ice sample. The ability to determine individual sources and pathways of aerosols, as well as mechanisms that rule precipitation efficiency and postdepositional effects, will allow the exceptionally detailed and accurate interpretation of glaciochemical records necessary for reconstructing past climate conditions with nearinstrumental quality.

\section{Note:}

This article was abstracted from Mayewski et al., in press. This paper summarizes ITASE accomplishments with references. For details concerning national programs, the ITASE Science and Implementation Plan (Mayewski and Goodwin, 1997), and other ITASE information refer to the SCAR Project Office maintained at the Climate Change Institute, University of Maine (www.ume. maine.edu/itase/).

\section{REFERENCES}

Bertler, N., Mayewski, P.A., Aristarain, A. and 46 others, in press: Snow chemistry across Antarctica, Annals of Glaciology.
Mayewski, P.A. and Goodwin, I. 1997: ITASE Science and Implementation Plan, Joint PAGES/GLOCANT Report. PAGES IPO, Bern - Switzerland

Mayewski, P.A., Frezzotti, M., Bertler, N., van Ommen, T., Hamilton, G.H., Jacka, J., Welch, B., Frey, M., Dahe, Q., Ren, J., Simoes, J., Fily, M., Oerter, H. Nishio, F., lasaksson, E., Mulvaney, R., Holmund, P., Lipenkov, V. and Goodwin, I., in press: The International Trans-Antarctic Scientific Expedition (ITASE) - An Overview, Annals of Glaciology.

\section{A new 3000 m deep ice core drilled at Dome Fuji, Antarctica}

YoshiYuki FUJII

National Institute of Polar Research, Tokyo, Japan; fujii@nipr.ac.jp

\section{Introduction}

On 23 January 2006, the Japanese Antarctic Research Expedition (JARE) succeeded in drilling a 3029 $m$ deep ice core at Dome Fuji in East Antarctica $\left(77^{\circ} 19^{\prime} 01^{\prime \prime} \mathrm{S}, 39^{\circ} 42^{\prime} 12^{\prime \prime} \mathrm{E}\right.$, $3810 \mathrm{~m}$ asl; Fig. 1). Dome Fuji is the third place where a more than 3000 $\mathrm{m}$ deep ice core was collected in Antarctica, after Vostok (3623 m in depth, January 1998) and Dome C (3270 $\mathrm{m}$ in depth, December 2004). The drilling will be continued next season in order to hit bedrock, which is estimated to be located $3030 \pm 15 \mathrm{~m}$ below the surface.

A previous deep ice core, of 2503 m length, was drilled at Dome Fuji in December 1996, tracing back to past $340 \mathrm{ka}$. The high resolution stable isotope record $\left(\delta^{18} \mathrm{O}\right)$ showed an extraordinary coherence (Watanabe et al., 2003) with the deep ice core from Vostok (Petit et al., 1999), which also reaches as far back in time but is located $1500 \mathrm{~km}$ away from Dome Fuji. This fact strongly supports a homogeneous climate development over the last 340,000 years on the high plateau of East Antarctica.

\section{Drilling of the new ice core}

During the 1996 drilling, the drill got stuck in the borehole and was not able to be recovered. A new drilling site was constructed in the

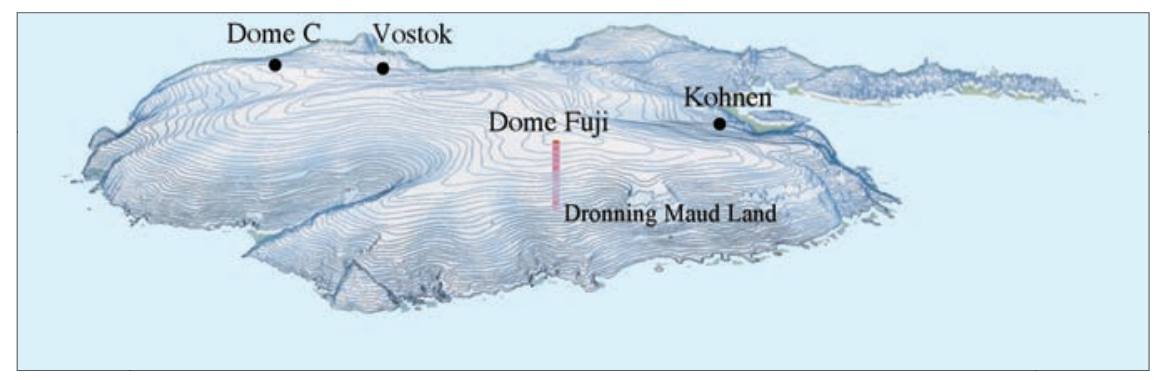

Fig. 1: A bird's eye view of the Antarctic ice sheet. Dome Fuji is located at the summit of Dronning Maud Land. This is the ideal place for ice core climate research because no horizontal ice flow movements occur.

2001/2002 season, and in December 2003, drilling was resumed 40 $\mathrm{m}$ away from the first borehole. This time, we utilized a newly developed, highly efficient drill, using a pipe with small holes $2 \mathrm{~mm}$ in diameter at intervals of $7 \mathrm{~mm}$ to act as a chip chamber to store icecutting chips. We also developed a bulb which prevents ice-cutting

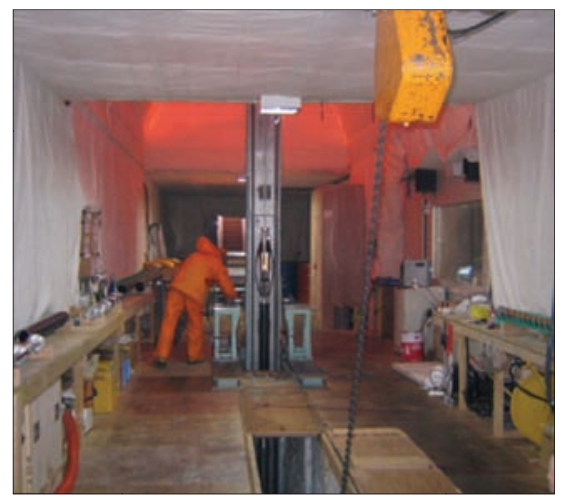

Fig. 2: Deep ice core drilling at Dome Fuji using a newly developed drill with highly efficient performance. chips from flowing out into the borehole when the drill is being winched up. The average drilling depth was $3.7 \mathrm{~m} / \mathrm{run}$ and the speed was $178 \mathrm{~m} /$ week until it got down to $3000 \mathrm{~m}$ depth. This is the fastest performance ever in deep ice core drilling in the Antarctica and Greenland. Figure 2 shows a scene of the deep ice core drilling at Dome Fuji.

Around $3000 \mathrm{~m}$ depth, the drilling speed decreased sharply as the drill hit "warm ice". We took measures against this warm ice, referring to the reports of deep ice coring at Dome C, NGRIP and others. We changed the shape of the drill cutter and the shape of the mount so that they would not easily get frozen and also coated the cutter with Teflon. However, freezing of "water" still made drilling difficult and we could drill only about $0.5 \mathrm{~m}$ each run. 


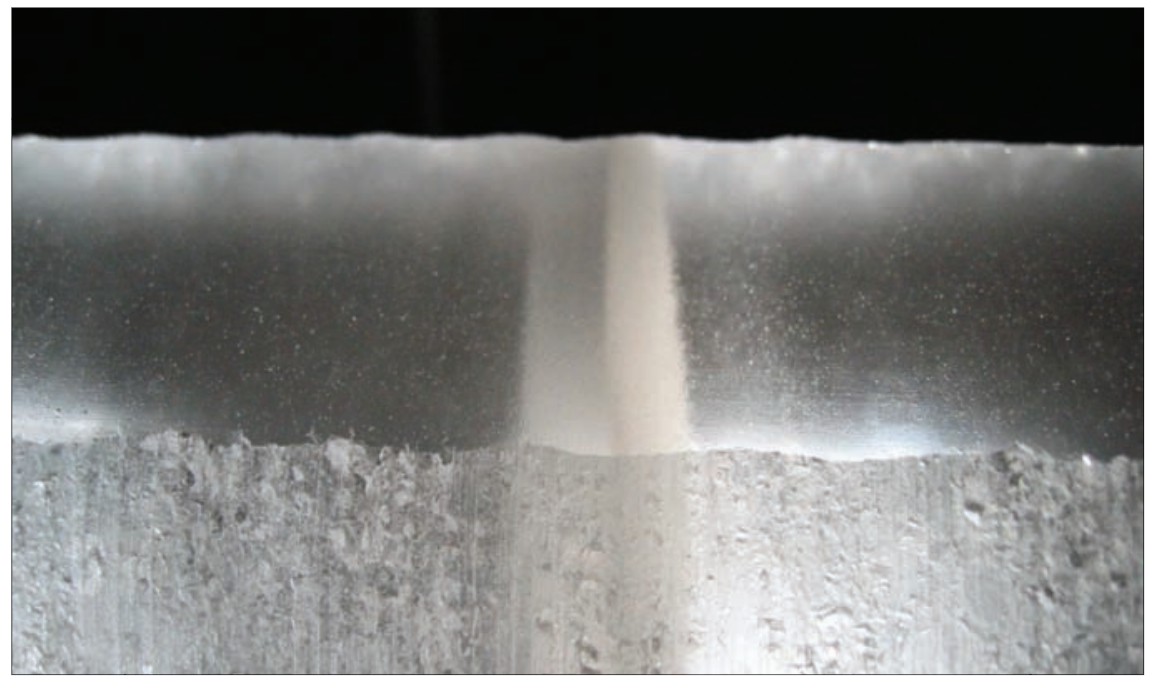

Fig. 2: A tephra layer in a half-cut ice core sample. There are a few tephra layers that were not found in the previous $2503 \mathrm{~m}$ deep ice core from Dome Fuji.

\section{Properties of the ice core}

In situ ECM (Electric Conductivity Measurement) and optical stratigraphic observations will be performed at Dome Fuji. The detailed analysis will be conducted in Japan, and we expect to determine the approximate age of the core by detecting glacial cycles and signals of the Brunhes-Matuyama magnetic reversal at around 780 $k a$, and by using a glaciological flow-model. It is difficult to say at present but we expect that the core may be $800 \mathrm{ka}$ old, as is the case for the Dome $\mathrm{C}$ deep ice core, or even older. This expected age is suggested from the fact that the geothermal heat flux in Dronning Maud Land where Dome Fuji is located is probably smaller than that of the eastern part of East Antarctica where Vostok and Dome C are located. We discovered new tephra layers (Fig. 3) that were not observed in the first $2503 \mathrm{~m}$ deep ice core.

\section{Outlook}

One half of the ice core will be kept in a storage trench at Dome Fuji and the other half will be brought back to Japan by our Antarctic research vessel in April. These ice cores will be used for various

\section{Project facts}

Project: Dome Fuji Ice Core

Contact: Yoshiyuki Fujii, fujii@nipr.ac.jp

Participants: Numerous scientists from the National Polar Institute, Tokyo, and several Japanese Universities.

Funding: Japanese National Funding

Where: Eastern Dronning Maud Land,

East Antarctica

When: 2004 ongoing

What: Deep ice cores to bedrock; Multiparameter analysis analyses at the National Institute of Polar Research, Hokkaido University, and other institutions in Japan. Our main research objectives are

1) To reconstruct the global climate and environmental changes that occurred during the past 800 ka to 1 million years.

2) To determine the impacts of the geomagnetic field reversal on the global climate and the environment around $780 \mathrm{ka}$ BP.

3) To clarify the relationship between the paleo-solar activity and the global climate.

4) To clarify the relationship between biological evolution of the ice core microbes and environmental changes.

Furthermore, if we can obtain samples of the bedrock, it may be possible to get information on the formative period of the Antarctic ice sheet in the Tertiary.

\section{REFERENCES}

Watanabe, 0., Jouzel, J., Johnsen, S., Parrenin, F., Shoji, H., and Yoshida, N., 2003: Homogeneous climate variability across East Antarctica over the past three glacial cycles, Nature, 422: 509-512.

Petit, J. R., Jouzel, J., Raynaud, D., Barkov, N.I., Barnola, J.-M., Basile, I., Bender, M., Chappellaz, J., Davis, M., Delaygue, G., Masson-Delmotte, V., Kotlyakov, V.M., Legrand, M., Lipenkov, V.Y., Lorius, C., Pepin, L., Ritz, C., Saltzman, E., and Stievenard M., 1999: Climate and atmospheric history of the past 420,000 years from the Vostok ice core, Antarctica, Nature, 399: 429-436.

\section{Vostok Ice Core project}

Vladimir Lipenkov ${ }^{1}$ on behalf of the Vostok Project Members

${ }^{1}$ Arctic and Antarctic Research Institute (AARI), St. Petersburg, Russia; lipenkov@aari.nw.ru

\section{Introduction}

Over the last 25 years, the three deep ice cores 3G, 4G and 5G, drilled at the Russian Vostok Station (Fig.1), have provided a wealth of information about past climate and environmental changes. At this site in East Antarctica, the ice thickness is $3750 \mathrm{~m}$ and the snow accumulation rate is only $2.1 \mathrm{~cm}$ of water equivalent per year. This provides the unique opportunity to obtain a long climatic record with relatively high time-resolution. In January 1998, the collaborative project between Russia, France and the United States to drill the $5 \mathrm{G}$ hole at Vostok yielded the Iongest ice core ever recovered, reaching a depth of $3623 \mathrm{~m}$. The drilling stopped $130 \mathrm{~m}$ above Lake Vostok, a deep subglacial water body that extends over a large area below the ice sheet. The $5 \mathrm{G}$ ice core can be separated into three distinct sections. The upper $3310 \mathrm{~m}$ of the core are characterized by an undisturbed sequence of ice layers. The analysis of this section of the core resulted in the first record of Antarctic ice extending through four climate cycles back to $420 \mathrm{kyr}$ BP (Petit et al., 1999). Between 3310 and $3539 \mathrm{~m}$, there are indications of ice-flow anomalies that could have altered the original stratig- 


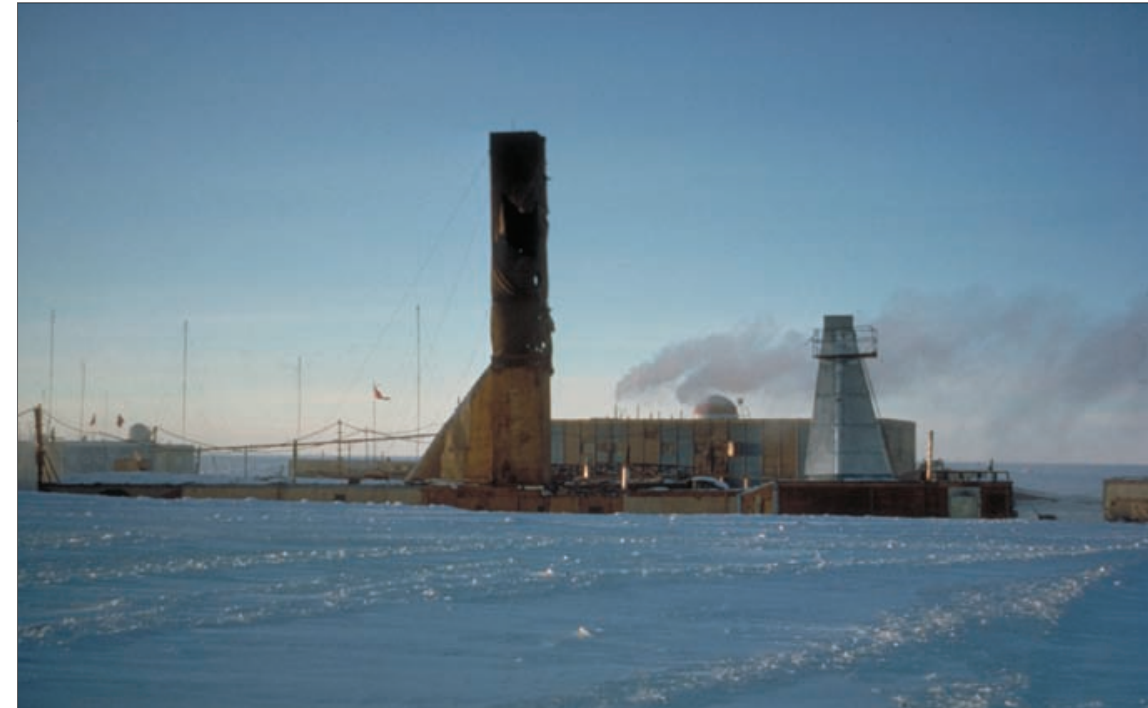

Fig. 1: Drill units at the Russian Vostok Station in East Antarctica.

raphy of glacial ice. Finally, below $3539 \mathrm{~m}$, the core consists of ice refrozen from lake water. Using an appropriate correction of the ice stratigraphy for flow disturbance in the 3320-3345 m interval, it has recently been possible to extend the Vostok ice record farther back to $440 \mathrm{kyr} B \mathrm{P}$, which implies full coverage of marine isotope stage (MIS) 11 (Raynaud et al., 2005).

\section{The 440 kyr climatic record from the Vostok ice core}

Figure 2 shows a series of selected Vostok records covering the last 440 kyr (adopted from Petit et al., 1999; Delmotte et al., 2004 and Raynaud et al., 2005). The records indicate that the climate on our planet during this time has always been in a state of change but with atmospheric and climate properties oscillating between stable bounds. Most of the climate variability during glacialinterglacial changes occurs with periodicities corresponding to that of the precession, obliquity and eccentricity of the Earth's orbit, with a larger concentration of variance in the 100-kyr band. The overall amplitude of the glacial-interglacial temperature change is $12^{\circ} \mathrm{C}$ at the ice-sheet surface, as judged from the Vostok isotope record.

The "sawtooth" pattern of the Vostok isotopic temperature record roughly mimics the sea level (reversed global ice volume) changes deduced from marine sediment studies. The much higher dust concentration during full glacial periods than during interglacials is interpreted as indicating more extensive deserts and continental areas (low sea

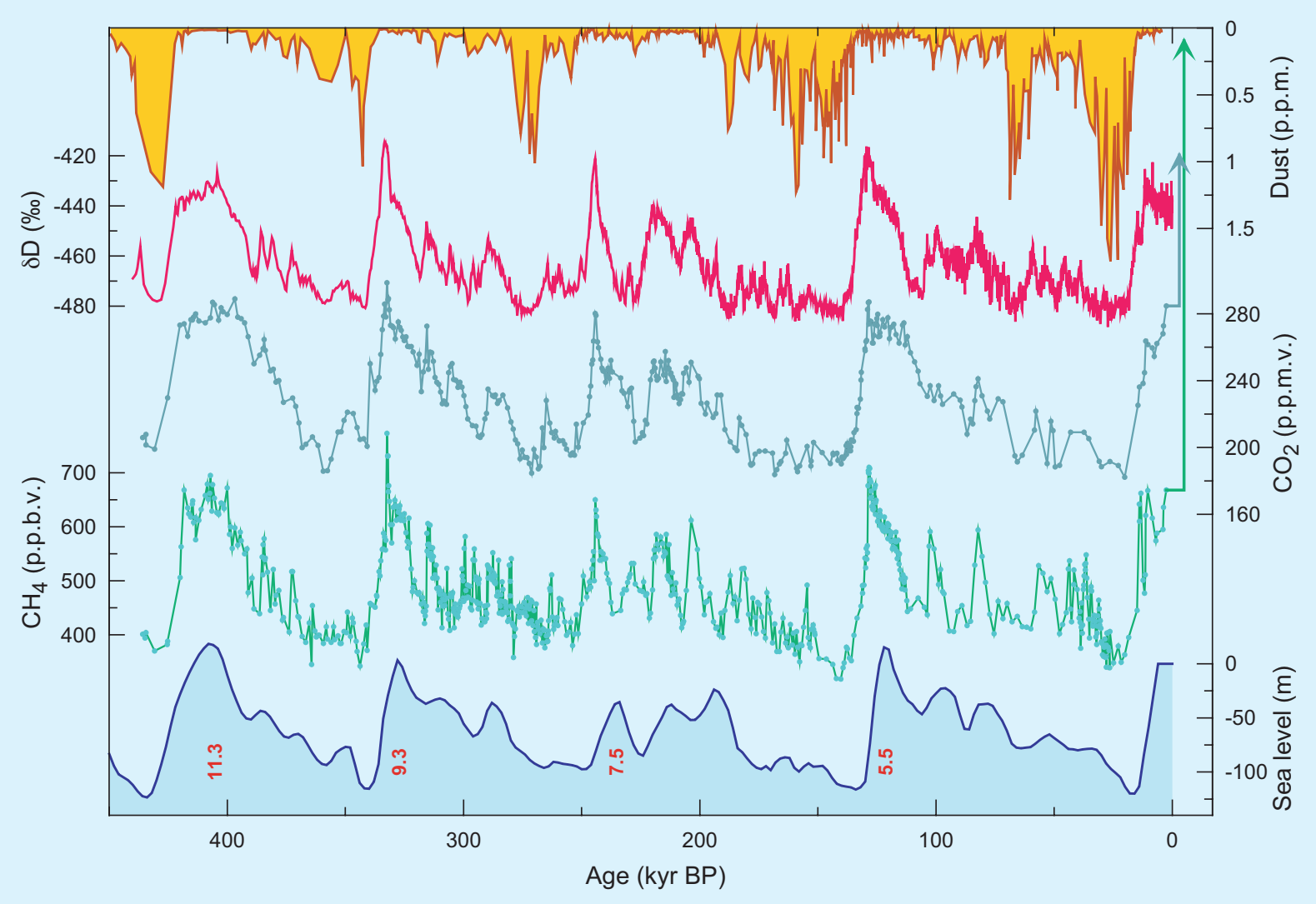

Fig. 2: Vostok time series and sea level derived by calibrating the marine $\delta^{18} \mathrm{O}$ record (Bassinot et al., 1994). The dust record provides information on aerosols of continental origin. The deuterium content of the ice $\delta D$ is taken as a proxy for Antarctic temperature; the warmest periods of the past correspond to MIS 5.5, 7.5, 9.3 and 11.3. The atmospheric concentrations of the two greenhouse gases $\left(\mathrm{CO}_{2}\right.$ and $\left.\mathrm{CH}_{4}\right)$ are measured on the air enclosed in the ice. The rapid anthropogenic rise in concentrations of $\mathrm{CO}_{2}$ and $\mathrm{CH}_{4}$ since the 1850's, up to present-day levels of 360 ppmv and 1750 ppbv, respectively, are indicated by arrows. The Vostok data (Petit et al., 1999; Delmotte et al., 2004; Raynaud et al., 2005) are plotted on the EDC2 timescale after Raynaud et al., 2005. 
level), more intense surface winds in the source regions, and/or more efficient meridional transport at the times of glacial maxima (Petit et al., 1999). The close linkage between climate and $\mathrm{CO}_{2}$ and $\mathrm{CH}_{4}$ concentrations documented in the Vostok core throughout the four climatic cycles supports the role of the greenhouse gases as amplifiers of initial orbital forcing.

The sequence of events during glacial terminations suggests that increases in Antarctic air temperature and atmospheric greenhouse gas concentrations lead sea level rise (Northern Hemisphere deglaciation) by a few thousands of years (Petit, et al., 1999, Sowers et al., 1991, Shackleton, 2000). It has also been shown that $\mathrm{CH}_{4}$ (Delmotte et al., 2004) and $\mathrm{CO}_{2}$ (Caillon et al., 2003; Fischer et al., 1999; Petit, et al., 1999; Pépin, et al., 2001) concentration increases lagged Antarctic warming by several hundreds of years. This natural scenario is, however, different from the present situation, where rise of greenhouse gases, as a result of anthropogenic activities, has been imposed first. The reconstructed record for MIS 11 indicates that concentrations of $\mathrm{CO}_{2}$ and $\mathrm{CH}_{4}$ throughout this 30-kyrlong interglacial period, which is considered an "orbital" analog for the Holocene, were close to the preindustrial levels and lower than during MIS 9.3 (Raynaud et al., 2005). Thus, the present-day increase in concentration of these greenhouse gases in the Earth's atmosphere seems to have been unprecedented during the past $440 \mathrm{kyr}$.

\section{Project facts}

Project: Vostok ice core project Contact: Vladimir Lipenkov, lipenkov@aari.nw.ru

Participants: Institutes and laboratories in Russia (AARI of Roshydromet; St. Petersburg Mining Institute; Institute of Microbiology, RAS; Kazan State University; Institute of Geography, RAS), in France (LGGE, CNRS, Université Joseph Fourier, Grenoble; Laboratoire des Sciences du Climat et de I'Environnement, CNRS-CEA, Saclay) and in the United States (laboratories funded by NSF).

Funding: The Vostok venture was made possible by the logistical support of Russian Antarctic Expedition (RAE), Institute Francais pour la Recherche et la Technologie Polaires (IFRTP) and the Office of Polar Programs (NSF). The development of drilling technology and the ice-core studies were funded by national contributions from Russia, France and the United States.

Where: East Antarctica $\left(78^{\circ} 28^{\prime} \mathrm{S}, 106^{\circ} 48^{\prime} \mathrm{E}\right.$, altitude $3488 \mathrm{~m}$ asl, ice thickness $3750 \mathrm{~m}$ )

When: 3 main deep holes (3G, 4G, 5G) were drilled from 1980 to 1998 . The ice core analyses are in progress.

What: 3 ice cores reaching depths of 2202 $m, 2546 \mathrm{~m}$ and $3623 \mathrm{~m}$. High-resolution records of atmospheric composition and climate covering the last $440 \mathrm{kyr}$.

Database: www.ncdc.noaa.gov/paleo/ icecore/antarctica/vostok/vostok.html

\section{Ongoing ice core studies}

Studies of the Vostok ice are now focused on the deepest section of the core, below $3310 \mathrm{~m}$. The extrapolation of the Vostok timescale to greater depths, made with the aid of an ice-sheet flow model, shows that the age of glacial ice just above its contact with accretion lake ice (at a depth of $3530 \mathrm{~m}$ ) may reach $\sim 2000$ kyr (Salamatin et al., 2004). We hope that the joint effort of scientists working in the fields of paleoclimate records and physical properties of ice will allow us to decipher information on some of the earlier climatic cycles archived in this section of the Vostok core. Meanwhile, comprehensive analysis of the now available accretion ice from depths below $3539 \mathrm{~m}$ is expected to provide a clue to understanding the extraordinary environment of subglacial Lake Vostok.

\section{References}

Caillon, N., Severinghaus, J., Jouzel, J., Barnola J.M., Kang, J. and Lipenkov, V.Ya., 2003: Timing of Atmospheric $\mathrm{CO}_{2}$ and Antarctic temperature changes across Termination III. Science, $\mathbf{2 9 9}$ 1728-1731

Masson-Delmotte, V., Chappellaz, J., Brook, E. Yiou, P., Barnola, J.M., Goujon, C., Raynaud, D. and Lipenkov, V.Ya., 2004: Atmospheric methane during the last four glacial-interglacial cycles:

Rapid changes and their link with Antarctic temperature. J. Geophys. Res., 109: D12104, doi: 10.1029/2003JD004417.

Fischer, H., Wahlen, M., Smith, J., Mastroianni, D. and Deck, B., 1999: Ice core records of atmospheric $\mathrm{CO}_{2}$ around the last three glacial terminations, Science, 283: 1712-1714.

Petit, J. R., Jouzel, J., Raynaud, D., Barkov, N.I., Barnola, J.-M., Basile, I., Bender, M., Chappellaz, J., Davis, M., Delaygue, G., Masson-Delmotte, V., Kotlyakov, V.M., Legrand, M., Lipenkov, V.Y., Lorius, C., Pepin, L., Ritz, C., Saltzman, E., and Stievenard M., 1999: Climate and atmospheric history of the past 420,000 years from the Vostok ice core, Antarctica, Nature, 399: 429-436.

Raynaud, D., Barnola, J.M., Souchez, R., Lorrain, R., Petit, J.R., Duval, P. and Lipenkov, V.Ya., 2005: The record for marine isotopic stage 11. Nature, $\mathbf{4 3 6}$ : 39-40.

Salamatin, A.N., Tsyganova, E.A., Lipenkov, V.Ya. and Petit, J.R., 2004: Vostok (Antarctica) ice-core time-scale from datings of different origins. Ann. Glaciol., 39: 283-292.

For full references please consult:

www.pages-igbp.org/products/newsletters/ref2006_1.html

\section{European Project for Ice Coring in Antarctica (EPICA)}

ERIC WolfF ${ }^{1}$ on behalf OF the EPICA COMMUNITY

'British Antarctic Survey, Cambridge, UK; ewwo@bas.ac.uk

\section{Introduction}

The last few hundred thousand years form the context in which we can learn how the Earth System (including its climate) works. Although the geological setting of the Earth was similar to today, very significant changes occurred in the climate, the circulation of the ocean, and the composition of the atmosphere. By learning about these changes, we can understand the processes that can occur, and that should be represented by models - the same models that will be used to predict future conditions.

Ice cores are particularly powerful because numerous climate responses and forcings (including greenhouse gas concentrations) are recorded in the same core. In early Antarctic cores covering complete glacial-interglacial cycles (notably Vostok and Dome Fuji), we were able to see the close connection between climate and greenhouse gas concentrations that prevailed through four glacial-interglacial cycles over the last $400 \mathrm{kyr}$ (Petit et al., 1999, Watanabe et al., 2003). 


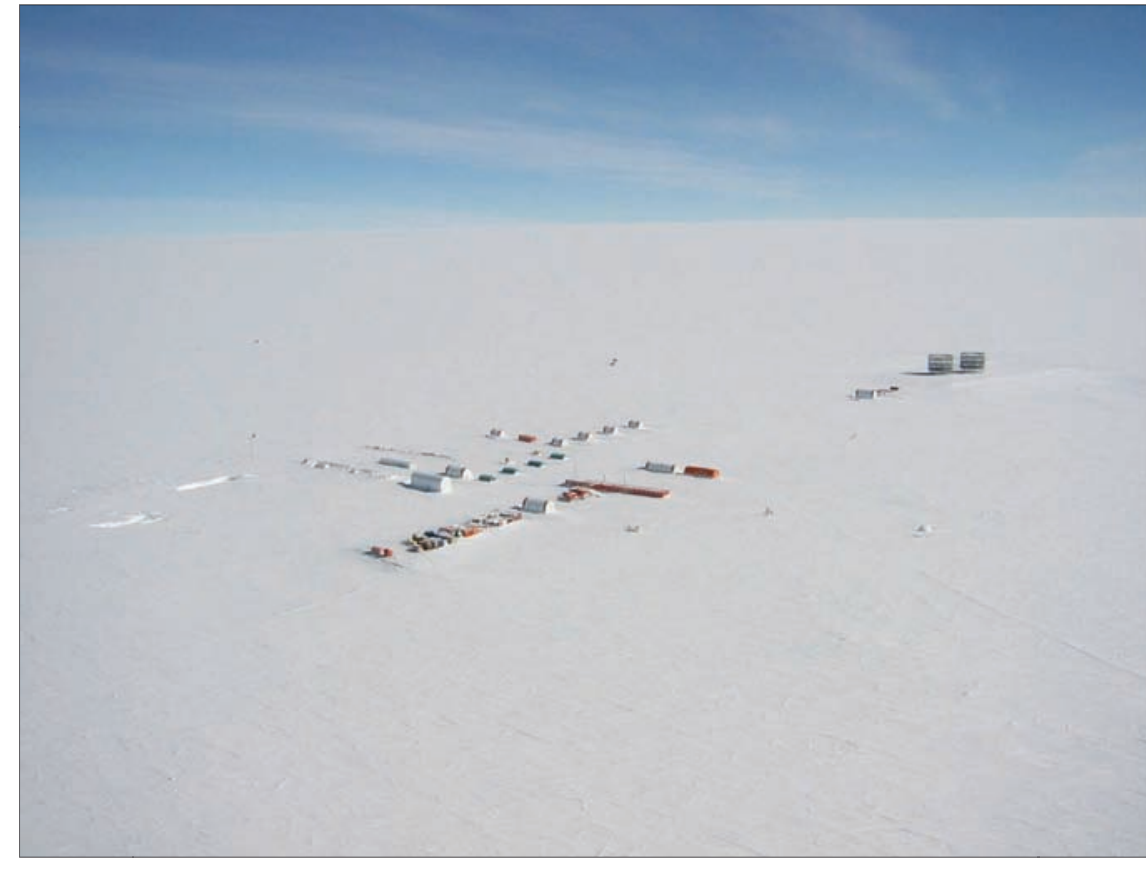

Fig. 1: Dome $C$ drilling location on the East Antarctic Ice Sheet $\left(75^{\circ} 06^{\prime} S, 123^{\circ} 21^{\prime} E\right.$, altitude $3233 \mathrm{~m}$ asl) as viewed from the air (Photo Borek Air, PNRA/EPICA).

Greenland ice cores (e.g. North Greenland Ice Core Project Members, 2004) most clearly revealed the importance of abrupt climate changes, probably resulting from changes in ocean heat transport, during the last climatic cycle.

The aim of EPICA was to drill two cores to bedrock in East Antarctica. At Dome C, the target was old ice; in Dronning Maud Land (DML), the aim was to obtain a South Atlantic counterpart to the high-resolution Greenland records, covering at least one climatic cycle. The drilling at Dome C (Fig. 1) is complete and the ice contains a record of 800 kyr of climate. At the time of writing, the drilling at DML was very close to the bed, and contained one climatic cycle at high resolution and probably several more at lower resolution.

\section{Eight glacial cycles in an ice core}

The records from Dome $\mathrm{C}$ show that the top $2770 \mathrm{~m}$ of ice correspond to the "Vostok" time period and nearly $500 \mathrm{~m}$ of older ice is below that. The initial timescale (EDC2) for Dome $\mathrm{C}$ was obtained using an ice flow model constrained by a small number of control ages. There are obvious similarities and differences between the resulting climate record and marine records.
The bottom of the data published so far (EPICA Community Members, 2004) is at about $740 \mathrm{kyr} \mathrm{BP}$, in the cold marine isotope stage (MIS) 18.4, although we are confident that we have a good climate record back as far as $800 \mathrm{kyr}$ BP (MIS 20.2).

The ice core record now extends through eight glacial cycles and is dominated by the 100 kyr cyclicity characteristic of the late Quaternary period. This is seen both in the temperature proxy (deuterium), and in physical and chemical measurements (such as dust and sea salt) that represent different aspects of the environment (Fig. 2). However, the "pre-Vostok" cycles are distinctly different from the later ones. Interglacials have a much lower amplitude before about $450 \mathrm{kyr}$ BP but appear to span a longer period in each cycle. This characteristic is also apparent in marine records but is more pronounced in the ice core record. There is no obvious external forcing responsible for such a change, however many of the internal feedbacks in the system reflect it. For example, both $\mathrm{CO}_{2}$ (Siegenthaler et al., 2005) and $\mathrm{CH}_{4}$ (Spahni et al., 2005) are at lower concentrations in the early interglacials. The close correspondence between $\mathrm{CO}_{2}$ and Antarctic temperature persists throughout the record.
One other early focus of the Dome C core was MIS11. This period is often seen as an analog for the present and near future (in the absence of anthropogenic influence) because the orbital forcing of climate is similar in the two periods (with low eccentricity and hence weak precessional forcing). Although we can discuss how to align the climate records from the two periods, it is true that MIS11 was a very long interglacial: $28 \mathrm{kyr}$, using a definition that makes the Holocene 12 kyr old so far. If this is a better analog than more recent short interglacials, then the "natural" Holocene would still have a long course to run.

\section{The Atlantic sector of the Southern Ocean}

The current snow accumulation rate is 2-3 times higher in DML than at Dome $\mathrm{C}$ and, consequently, the last climatic cycle is found at much better resolution there. Annual layers can still be observed even in the glacial ice, and the difference between the age of the ice (containing the climate record) and that of the air bubbles (containing the greenhouse gas record) is relatively small. This should allow us to link the Antarctic records with the sequence of rapid climate changes (Dansgaard-Oeschger (D-O) events) seen in Greenland cores, with only a small time uncertainty. It already appears that every D-O event found in Greenland has a counterpart in the Antarctic records, and learning about the relative phase and amplitude of the Greenland and Antarctic events will be critical in distinguishing between mechanisms and in testing models. The differences in response across the continent of Antarctica will also be of great interest, since although the deuterium (temperature) records have great similarities at Dome $\mathrm{C}$ and $D M L$, there are big differences in the magnitude of concentrations of chemical species at the two sites.

\section{Continuing analysis}

While the EPICA drilling operations are essentially complete, much remains to be done in 


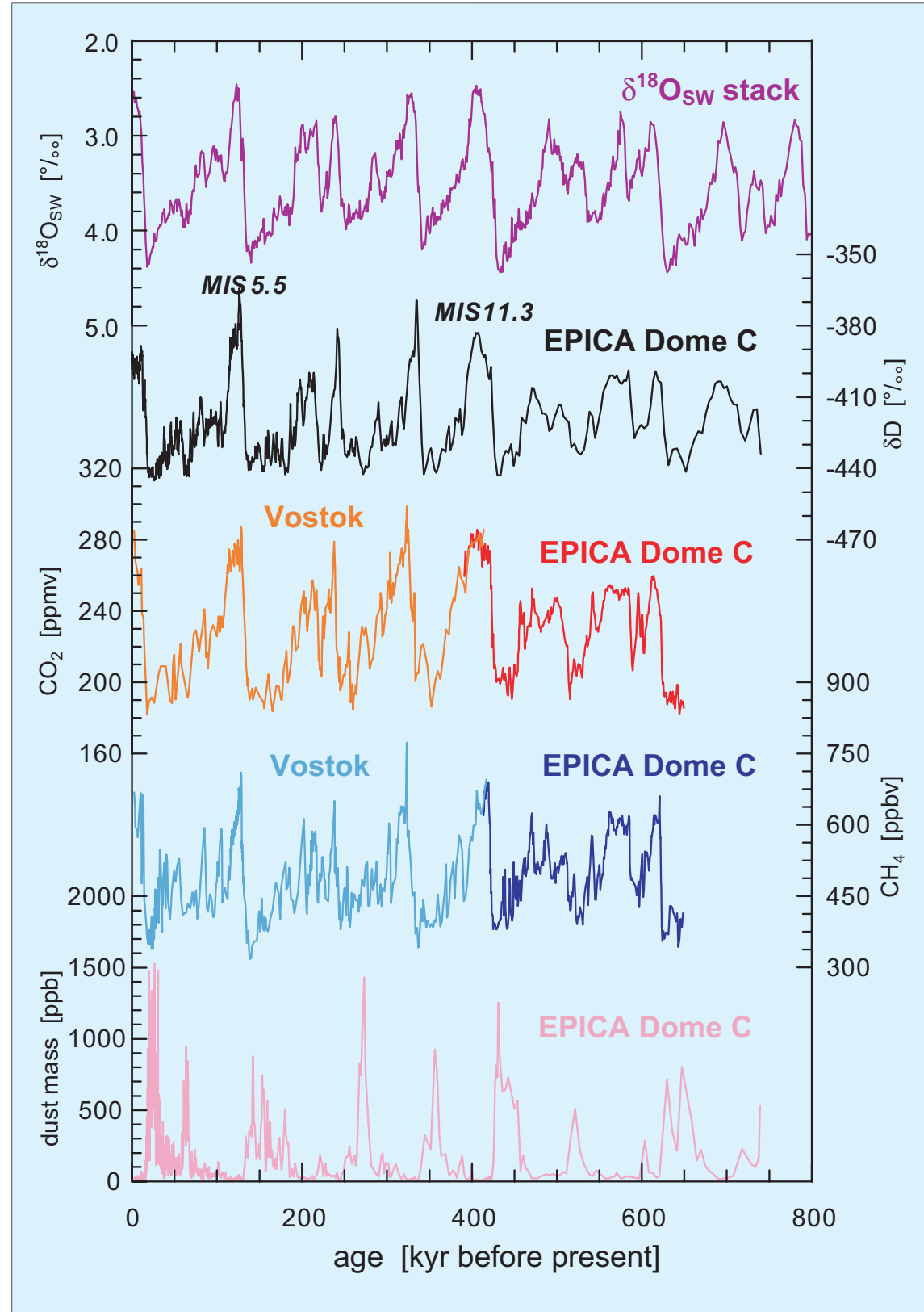

Fig. 2: Ice core parameters over $740 \mathrm{kyr}$, along with the recently compiled benthic marine oxygen isotope record (Lisiecki \& Raymo, 2005). The Dome C $\delta D$ and dust data are on the EDC2 timescale (EPICA Community Members, 2004) and the marine data on the LR04 timescale. $\mathrm{CO}_{2}$ and $\mathrm{CH}_{4}$ data are from Dome C (Siegenthaler et al., 2005; Spahni et al., 2005) and Vostok (Petit et al., 1999). MIS 5.5 and 11.3 are marked to provide reference points.

analysis and interpretation of the cores. EPICA has given us the first glimpse of an earlier period of Earth history, and the chance to compare behavior across the vast continent of Antarctica throughout a glacial cycle. Intensive work is now underway to provide the extended record from Dome C and the high-resolution record from DML. We will use additional parameters, such as particulate and dissolved aerosol species in the ice, to define the climate, and use the detail of the two records to understand variability. Further work will help us to elucidate the underlying mechanisms governing the highly variable behavior of the Earth System.

\section{REFERENCES}

EPICA Community Members, 2004: Eight glacial cycles from an Antarctic ice core. Nature, 429: 623-628.

Lisiecki, L. E. and Raymo, M. E., 2005: A PliocenePleistocene stack of 57 globally distributed benthic delta 0-18 records. Paleoceanography, 20: PA1003; doi:10.1029/2004PA001071.

North Greenland Ice Core Project Members, 2004: High-resolution record of Northern Hemisphere climate extending into the last interglacial period. Nature, 431: 147-151.

Petit, J. R., Jouzel, J., Raynaud, D., Barkov, N.I., Barnola, J.-M., Basile, I., Bender, M., Chappellaz, J., Davis,

\section{Project facts}

Project: European Project for Ice Coring in Antarctica (EPICA)

Contact: Eric Wolff, ewwo@bas.ac.uk

Participants: Numerous scientists from laboratories in 10 European nations, under the auspices of the European Science Foundation (ESF) and European Union (EU).

Funding: Funded by the EU (EPICA-MIS) and by national contributions from Belgium, Denmark, France, Germany, Italy, The Netherlands, Norway, Sweden, Switzerland, and the U.K. The science was made possible only by the efforts particularly of the French (IPEV) and Italian (PNRA) logistic agencies for Dome $C$, the Alfred Wegener Institute in Germany for DML, and the drilling teams led by Laurent Augustin (Dome C) and Frank Wilhelms (DML).

Where: East Antarctic Ice Sheet (Dome C: $75^{\circ} 06^{\prime} \mathrm{S}, 123^{\circ} 21^{\prime} \mathrm{E}$, altitude $3233 \mathrm{~m}$ asl, ice thickness $\sim 3270 \mathrm{~m}$; DML: $75^{\circ} 00^{\prime} \mathrm{S}$, $0^{\circ} 04^{\prime} \mathrm{E}$, altitude $2892 \mathrm{~m}$ asl, ice thickness $\sim 2780 \mathrm{~m}$ ).

When: Drilling: 1996-2006 (survey work predates this and analysis continues).

What: 2 deep ice cores to bedrock, multiparameter analysis

Web Page: www.esf.org/esf_article. php?activity $=1$ \&article $=85 \&$ domain $=3$

Databases: www.pangaea.de/Projects/EPICA/ www.ncdc.noaa.gov/paleo/icecore/antarctica/domec/domec_epica_data.html

M., Delaygue, G., Masson-Delmotte, V., Kotlyakov V.M., Legrand, M., Lipenkov, V.Y., Lorius, C., Pepin, L., Ritz, C., Saltzman, E., and Stievenard M., 1999: Climate and atmospheric history of the past 420,000 years from the Vostok ice core, Antarctica, Nature, 399: 429-436.

Siegenthaler, U., Stocker, T. F., Monnin, E., Luthi, D., Schwander, J., Stauffer, B., Raynaud, D., Barnola, J. M., Fischer, H., Masson-Delmotte, V. and Jouzel, J., 2005: Stable carbon cycle-climate relationship during the late Pleistocene. Science, $\mathbf{3 1 0}$ : 1313-1317

Spahni, R., Chappellaz, J., Stocker, T. F., Loulergue, L., Hausammann, G., Kawamura, K., Fluckiger, J., Schwander, J., Raynaud, D., Masson-Delmotte, V. and Jouzel, J., 2005: Atmospheric methane and nitrous oxide of the late Pleistocene from Antarctic ice cores. Science, 310: 1317-1321.

Watanabe, 0., Jouzel, J., Johnsen, S., Parrenin, F. Shoji, H. and Yoshida, N., 2003: Homogeneous climate variability across East Antarctica over the past three glacial cycles, Nature, 422: 509-512. 


\section{A 425-year precipitation history from documentary weather anomalies and climate records at Palermo, Italy}

Nazzareno Diodato

Monte Pino Research Observatory on Climate and Landscape, GTOS/TEMS, Benevento, Italy; nazdiod@tin.it

For southern Europe, especially mediterranean Italy, our knowledge of environmental and climatic variations has until now been discontinuous or founded on very few multisecular precipitation series (Cantù and Narducci, 1967; Brunetti et al., 2004). Fortunately, the Italian area offers a wide range of descriptive documentary data (i.e., reports from chronicles, daily weather reports, religious ceremonies, local books, etc.), that makes this area ideal for climate reconstructions on various time and spatial scales prior to the instrumental period (Enzi and Camuffo, 1996; Diodato, 1999; Luterbacher et al., 2005). The pre-instrumental epoch includes the so-called Little Ice Age (LIA), variously assessed as AD $1300-1900$, that is not expected to be homogeneous and sustained over large climatic regions (Bradley and Jones, 1993). So, climatic research at regional and sub-regional scales for the pre-instrumental epoch is useful for understanding the nature of climate variability on multi-decadal and longer timescales. In the last decades, several studies have reported climate reconstructions in some European localities based on documentary sources (for a synthesis see Brádzil et al., 2004). This research suggests that pre-instrumental documentary indices are promising tools for the reconstruction of rainfall and thermal regime fluctuation. In this way, precipitation history for southern Europe during the period 15802004 AD was analyzed at the Palermo Astronomical Observatory (Sicily, Italy; Fig. 1a).

\section{Data and methods}

The Sicily region is characterized by a typical Mediterranean regime, with very dry summers and moist cold seasons (Autumn-Winter) when most precipitation occurs. Climate in Palermo Province is represented by both steppe-lake and semi-arid zones (Fig. 1b). Historical written records of weather conditions that affect agricul-

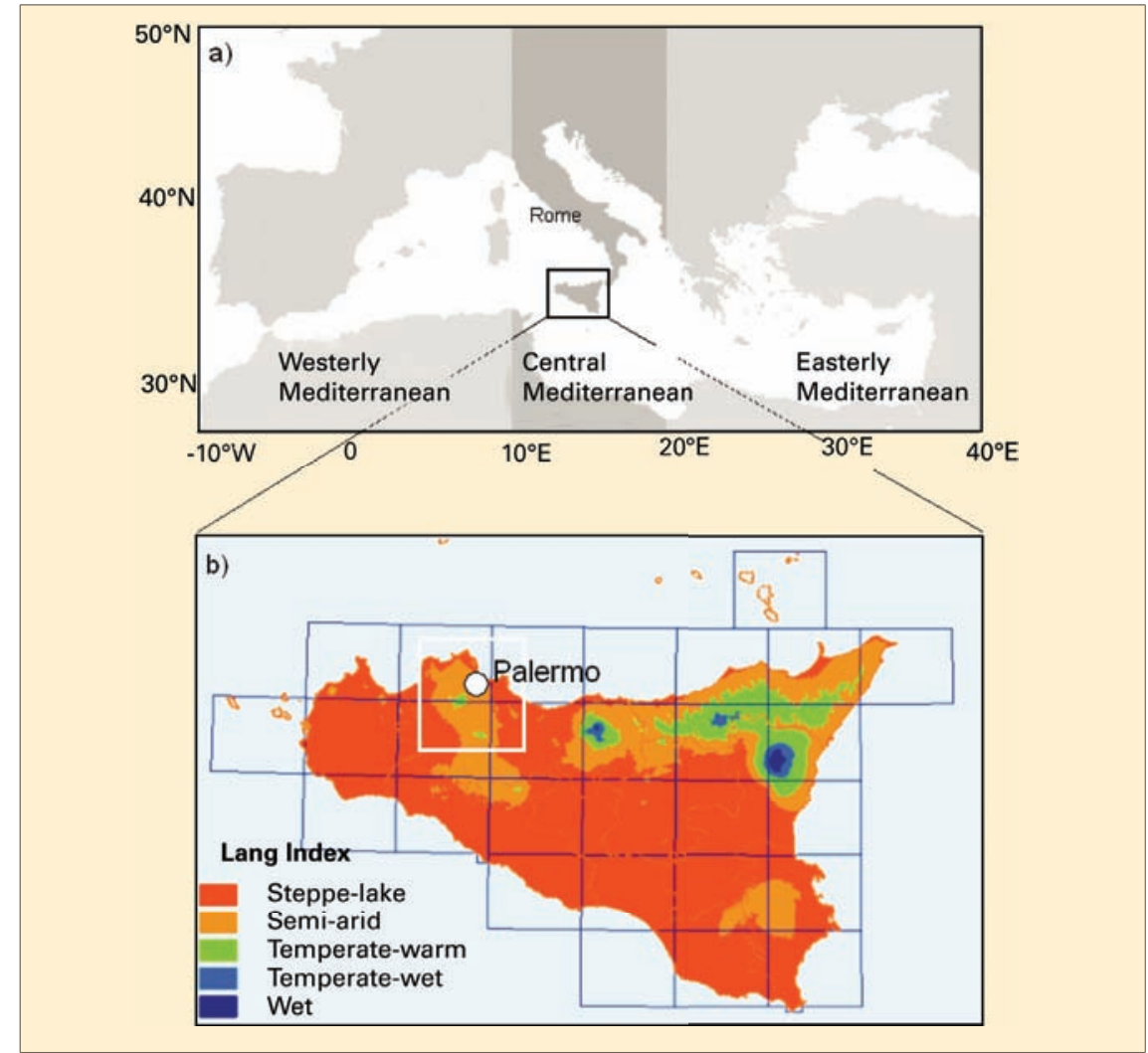

Fig. 1: Geographic location (a); map of the Lang Index (b) with Palermo Province (white square box) and Palermo Observatory (white circle).

ture and living conditions have been taken as a proxy for instrumental observations of the relative wetness and dryness. Data were compiled from various kinds of documents, including chronicles (Moio and Susanna, 1500-1769), annals (Corradi, 1865-94), archival records (Piervitali and Colacino, 2001) and two databanks of the SICI-CNR Project (available online at http://sici.irpi.cnr.it/giano.htm), referring mainly to Palermo Province (Fig. 1b). As a consequence, a numerical index was established to characterize the rainfall regime and its evolution. The compilation of the data is based on the method introduced by Pfister (1988). However, in this work, due to the regional climate peculiarities, the weather anomalies related to rainfall were coded following the modified classification of Rodrigo et al. (1998): meteorological drought from October to April (Precipitation Index, $\mathrm{PI}=$ $-1)$; meteorological droughts in May or September $(\mathrm{PI}=-0.5)$; since precipitation is almost zero during the summer, PI was halved for June, July and August $(P I=0)$; intensive and/or continuous rains $(\mathrm{PI}=+1)$; rains with floods $(P I=+2)$. When the authors did not comment on the meteorological conditions, the situation was considered as 'normal' and was assigned the index $\mathrm{PI}=0$. Rodrigo's indices were modified to weighted seasonal indices by minimizing the sum squared errors (SSE) between the Annual Rainfall Anomalies (ARA) and Precipitation Index Sum (PIS) in the calibration period - overlapping indexed and measured precipitation records (1839-1868) - as:

$$
\mathrm{SSE}=\sum_{\mathrm{j}=1}^{\mathrm{N}}\left(\mathrm{ARA}_{\mathrm{j}}-\mathrm{PIS}_{\mathrm{j}}\right)^{2}
$$

where PIS is the sum of the monthly index for each year, j. Using the PIS index as the independent variable and measured annual rainfall anomalies as the dependent variable, a determination coefficient value, $r^{2}$ $=0.64$ (statistically significant at the 


\section{Science Highlights}

$95 \%$ confidence level by a t-test), derived from the following linear equation: $\mathrm{EPA}=(19.41+50.76 \cdot \mathrm{PIS})$; where EPA is the Estimated Precipitation Anomalies ( $\mathrm{mm}$ ), corresponding to the estimated value of total annual rainfall anomalies. Finally, annual reconstructed precipitation (RP) were computed following Fritts et al. (1979) by multiplying each value by the empirical standard deviation of instrumental data (SDMPA), and dividing it by the empirical standard deviation of estimations (SDEPA), as: RP = (EPA - (SDMPA / SDEPA) + PM); where the standard deviation ratio is equal to 1.35 and $\mathrm{PM}$ is the precipitation mean $(\mathrm{mm})$ estimates over the calibration period. The non-parametricThom test (Thom, 1966) was also performed, resulting in a homogeneous series.

\section{Results}

The final result of the precipitation reconstruction is shown in Figure 2a, allowing a preliminary view of temporal evolution of annual RP from 1807 onwards, where instrumental data (Micela et al., 2001) began. That is, after several years of high climatic variability (from 1660 to 1930) during the first three centuries of the series, a period of lower climatic variability followed (from 1940 to 2000). In particular, the 18th century was punctuated with alternating extreme drought and wet periods (including frequent floods), which exceeded the 10th and 90th percentiles, respectively. In order to identify possible climatic change, Standardized $\mathrm{Cu}$ mulative Anomalies (SCA) was also computed after Mächel et al. (1998) and Jacobeit et al. (2001). Thus, sustainably declining/rising values in cumulative anomalies indicate the prevalence of negative/positive annual anomalies, and major turning points in cumulative anomalies indicate transitions between periods predominated by contrasting annual anomalies. However, this method does not identify the character of the change or the stability of the series before and after the change point, so the results should be considered cautiously. Figure 2b illustrates the SCA series. It reveals notable and marked differences between the periods before and after the 20th century, with

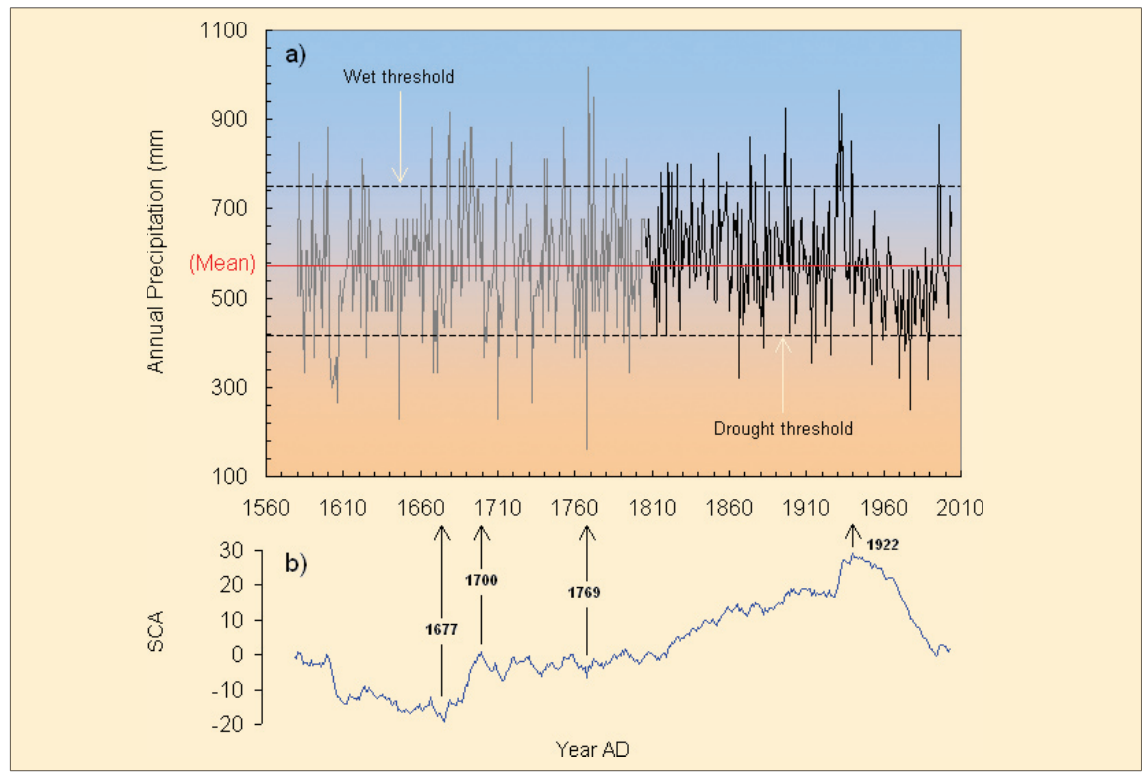

Fig. 2: Historical precipitation series (1580-2004) at Palermo Astronomical Observatory (a) grey line: precipitation reconstructed; black line: instrumental data from 1806 onwards; horizontal red line: mean value; dashed lines: threshold corresponding to 10th and 90th percentiles. Standardized Cumulative Anomalies (SCA) (b) with changes in 1677, 1700, 1769 and 1922 in the precipitation series.

some particular contrasts in each of sub-time series. Thus, SCA indicates a change in the slope of the curve in the years 1677, 1700, 1769 and 1922 AD. The length of these periods reveals no regular pattern. Notable was the wet period between 1677-1700 that appears to be within the Maunder Minimum (1675-1715 AD), indicating that solar activity is likely an important forcing of climatic change in the study region, in according with findings from Greece (Xoplaki et al., 2001) and Spain (Barriendos, 1997). The longer and last wet phase is recorded between 1769 and 1922 AD.

\section{Conclusions}

Longer timescale series are important to understanding climatic variations on multi-decadal and centennial timescales. In this paper, documentary sources were an important proxy in a first and preliminary investigation of precipitation fluctuation for an Italian island of the Central Mediterranean (Sicily). Over the last 5 centuries, different climatic epochs have alternated with the respective transitions periods: the Little Ice Age and the Present-Day Warming with transition sub-periods. The last period of the 20th century rainfall series shows a behavior dissimilar to those of other periods in the past, with a reduction of the climate variability and a strong decrease of precipitation amount. This is in contrast to very recent years that again show rainfall peaks that could increase the environmental risk connected with the sensitive landscape.

More information about Global Terrestrial Observing System/Terrestrial Ecosystem Monitoring Sites (GTOS/TEMS) can be found at: www. fao.org/gtos/tems/index.jsp

\section{ACKNOWLEDGEMENTS}

Thanks to Dr. Vincenzo luliano (Palermo - Astronomical Observatory, University of Study) who facilitated the data collection on the precipitation series.

\section{REFERENCES}

Bradley, R.S. and Jones, P.D., 1993: Little Ice Age summer temperature variations: their nature and relevance to recent global warming trend. The Holocene, 3: 367-376.

Brádzil, R., Pfister, C., Wanner, H., Von Storch, H. and Luterbacher, J., 2004: Historical climatology in Europe - the state of the art. Climatic Change, $\mathbf{7 0}$ : 363-430.

Brunetti, M., Maugeri, M., Monti, F. and Teresa, N., 2004: Changes in daily precipitation frequency and distribution in Italy over the last 120 years. Journal of Geophysical Research, 109: D05102, doi:10.1029/ 2003JD004296.

Jacobeit, J., Jönsson, P., Bärring, L., Beck, C. and Ekström, M., 2001: Zonal indices for Europe 17801995 and running correlations with temperature. Climatic Change, 48: 219-241.

Rodrigo, F.S., Esteban-Parra, M.J. and Castro-Diez, Y., 1998: On the use of the Jesuit private correspondence records in climate reconstructions: a case study from Castille (Spain) for 1634-1648 A.D. Climatic Change, 40: 625-645.

For full references please consult:

www.pages-igbp.org/products/newsletters/ref2006_1.html 


\title{
Paleo sea-level changes in the Black Caspian Seas: Links to river runoff and global climate change
}

\author{
Alexander Kislov and Pavel Toropov \\ Dept. of Meteorology and Climatology, Faculty of Geography, Moscow State University, Russia; avkislov@mail.ru, tormet@inbox.ru
}

\section{Introduction}

To assess the link between climate variability and hydrological regime, we focused our study on the mid-Holocene (6 ka years BP) and the last cold period of the Late Quaternary (21 ka BP). We discuss how well current general circulation models (GCMs) can reproduce river runoff changes and, consequently, variations in closed lake level under contrasting climate conditions. The Paleoclimate Modeling Intercomparison Project (PMIP) (Joussaume and Taylor, 1995) has run simulations that are used in this study. The rivers of the East European Plane (EEP) were selected for analysis. Feed of rivers is determined by the balance of precipitation and evaporation in the catchment, hence river runoff change responds immediately to climate changes. It is important that both precipitation and evaporation are calculated by a GCM. Moreover, on large planes, such as the EEP, GCM data much better reflect the state of climate compared to areas with complex mosaic surface conditions. Additionally, large amounts of paleoclimate data exist on the EEP for selected periods of the past.

\section{Modern GCM runs}

Prior to investigating river runoff changes in the past, it is necessary to be convinced that GCMs are capable of simulating the modern climate state. It was shown that only large river catchments (covered by about 15 GCM cells with typical GCM horizontal resolution $2.5 \times 2.5^{\circ}$ ) can be correctly analyzed and analyzing the smaller river basins is not meaningful. The runoff value is estimated in the framework of a GCM as the annual value P-E (precipitation minus evaporation). If the error of modeled runoff is $\pm 20 \%$, the result was considered to be "successful" because in this case deviation does not exceed observed natural variability. The data of these "successful" models were examined more closely by running

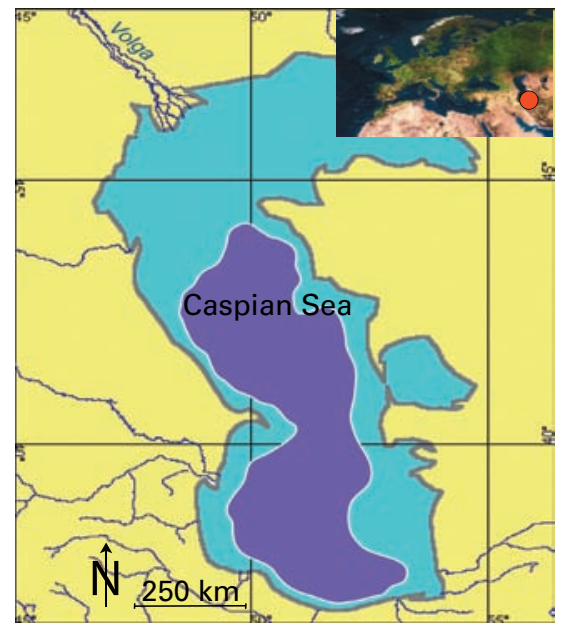

Fig. 1: Area of the Caspian Sea during the midHolocene/modern (blue color) and regression stage of the LGM evaluated based on the PMIP1 data (purple color).

simulations of other climate regimes. Validation can be done on the basis of comparison of modeled P-E with data of standard hydrological observation in river estuaries. The majority of models simulate runoff to the Baltic Sea well (Table 1), but only a few models are capable of reproducing runoff to the Black Sea and the Caspian Sea with good accuracy.

\section{The mid-Holocene}

The mid-Holocene study within PMIP 1 focussed on the 6 ka BP climate. As a first approximation, SSTs were prescribed to be the same as today, the $\mathrm{CO}_{2}$ concentration was similar to its pre-industrial value of $280 \mathrm{ppm}$, and vegetation and land-surface characteristics were held constant. Climate change is only influenced by the change of insolation forcing.

Calculations indicate that at $6 \mathrm{ka}$ $\mathrm{BP}$ there is no significant change of the EEP river runoff (see Table 2). The Volga River contribution to the total volume of water running to the Caspian Sea slightly increases (93\%) compared to today's climate $(88 \%$ according to PMIP 1 model simulations and $84 \%$ based on observation). In spite of the slight reaction of river runoff to external orbital forcing, it is unexpected that the Caspian Sea level was not stable during the Holocene. The amplitude of sea-level perturbations was several meters (Varushenko et al, 1987).

\section{The LGM}

The time slice at $21 \mathrm{ka} \mathrm{BP}$, as an example of the last glacial maximum (LGM), involves large changes in the surface boundary conditions: ice sheet extent and height, changes in SSTs, albedo, sea level and concentration of greenhouse gases and aerosols, but only minor changes in solar radiation at the top of the atmosphere. Here we look at the results of calculation of annual river runoff volumes for the Caspian and Black Seas. The regions of the modern Baltic Sea and Arctic seas were strongly perturbed during the LGM, and are therefore not included in this study.

At $21 \mathrm{ka} \mathrm{BP}$, the total river runoff to the Caspian Sea (calculated by "successful" models) was substantially decreased ( $50 \%)$ compared to today's climate (see Table 3). The relative contribution of Volga River runoff is $72 \%$. These facts are in accordance with the observational data (Varushenko et al, 1987).

\section{Implications for sea level}

Information about river runoff change also provides a useful guide for conclusions about the status of the Caspian Black Seas. According to the definition of the water budget for closed lakes, the steady-state equation of the annual water budget is:

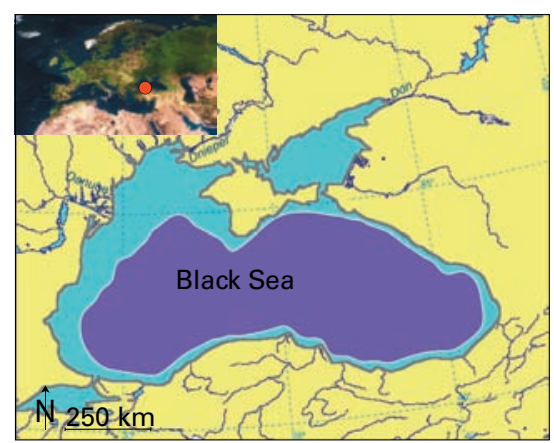

Fig. 2: Area of the Black Sea during the midHolocene/modern (blue color) and regression stage of the LGM evaluated based on the PMIP1 data (purple color). 
Table 1: Today's annual volume of the EEP river runoff $\left(\mathrm{km}^{3}\right)$ into different ocean basins, simulated by the PMIP1 GCMs.

\begin{tabular}{|c|c|c|c|c|c|c|c|c|}
\hline \multirow{3}{*}{ GCM } & \multicolumn{8}{|c|}{ B A S I N S } \\
\hline & \multicolumn{2}{|c|}{ Black Sea } & \multicolumn{2}{|c|}{ Caspian Sea } & \multicolumn{2}{|c|}{ European Arctic seas } & \multicolumn{2}{|c|}{ B altic Sea } \\
\hline & runoff, $\mathrm{km}^{3}$ & error' & runoff, $\mathrm{km}^{3}$ & error & runoff, $\mathrm{km}^{3}$ & error & runoff, $\mathrm{km}^{3}$ & error \\
\hline BM RC & 6,0 & -98 & 68,0 & -75 & 174,2 & -62 & 377,0 & -20 \\
\hline CCC2 & 182,7 & -41 & 242,6 & -11 & 440,6 & -3 & 518,9 & 10 \\
\hline сCM3 & 358,2 & 9 & 308,7 & 13 & 422,5 & -7 & 535,6 & 14 \\
\hline CCSR & 341,7 & 15 & 195,5 & -29 & 307,2 & -32 & 491,1 & 4 \\
\hline CNRM1 & 262,1 & -16 & 191,8 & -30 & 407,4 & -10 & 568,6 & 21 \\
\hline CSIRO & 251,2 & -20 & 209,5 & -24 & 272,8 & -40 & 372,7 & -21 \\
\hline ECHAM3 & 161,1 & -48 & 173,6 & -37 & 462,7 & 2 & 488,7 & 4 \\
\hline GEN2 & 225,2 & -27 & 94,5 & -66 & 222,4 & -51 & 402,9 & -14 \\
\hline GFDL & 238,8 & -23 & 44,3 & -84 & 250,6 & -45 & 416,4 & -12 \\
\hline GISS & 41,3 & -87 & 94,5 & -66 & 277,2 & -39 & 308,1 & -35 \\
\hline LMD5 & 653,3 & 109 & 187,9 & -31 & 201,6 & -55 & 330,2 & -30 \\
\hline MRI2 & 233,1 & -25 & 132,8 & -52 & 308 & -32 & 425,4 & -10 \\
\hline UGAMP & 335,1 & 7 & 229,3 & -16 & 407,5 & -10 & 450,1 & -4 \\
\hline UKMO & 303,8 & -3 & 138,1 & -50 & 339,6 & -25 & 496,3 & 5 \\
\hline UIUC & 515,9 & 65 & 141,6 & -48 & 251,8 & -44 & 434,0 & -8 \\
\hline YONU & 566,5 & 82 & 211,8 & -23 & 262,3 & -42 & 414,8 & -12 \\
\hline ENS $^{2}$ & 292,3 & -6 & 166,5 & -39 & 313 & -31 & 439,4 & -7 \\
\hline SUCS $^{3}$ & 308,7 & -1 & 260,2 & -5 & 428,1 & -5 & 454,3 & -3 \\
\hline $0 \mathrm{bs}^{4}$ & 312 & - & 274 & - & 453 & - & 470,6 & - \\
\hline
\end{tabular}

${ }^{1}$ Relative error (\%); ${ }^{2}$ ENS: Ensemble mean of GCMs data; ${ }^{3}$ SUCS: Ensemble mean of successful GCM data (selected in Table 1); ${ }^{4}$ Obs: Mean of observational data

$$
\text { ef }=Y F
$$

where $F, f, e$, and $Y$ stand for the catchment area, lake area, difference (E-P) over the lake area, and the river runoff from the catchment into the lake, respectively. Variation of the lake area relative to the present status (denoted by index ' 0 ') may be expressed by:

$$
\frac{\Delta f}{f_{0}}=\frac{\Delta Y}{Y_{0}}+\frac{\Delta F}{F_{0}}-\frac{\Delta e}{e_{0}}
$$

It allows us to evaluate the contribution of different factors to change of the level (h) as:

$$
\Delta h=(\Delta h)_{Y}+(\Delta h)_{F}+(\Delta h)_{e}(3)
$$

It is supposed (based on geomorphological evidences) that the configuration of the catchment area of the rivers was principally unchanged at

$21 \mathrm{ka} B \mathrm{P}$, therefore the second term in the Eq. (3) is equal to zero. Value over the Caspian Sea was estimated (based on regional climate modeling (Kislov and Surkova, 1997)) to be small relative to the first term in Eq. (2). Calculations indicate that a decrease of the river runoff causes a substantial drop in the Caspian Sea level $(\sim 50 \mathrm{~m})$ (see Fig. 1). The calculated river runoff for the Black Sea is also substantially decreased ( 50\%) (see Table 3). This fact, coupled with the assumption that due to decreasing sea level the Black Sea was a closed lake at $21 \mathrm{ka} \mathrm{BP}$, allows us to estimate that the drop in level was approx. $200 \mathrm{~m}$ (Fig. 2).

\section{Conclusions}

GCMs are able to correctly repro-

\begin{tabular}{|c|c|c|c|c|c|c|c|c|}
\hline \multirow{2}{*}{ bCMs } & \multicolumn{2}{|c|}{ Black Sea } & \multicolumn{2}{|c|}{ Caspian Sea } & \multicolumn{2}{|c|}{ European Arctic seas } & \multicolumn{2}{|c|}{ Baltic Sea } \\
\hline & runoff, $\mathrm{km}^{3}$ & deviation ${ }^{1}$ & runoff, $\mathrm{km}^{3}$ & deviation & runoff, $\mathrm{km}^{3}$ & deviation & runoff, $\mathrm{km}^{3}$ & deviation \\
\hline BMRC & 337 & $>1000$ & 385,2 & 466 & 564,5 & 224 & 695,1 & $>1000$ \\
\hline CCC2 & 181,7 & -1 & 260,9 & 8 & 425,7 & -3 & 494,1 & -5 \\
\hline CCM3 & 375,2 & 5 & 356,1 & 15 & 419,1 & -1 & 517,5 & -3 \\
\hline CCSR & 304,2 & -11 & 166 & -15 & 311,7 & 1 & 442,2 & -10 \\
\hline CNRM1 & 185,8 & -29 & 153,9 & -20 & 404,9 & -1 & 580,4 & 2 \\
\hline CSIRO & 30,5 & -88 & 60,8 & -71 & 217,5 & -20 & 303,3 & -19 \\
\hline ECHAM 3 & 101,3 & -37 & 138,3 & -20 & 445,8 & -4 & 501,0 & 3 \\
\hline GEN2 & 250,2 & 11 & 88,4 & -6 & 193,9 & -13 & 365,6 & -9 \\
\hline GFDL & 236,2 & -1 & 46,6 & 5 & 249,8 & 0 & 446,7 & 7 \\
\hline GISS & 14,5 & -65 & 115,5 & 22 & 315,3 & 14 & 279,9 & -9 \\
\hline LMD5 & 1088,4 & 67 & 414,8 & 121 & 315,3 & 56 & 652,4 & 98 \\
\hline MRI2 & 239,2 & 3 & 112,7 & -15 & 238,5 & -23 & 408,7 & -4 \\
\hline UG AMP & 327,5 & -2 & 221,8 & -3 & 322,8 & -21 & 371,5 & -17 \\
\hline UKMO & 335,7 & 11 & 146,5 & 6 & 293,7 & -14 & 405,8 & -18 \\
\hline UIUC & 521,2 & 1 & 156,4 & 10 & 232,8 & -8 & 390,1 & -10 \\
\hline YONU & 575,7 & 2 & 209,1 & -1 & 258 & -2 & 412,4 & -1 \\
\hline ENS & 319 & 9 & 189,6 & 14 & 326 & 4 & 454,2 & 3 \\
\hline sucs & 305,7 & -5 & 262 & 5 & 403,7 & -6 & 432,3 & -7 \\
\hline
\end{tabular}
duce elements of the hydrological

Table 2: Annual volume at $6 \mathrm{ka} \mathrm{BP}$ of the EEP river runoff $\left(\mathrm{km}^{3}\right)$ into the different basins cycle (precipitation, evaporation and runoff) for large rivers under different climatic situations. The differences in hydrological mode of the rivers of the EEP between 6000 years BP and today are small. This fact corresponds to results of paleohydrological reconstructions and is particularly interesting from the point of view that the warm mid-Holocene is often considered to be an analog of expected future climate warming conditions.

The results of modeling have shown that during the LGM, the runoff of the EEP rivers was considerably decreased ( $50 \%)$ and provided strong regression of the Caspian and Black Seas. Comparing our modeling results with geological evidence, we suppose that simulated conditions reflect the so-called Atelskay regression stage of the Caspian Sea and the so-called Postkarangatskay regression stage of the Black Sea (Varushenko et al, 1987; Svitoch, 2003). This

Table 3: Annual volume at $21 \mathrm{ka}$ BP of the EEP river runoff $\left(\mathrm{km}^{3}\right)$ into different ocean basins, simulated by the ensemble and the "successful" PMIP1 models

\begin{tabular}{|c|c|c|c|c|}
\hline \multirow{2}{*}{ basins } & \multicolumn{2}{|c|}{ Black Sea } & \multicolumn{2}{c|}{ Caspian Sea } \\
\cline { 2 - 5 } GCMs & runoff, $\mathrm{km}^{3}$ & deviation & runoff, $\mathrm{km}^{3}$ & deviation \\
\hline ENS & $\mathbf{2 3 2}$ & $\mathbf{- 2 2}$ & $\mathbf{1 1 5}$ & $\mathbf{- 3 9}$ \\
\hline SUCS & $\mathbf{1 7 1}$ & $\mathbf{- 4 5}$ & $\mathbf{8 3}$ & $\mathbf{- 5 6}$ \\
\hline
\end{tabular}

For definitions, see Table 1; 'Relative deviation from today's value (\%)

lends credit to the idea of the connection between Late Quaternary glacial/ cooling/drying planetary events and deep regression states of the Caspian Sea and the Black Sea.

\section{ACKNOWLedgments}

This research was funded by the Russian Fund for Basic Research. More information about PMIP is available at www-pcmdi.Inl. gov/pmip and www-lsce.cea.fr/pmip2.

\section{REFERENCES}

Joussaume, S. and Taylor, K., 1995: Status of the paleoclimate modeling intercomparison project (PMIP). Proc. First International AMIP Sci. Conf: 425430. WCRP 92, WMO/TD 732, Geneva.

Kislov, A.V., and Surkova, G.V., 1997: Simulation of the Caspian Sea level changes during the last 20000 years. In: Benito G., Beker V.R and Gregory K.J. (editors) - Palaeohydrology and environmental change: 235-244. John Wiley \& Sons, Chichester.

Svitoch, A.A., 2003: Marine Pleistocene of Russian seashore. GEOS, Moscow, 362p. (In Russian).

Varushenko, S.I., Varushenko, A.N., Klige, R.C., 1987: Level changes of the Caspian Sea and closed lakes in the past. Nauka, Moscow, 255p. (In Russian). 


\section{Quaternary climate change in south-eastern Arabia}

Frank Preusser ${ }^{1}$ and Dirk Radies ${ }^{2}$

${ }^{1}$ Institute of Geological Sciences, University of Bern, Switzerland; preusser@geo.unibe.ch

${ }^{2}$ Geological Institute, RWTH Aachen University, Germany; email; dradies@web.de

The present day climate over the south-eastern Arabian Peninsula is characterized by pronounced arid conditions. The aridity is due to the presence of the Intertropical Convergence Zone (ITCZ) over the southernmost part of the peninsula during summer, which prevents the movement of humid air masses north (Fig. 1a). Precipitation, resulting from moisture transported by southwesterly winds across the Indian Ocean and towards the Tibetan Plateau (Summer Monsoon), is only recognized as coastal fog and seasonal rainfall in the southern part of Oman (Dohfar), without affecting other parts of the region. During the winter, when the ITCZ is positioned south of the equator, a persistent high-pressure cell, accompanied by weak wind and very low precipitation, establishes itself over central Oman (Fig. 1b).

\section{Increased precipitation in the past}

Past humid periods are evidenced by the presence of ancient lake deposits in the south-western Rub' al Khali of Saudi Arabia and Yemen (McClure, 1976; Lezine et al., 1998) and, more recently, in the Wahiba Sand Sea of eastern Oman (Radies et al., 2005). These deposits, based on radiocarbon and luminescence dating, are attributed to a period of humid conditions during the early to middle Holocene (ca. 10,000 to 5000 yr ago). Faunal assemblages from the Wahiba Sand Sea reveal that these lakes were permanent with a developed shore margin environment. The availability of water was sufficient to sustain a vegetation cover in the wider surroundings of the lakes, attracting large herbivores, as indicated by the presence of dung beetle balls and cocoons. Neolithic arrowheads, found in association with the former lake deposits, indicate the presence of human hunter communities in the region. If all other climatic variables are kept constant, an increase in an-

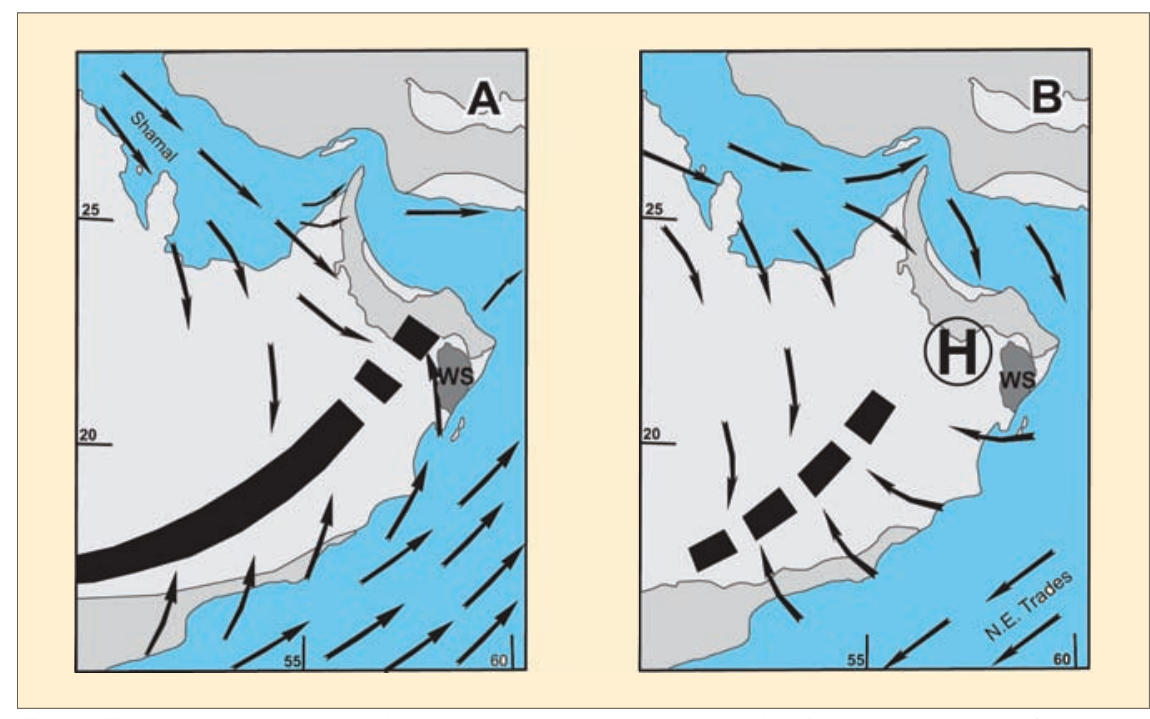

Fig. 1: The present low-level circulation pattern over the Arabian Peninsula during (a) summer and (b) winter, with the approx. summer position of the ITCZ. WS marks the position of the Wahiba Sand Sea. The dashed line in (b) represents the temporally occurring local convergence and $\mathrm{H}$ marks the approx. position of the winter high-pressure cell (modified after Preusser et al., 2002).

nual precipitation from the present value of less than $100 \mathrm{~mm}$ to about $250 \mathrm{~mm}$ would be necessary to sustain such environmental conditions (Radies et al., 2005).

Evidence for the Early Holocene wet period is also recorded in the growth of speleothems. $\delta^{18} \mathrm{O}$ records of the speleothems indicate a rise in precipitation starting at about 10,000 yr ago (Burns et al., 1998, 2001; Fleitmann et al., 2003 a, b). The increase in precipitation is interpreted to result from a northward shift of the ITCZ that forced moisture from the Indian Ocean over the Arabian Peninsula. Speleothems from southern Arabia give evidence for further humid periods in the past, dated by Th/U to 320,000 $300,000,200,000-180,000,135,000$ 120,000 , and $82,000-78,000 \mathrm{yr}$ ago (Burns et al., 2001) (Fig. 2). All these periods represent times of higher summer insolation on the northern hemisphere and correspond with interglacial conditions in the middle to high latitudes (apart from the period 82,000-78,000 yr ago which corresponds to pronounced interstadial conditions). This indicates that the Arabian Peninsula experienced periods of higher mean annual precipitation in the past due to a strengthening of monsoon circulation associated with a northward shift of the ITCZ.

Changes in moisture availability also had an impact on the sedimentary architecture of the Wahiba Sand Sea. Between 170,000-140,000 and $120,000-100,000$ yr ago, periodic changes in moisture availability led to the establishment of a dominantly groundwater-controlled eolian architecture characterized by numerous paleosol horizons intercalated with dune deposits. This implies that these periods were probably characterized by a high variability of mean annual precipitation on a millennial scale. On the other hand, younger eolian deposits formed between 35,000-8,000 yr ago show no evidence of paleosol development, which implies that this period reflects more pronounced arid conditions on a scale of some ten thousand years (Radies et al., 2004; Preusser et al., 2005).

\section{Atmospheric circulation during glacial periods}

During times of insolation minima in the northern hemisphere, monsoon precipitation was weaker than today with the resultant more intense arid conditions. These periods 


\section{Science Highlights}

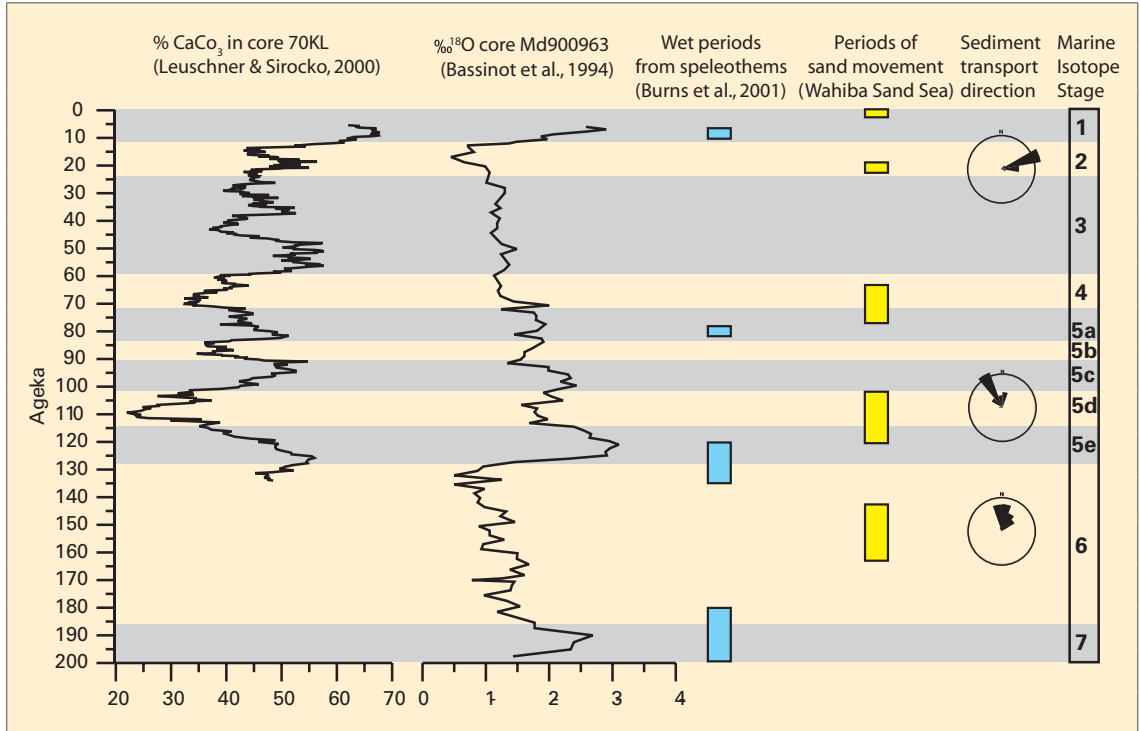

Fig. 2: Comparison of $\mathrm{CaCO}_{3}$ content in core $70 \mathrm{KL}$ (as an inverse measure of dust input), and the oxygen isotope record from core Md900963 from the Maldives area las a measure of global ice volume and global sea level), with the timing of eolian deposition in the Wahiba Sand Sea. The individual duration of these periods was calculated from the standard deviation of weighted mean luminescence ages. Rose-diagrams show the distribution of sand transport vectors in the Wahiba Sand Sea from outcrop studies. Additionally shown are periods attributed to higher than present precipitation, as deduced from speleothem growth (modified after Preusser et al., 2002).

of pronounced aridity are reflected in the increase of terrestrial dust in marine sediments of the Arabian Sea (Sirocko et al., 1991, 1993; Leuschner and Sirocko, 2000, 2003). The increase of eolian input has been explained by northwesterly winds transporting dust from the north towards the ITCZ. This implies that the ITCZ established a summer position further south than today and was located over the Arabian Sea (Sirocko et al., 1991). While this scenario appears almost conclusive, it has been questioned by recent evidence from the Wahiba Sand Sea of eastern Oman (Fig. 1).

The Wahiba Sand Sea is characterized by widespread eolian sand deposits that partially form mega-dune ridges up to $70 \mathrm{~m}$ high. The sand deposits comprise large amounts of bioclasts, such as shell debris, etc., implying a continental shelf source that was exposed during periods of low global sea level. Southerly winds transported this sand from the shelf onto the continent. Interestingly, the northern margin of the area, covered by large amounts of eolian sands, coincides approx. with the southern edge of the present position of the ITCZ during summer. At this position, wind velocity dissipates, preventing any further substantial transport of sand grains towards the north. Luminescence dating of several outcrops, together with two sediment cores from the northern Wahiba Sand Sea, confirms the correlation of sand accumulation with periods characterized by prominent decreases of global sea level (Fig. 2). The dating results indicate periods of pronounced eolian deposition in the northern part of the Wahiba Sand Sea between 160,000$140,000,120,000-100,000,78,000-$ 64,000 , and 22,000-18,000 yr ago (Preusser et al., 2002). Moreover, dip directions of dune fore-sets indicate an exclusively northbound transport of sand.

This evidence from continental environments contradicts the assumption by Sirocko et al. (1991, 1993) that the ITCZ established a summer position south of the Arabian Peninsula during glacial times. In that case, the area of the Wahiba Sand Sea would have been situated north of the ITCZ and dominated by winds with a southeasterly direction, which would have inhibited the development of a sand sea with strong bioclastic input. Sirocko et al. (1991) concluded from the mineralogical composition that the dust probably derived from the Persian Gulf area. The rather shallow Persian Gulf was a dry basin during most of the Quaternary and an ideal source area for the dust found in Arabian Sea sediments. The most prominent input of dust in the Arabian Sea at around 110,000 yr ago concurs with the sudden drop of sea level immediately following the Last Interglacial (Fig. 2). This time is also characterized as the most prominent period of deposition in the Wahiba Sand Sea. While Sirocko et al. (1991) favored a lowlevel atmospheric transport of dust towards the south, Preusser et al. (2002) suggest that the dust was first transferred into the higher atmosphere. The persistent NW-SE oriented jet stream present over the Arabian Peninsula could have transported the dust into higher atmospheric layers, across the ITCZ and released the material into the Arabian Sea. Alternatively, dust input into the Arabian Sea could have been derived from even more northerly sources, such as the interior deserts of Iran and Afghanistan, during winter months. A recent dust storm event in December 2003 covered the Arabian Sea and southeastern Arabia for several days. Both scenarios reconcile evidence from marine and continental environments but imply that the ITCZ had a similar summer position over the eastern Arabian Peninsula during glacial times as it has today.

\section{REFERENCES}

Burns, S.J., Fleitmann, D., Matter, A., Neff, U. and Mangini, A., 2001: Speleothem evidence from Oman for continental pluvial events during interglacial periods. Geology, 29, 623-626.

Preusser, F., Radies, D. and Matter, A., 2002: A 160,000-Year record of dune development and atmospheric circulation in Southern Arabia. Science, 296: 2018-2020

Radies, D., Preusser, F., Matter, A. and Mange, M., 2004: Eustatic and climatic controls on the development of the Wahiba Sand Sea, Sultanate of Oman. Sedimentology, 51: 1359-1385.

Radies, D., Hasiotis, S.T, Preusser, F., Neubert, E. and Matter, A., 2005: Paleoclimatic significance of Early Holocene faunal assemblages in wet interdune deposits of the Wahiba Sand Sea, Sultanate of Oman. Journal of Arid Environments, 62, 109-125.

Sirocko, F., Sarnthein, M., Lange, H. and Erlenkeuser, H., 1991: Atmospheric summer circulation and coastal upwelling in the Arabian Sea during the Holocene and the Last Glaciation. Quaternary Research, 36: 72-93.

For full references please consult: www.pages-igbp.org/products/newsletters/ref2006_1.html 


\section{2nd Southern Deserts Conference: "Human-environment interactions in southern hemisphere deserts-past, present and future"}

Arica, Chile; 10-14 0ctober 2005

This four-day conference was designed to help develop a comparative Southern Hemisphere perspective on the ways in which humans have interacted with and responded to the evolution of arid environments from prehistoric times to the present. It proved to be a very successful follow-up to the initial Southern Deserts Conference, held in Canberra, Australia, in January 2003 , and will be followed by a meeting in the third desert area of the hemisphere, southern Africa, in September 2008.

The conference was structured into three symposia: 'Late Quaternary Palaeoenvironments, Climate and Culture', 'Resource Use in Pre-Historic, Pre-Industrial and Industrial Times' and 'Holocene and Modern Spatial and Social Organisation', with almost all the 70 or so registrants from 14 countries presenting a paper or poster. There was good coverage of all major deserts across the Tropic of Capricorn but some real insights were provided into those from South America, through an excellent and comprehensive series of papers. Although the first symposium was most focused on PAGES activities, the whole meeting was relevant to the spirit of PAGES and provided a holistic feel of human-environment relationships.

The strong messages emerging from the meeting were:

1. The diversity of deserts, with contrasts between the highaltitude desert of the Atacama, the sand deserts of southern Africa and the 'wet' deserts of Australia.

2. The strong environmental control over human settlement and development of culture in desert environments.

3. The differences but also some notable similarities in human adaptation to the various desert environments.

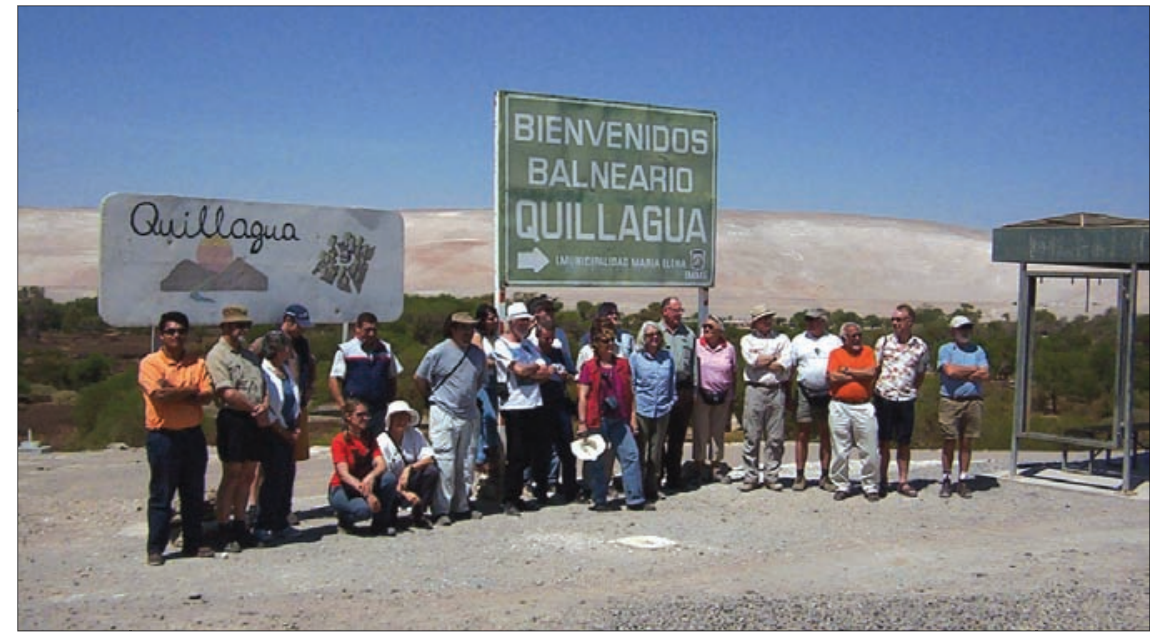

Fig. 1: The post-conference field excursion group experiencing the driest place on Earth. Although it never rains, riparian vegetation is supported by water from the mountains on the Altiplano.

The conference themes, and their integration, were investigated and cemented on pre-and post-conference excursions from the coast to the Andean Altiplano along oasis corridors. Dramatically marked by huge slope-covered geoglyphs, these ancient traveling routes allowed maintenance of communication between peoples across the centuries and indeed millennia. Prior to the conference, delegates traveled west from Arica into the Andes to the Bolivian border, following Inca trails and appreciating how pre-Incan Indigenous peoples harnessed and managed precious water, modified their landscapes and commenced a history of animal and plant domestication. The post-conference tour experienced the driest place on Earth, where it never rains; lakes and middens of pollen sequences on the Altiplano; and archeology through the whole time range of human occupation from the early Holocene, including the world's oldest mummies, to a nitrate mine settlement abandoned in the 1970s and now a World Heritage site.

I welcomed the opportunity to experience and expand my knowledge of this part of the world and to make the contacts that will facilitate integrated southern hemisphere projects as part of the new PAGES program. Although South American researchers have contributed substantially to PAGES, a number of participants (especially archeologists and those from elsewhere) were unfamiliar with the organization. An impressive background to the new PAGES initiative on variability in South American climate over the last 500-2000 years, featured in the last PAGES News issue, was presented by Martin Grosjean.

As a consequence of the interdisciplinary nature of the conference, there was a great deal of interaction between participants from diverse backgrounds. This interaction will be maintained through joint involvement in the production of a proceedings of the conference, planned for a special issue of 'Chungara Revista de Antrepologia Chilena'. It appropriately focuses on integration, by the writing of joint papers on particular themes arising from the conference.

\section{ACKNOWLEDGMENTS}

The conference was hosted by Centro de Investigaciones del Hombre en el Desierto, in association with the Universidad of Tarapaca, and received sponsorship from PAGES.

\section{Peter Kershaw,}

Monash University, Melbourne, Australia, peter.kershaw@arts.monash.edu.au 


\section{British-Russian workshop for young scientists: "Climate Change, the tree growth response, and reconstruction of climate"}

KRASNOYARSK, RUSSIA; 25-29 JaNUARY 2006

From 25-29 January, young researchers from the UK and Russia came together in Krasnoyarsk at a workshop organized by the British Council, Russia (within the International Networking for Young Scientists program), in collaboration with the Climatic Research Unit (University of East Anglia, Norwich, UK; www.cru.uea.ac.uk) and the Sukachev Institute of Forest (Krasnoyarsk, Russia; http://forest.akadem.ru). The primary focus of the workshop was on dendroclimatology.

Over the last decade or so, the number of reconstructions of global, or more particularly Northern Hemisphere, temperature changes during the last $1000-2000$ years has proliferated, as the debate on the causes of recent warming has intensified. These new reconstructions, using variously selected combinations of proxy data and different statistical approaches in their interpretation, have one thing in common: they are all heavily dependent on the information provided by tree-ring data.

In the depths of a severe Siberian winter, students and young researchers, all working within this field, came together to make presentations describing their work and to hear lectures given by established researchers from the UK, USA and Russia. The talks and several round-table discussions focused on issues directly related to the need for tree-ring studies to provide realistic estimates of past climatic changes. The topics included:

- chronology construction methods and the preservation of long-timescale signals.

- tree-growth modeling techniques and their value in climate reconstruction

- statistical methods for identifying optimal climate forcing on tree growth

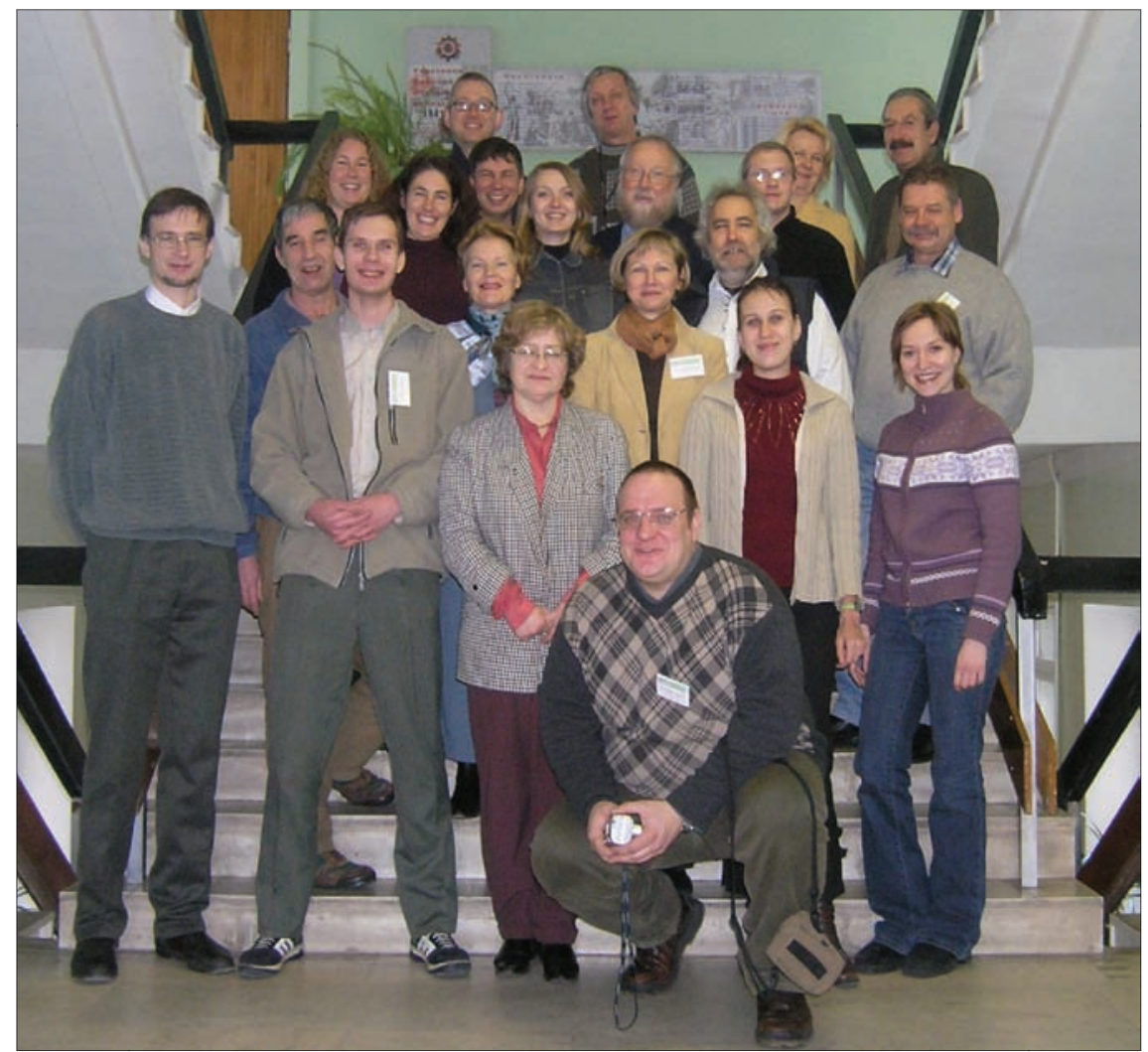

Fig. 1:Participants of the British-Russian workshop "Climate change, the tree growth response, and reconstruction of climate" (25 - 29 January 2006, Krasnoyarsk, Russia)

- synthesis of the evidence for climate change as derived from different tree-ring parameters (e.g. ring width, density and isotopic composition).

This meeting provided a rare opportunity to bring together young scientists from widely separated parts of the globe and with wideranging specialties, allowing them to re-examine their work in the context of climate change. It is hoped that it widened their horizons and suggested new approaches. It certainly broke down barriers and may even have initiated collaborations that will endure for many years to come.

\section{AcKnowledgments}

We wish to thank the British Council, Russia for their provision of funding and their assistance in the logistics required in the arrangement of this workshop. We also wish to thank PAGES for their provision of funding for visiting experts.

\section{VLAdimiR SHISHOV}

Sukachev Institute of Forset, Akademgorodok, Krasnoyarsk, Russia

shishov@forest.akadem.ru

\section{KeIth BRIfFA}

University of East Anglia, Norwich, UK k.briffa@uea.ac.uk

\section{Tom Melvin}

University of East Anglia, Norwich, UK t.m.melvin@uea.ac.uk 


\section{Global climate during Marine Isotope Stage 11 (MIS 11)}

INQUA INTERNATIONAL WoRKSHOP, Lesvos, GREecE; 5-7 September 2005

The warm interval associated with Marine Isotope Stage 11 (MIS 11) approx. 400,000 years ago may be an appropriate analog for the natural progression of the Holocene interglacial climate. Atmospheric greenhouse gas concentrations were very similar to pre-industrial values, and the nearly circular orbit (low eccentricity) of the Earth at that time resulted in similar seasonal distributions of sunlight to today. The global climate response at that time is less well known, and a number of efforts are underway to improve our understanding of it. INQUA Project 0405 is focused on the goals of facilitating and coordinating research on MIS 11. A workshop was held to assess the current state of knowledge of various aspects of the chronology; external forcing by insolation and internal greenhouse-gas trapping of radiation; sea level height/ice volume; carbon cycle; and the mean state, regional patterns, and variability of the climatic and environmental responses during MIS 11.

The workshop was organized by Chronis Tzedakis at the University of the Aegean. Five key areas of research were identified:

1) climate forcing during MIS 11

2) absolute timing and duration of MIS 11

3) nature and magnitude of the climate response in different parts of the Earth system, including spatial and temporal patterns, and the presence of stability or instability

4) operation of the carbon cycle

5) integration of paleo-data with modelling studies

Presentations during the first day focused on paleodata from terrestrial, ice and marine archives. These included results from the EPICA Dome C ice core regarding the chronology of events, atmospheric greenhouse concentrations, the phasing between temperature, $\mathrm{CO}_{2}$ and $\mathrm{CH}_{4}$ changes, and compari-

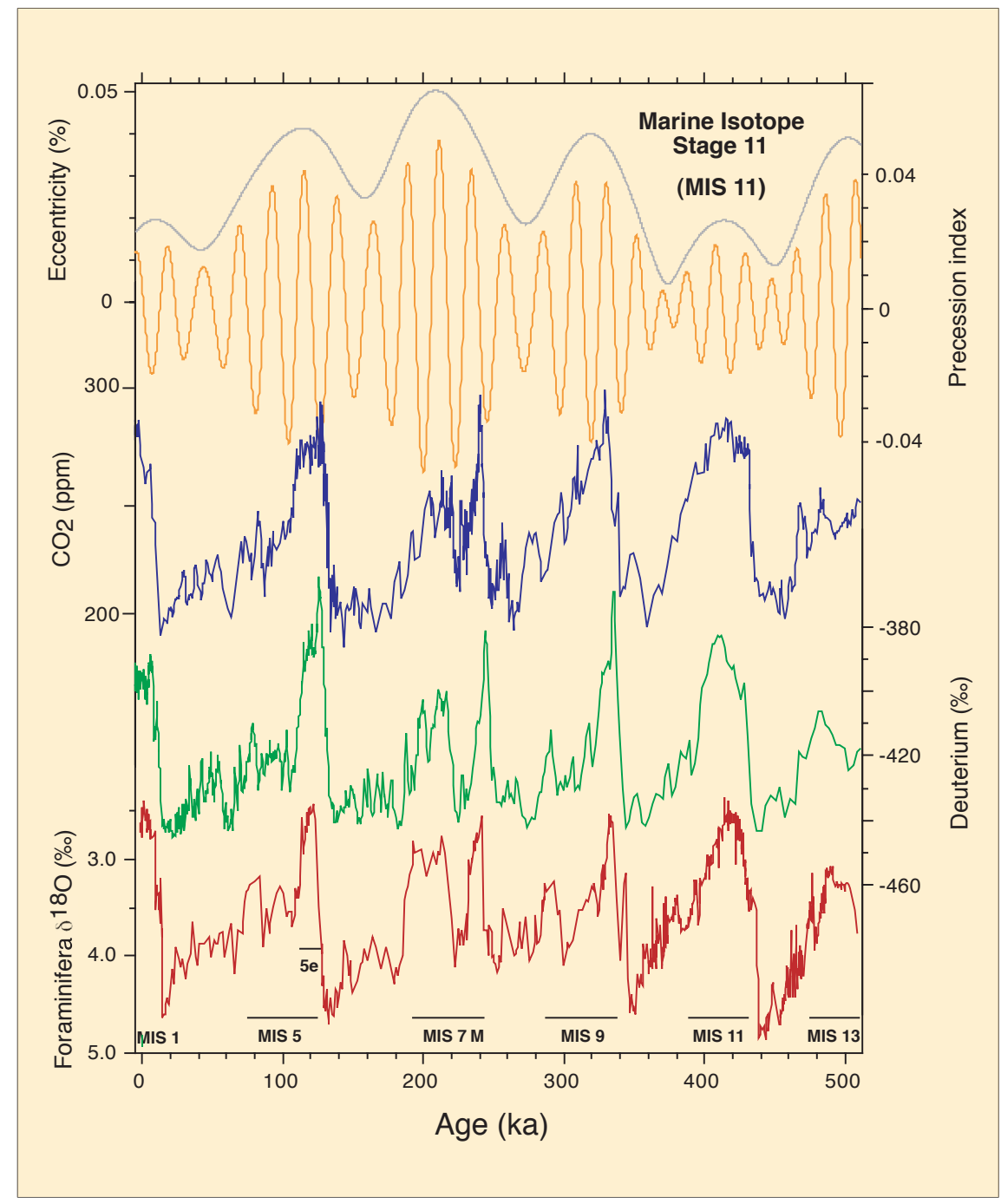

Fig. 1: Climate forcing and response over 0.5 million years. Eccentricity of Earth's orbit and precessional index (Berger and Loutre, 1991), atmospheric carbon-dioxide concentration (Petit et al., 1999; Monnin et al., 2001; Siegenthaler et al., 2005), deuterium ( $D$ D) in Antarctica (Wolff et al., 2003), and deep Atlantic benthic foraminifera oxygen isotope ratio (Oppo et al., 1998; McManus et al., 1999).

sons with the Holocene (Dominique Raynaud). They also included a discussion of evidence for sea levels $20 \pm 10 \mathrm{~m}$ higher than present, and possible explanations for the apparent discrepancy between coral/ shoreline and marine isotopic data (Jerry McManus). Additional presentations from marine archives included a demonstration of the scale of coral reef growth at the onset of MIS 11 (Andre Droxler) and a discussion of evidence for pronounced and prolonged marine carbonate dissolution from about 600 to 200 ka (Stephen Barker). A suite of proxies, indicating a long and stable interglacial interval in the
North Atlantic, was discussed and compared to widespread evidence for similar marine conditions (Jerry McManus), followed by a synthesis of research based on deep-sea cores from the Australian margin (Peter Kershaw). Terrestrial evidence was presented using marine pollen sequences from the Iberian margin that indicate the occurrence of one long interglacial interval followed by three shorter oscillations (Stephanie Desprat). A comparison of marine and terrestrial pollen records from southern Europe indicate that the most extensive tree population expansion during MIS 11 was coeval with both the insolation 


\title{
Workshop Reports
}

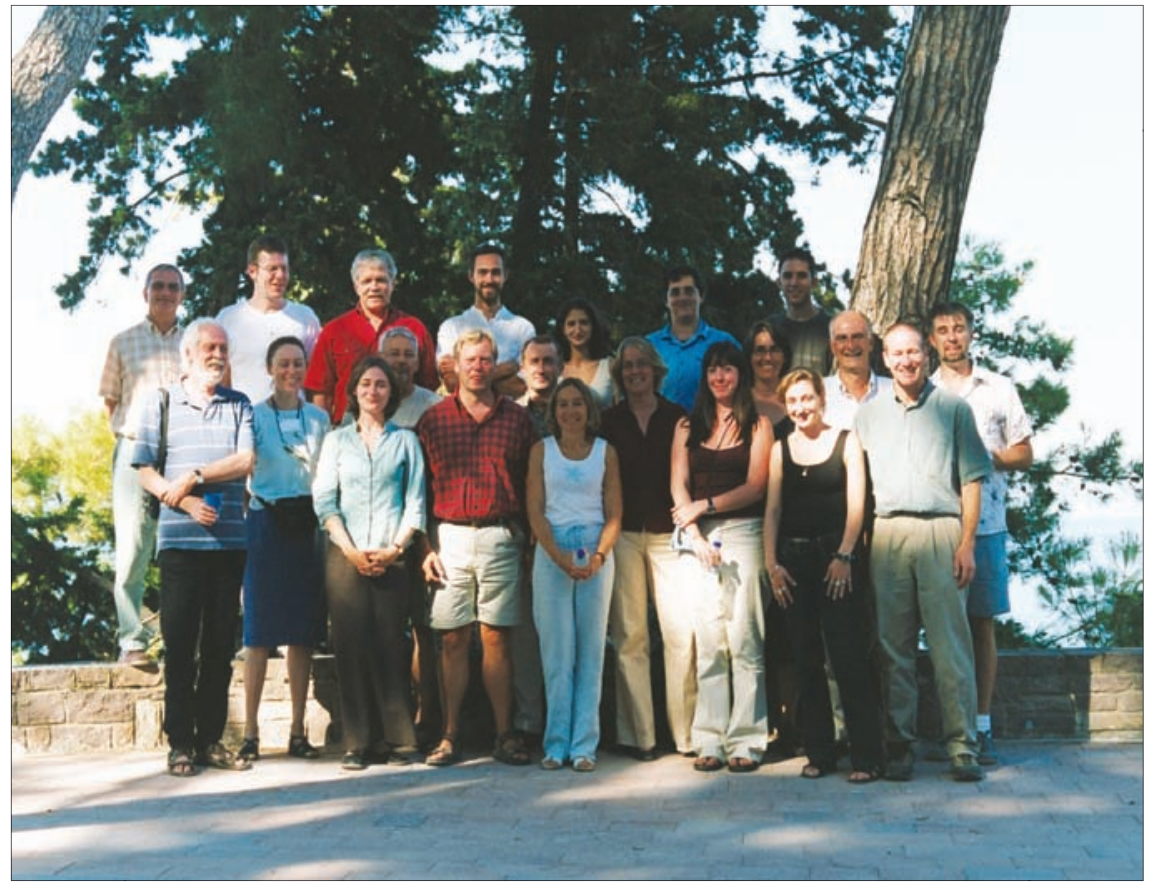

Fig. 2: Group photo of the MIS-11 workshop participants in Lesvos, Greece.

and atmospheric methane maxima (ChronisTzedakis), and some recent high resolution work was presented from annually laminated sediments from maar lakes in the Eifel region, Germany, which have the potential for constraining the duration of interglacial warmth (Frank Sirocko). New results were also presented from Lake Baikal, as was a synthesis of soil/loess sequences from China, Siberia and Russia (Sasha Prokopenko).

The second morning of the workshop was devoted to discussions of models, including the results of recent simulations for MIS 11 using the MoBidiC climate model that emphasized the importance of identifying appropriate vegetation inputs for the model (Marie-France Loutre). Climate simulations using the CLIMBER 2.3 model were presented, showing the pronounced geographical differences in the nature and timing of responses during MIS 11 (Claudia Kubatzki). Additional experiments using the CLIMBER model, indicating the terrestrial realm as a climate amplifier that had the potential to cause thresholds in the system to be crossed, were also presented and examined in the context of the global carbon cycle (Victor Brovkin). A new perspective on the entire problem of ice-age cycles was also presented, emphasizing the importance of putting the variability of the last few hundred thousand years in the context of a longer term view of climate evolution over the last few million years (Tom Crowley). The oral presentations of the workshop were followed by a poster session and a roundtable discussion of the arising scientific issues. The final day included presentations and discussion on the progress of the different study groups: Eurasian; Southern Hemisphere; Integration of marine, ice core and terrestrial records; Paleoclimate; and Carbon cycle. Progress was noted and gaps were identified in each of these areas.

The Lesvos workshop marked the mid-point of the INQUA inter-Congress period. Subsequent plans for the MIS 11 project include a workshop to be held at Woods Hole in 2006, and a symposium to be organized as part of the 17th INQUA Congress in Cairns, Australia in 2007.

\section{JeRRY McManus}

Woods Hole Oceanographic Institution, Woods Hole, USA

jmcmanus@whoi.edu

\section{Chronis Tzedakis}

University of Leeds, Leeds, UK P.C.Tzedakis@leeds.ac.uk

\section{Call for Contributions: General PAGES Activities}

\author{
All PAGES Newsletters now have an open section for general contributions. If you \\ would like to contribute a "Science Highlight", "Workshop Report", "Program \\ News", or an amusing "Tales from the field" story for the forthcoming July 2006 \\ issue of PAGES News, please contact Christoph Kull (kull@ pages.unibe.ch). \\ The deadline is 15 May 2006. \\ Information and guidelines are available at: \\ http://www.pages-igbp.org/products/contribute.html\#2
}




\section{Last PACEE}

\section{Calendar
2006}

May 26 - 29, 2006, Baile Herculane, Romania IVth International Conference "Climate Change: the Karst Record" (KR IV)

Further Information:

www.karst.ro/

June 11 - 17, 2006, Beijing, China

7th International Conference on Dendrochronology:

Cultural Diversity, Environmental Variability

Further Information:

http://7thicd.ibcas.ac.cn/pages/index.asp

July $17-21,2006$, Espoo, Finland

Living with Climate Variability and Change: Understanding the Uncertainties and Managing the Risks

Further Information:

www.livingwithclimate.fi/

Aug. 17 - 20, 2006, Bozeman, USA

American Quaternary Association (AMQUA) 36th

Biennial Meeting - several PAGES-related sessions

Further Information:

www.pages-igbp.org/calendar/calendar06.html
Aug. 21 - 25, 2006, Cambridge, UK International Glaciological Society Symposium Cryospheric Indicators of Global Climate Change

Further Information:

www.igsoc.org/symposia/2006/cambridge/

Sept. 19 - 22, 2006, Bremen, Germany

6th European Coral Reef Conference

Further Information:

http://isrs2006.zmt.uni-bremen.de/

0ct. 24 - 27, 2006, Birmingham, UK

Rapid Climate Change - International Science

Conference

Further Information:

www.noc.soton.ac.uk/rapid/rapid2006/

Nov. 9 - 12, 2006, Beijing, China

ESSP 0pen Science Conference -

Global Environmental Change: Regional Challenges

Further Information:

www.essp.org/essp/ESSP2006/

\section{Tales from the field}

Do you have an interesting and humorous story from your paleoenvironmental fieldwork? Send us your tale (max. 500 words) so that we can publish it in PAGES News!

\section{PAGES Guest Scientist Program \\ PAGES IPO - Bern, Switzerland}

Are you looking for a place to spend a short sabbatical? PAGES hosts scientists working on quantitative reconstruction of late Quaternary climatic and environmental change for short stays at the International Project Office (IPO) in Bern, Switzerland.

By hosting guest scientists, PAGES hopes to enhance the interaction between the IPO and the many researchers involved in PAGES projects. Past guest scientists have taken on tasks such as hosting workshops, guest-editing special issues of PAGES News, editing books and special issues arising from PAGES activities, developing new initiatives, and enhancing PAGES visibility in their home country. Senior visitors have benefited from an opportunity to get away from their home institution for a period to focus on a PAGES project or to develop new interactions. Younger scientists have benefited from taking on interesting and challenging tasks that would not normally arise in their work, and from making new contacts within the PAGES scientific network.

Please note that PAGES cannot pay a salary to guests during their stay at the IPO, however, some money is usually provided towards travel costs.

If you are interested in spending a sabbatical at PAGES and would like to find out how to apply, please read the application guidelines at www.pages-igbp.org/people/guidelines.html. 